№ 6 Marzo 2009
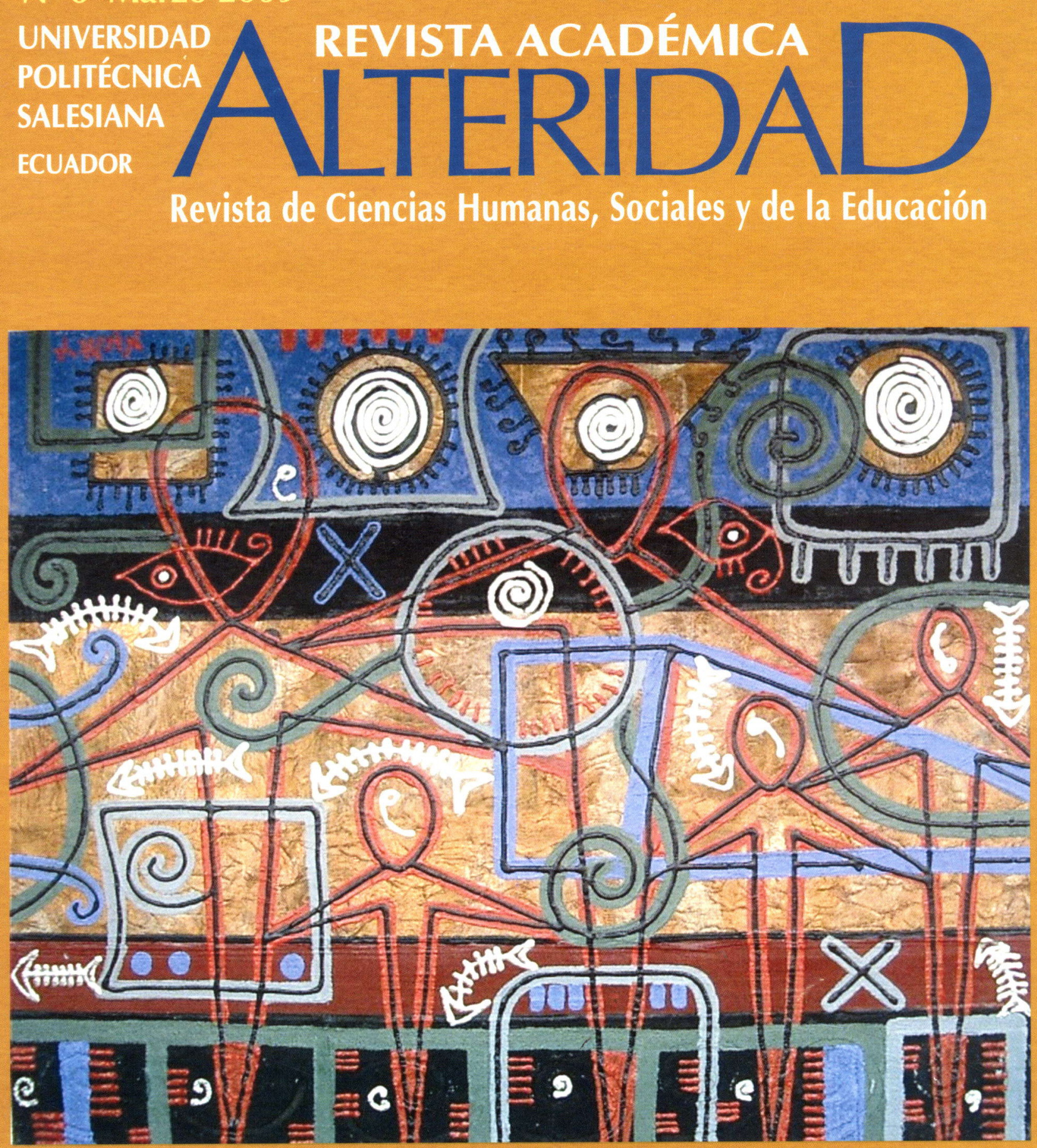

¿Puede haber algo que se llame una política ambiental?
Sumak kawsay en la

Constitución ecuatoriana

Tema central: Desarrollo y soberanía alimentaria

Movilizaciones del Sur frente a la crisis alimentaria

La construcción del sistema de soberania alimentaria y nutrición del Ecuador

Soberania alimentaria y derecho a la alimentación

Agrocombustibles en las llamadas tierras marginales 


\section{Índice}

Presentación.

Sebastián Granda y Lola Vásquez

TEMA CENTRAL: DESARROLLO Y SOBERANÍA ALIMENTARIA

Movilizaciones del Sur frente a la crisis alimentaria

Laurent Delcourt

La construcción del sistema de soberanía alimentaria y nutrición del Ecuador

Fernando Rosero

Soberanía alimentaria y derecho a la alimentación: Elección de políticas públicas desde el enfoque de la economía solidaria

Verónica Andino

Agrocombustibles en las llamadas tierras marginales...

Elizabeth Bravo

\section{CONTRIBUCIONES ESPECIALES}

¿Puede haber algo que se llame una política ambiental?

Freddy Álvarez

Sumak kawsay en la Constitución ecuatoriana del 2008.

Pablo Ortiz

Economía solidaria

Diego Obando

\section{ACRIVIDADES ACADÉMICAS}

Centro Psicológico y Carrera de Psicología ……........................................................................... 100

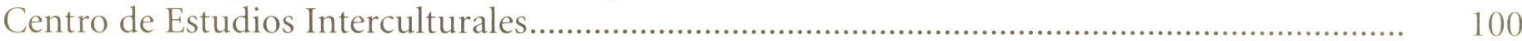

Carrera de Gestión para el Desarrollo Local Sostenible .............................................................. 101

Carrera de Antropología Aplicada...............................................................................................

GALERÍA DE ARTE

Obras de la artista Lilia Luján

La obra de Lilia Luján (México, D.F. 1965) ilustra este número de Alteridad. Artista autodidacta, cuenta con una copiosa obra que incluye pintura, escultura alternativa, arteobjeto, arte-rip, diseño de joyería, textiles, marcos y lámparas, entre otras piezas. La portada despliega un lienzo en técnica mixta titulado Omnipresencia. El motivo decorativo que acompaña la paginación pertenece a Delirio, acrílico sobre papel. Las ilustraciones en blanco y negro de los interiores reproducen cuadros completos o fragmentos de su obra realizada en técnica mixta sobre lienzo o con acrílico sobre papel hecho a mano. Los editores, a la vez que agradecen a la artista su cálida contribución, invitan a los lectores a admirar su obra ingresando al portal www.lilialujan-arte.com 


\section{Presentación}

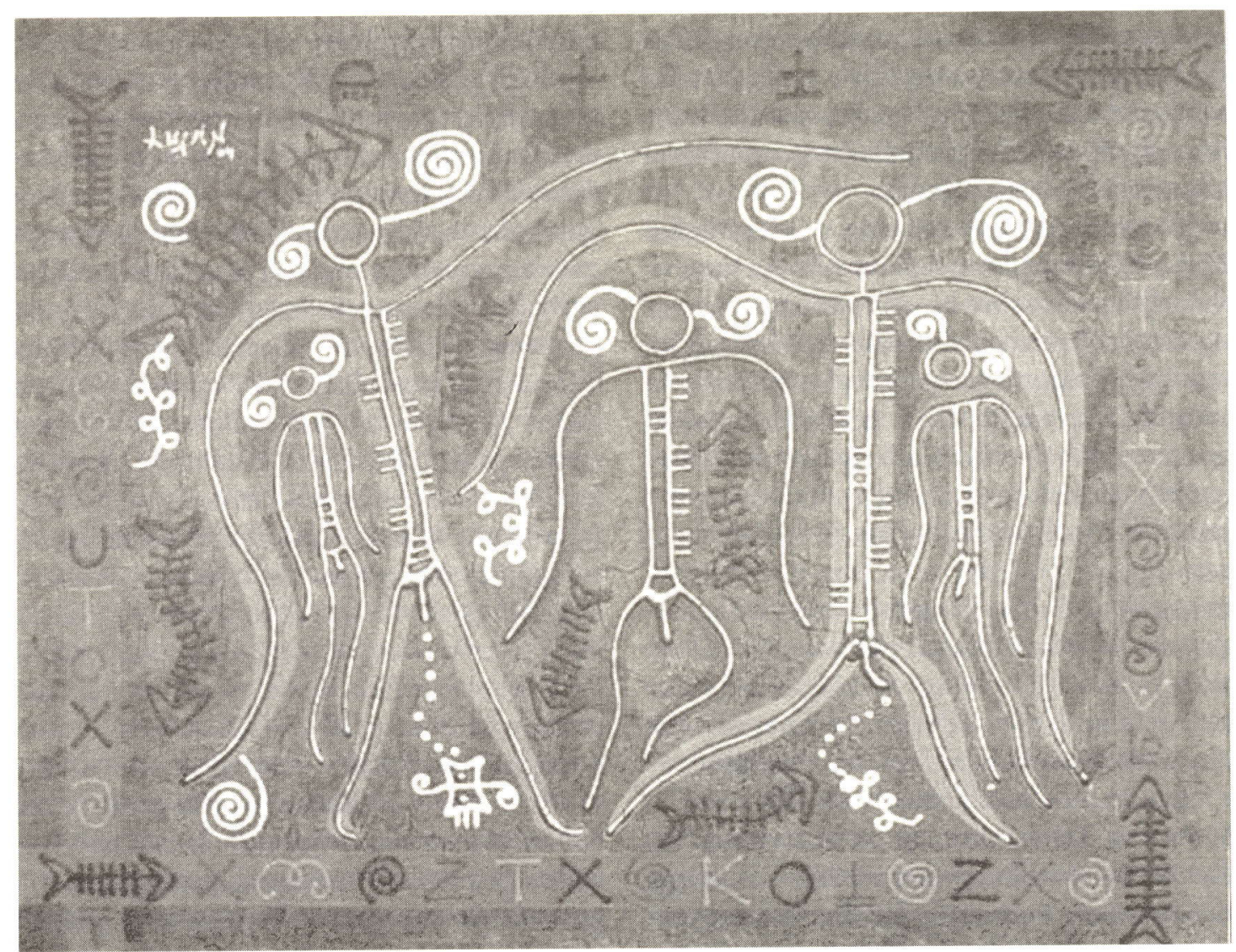

Extramuros. Técnica mixta sobre lienzo

El nuevo número de la Revista Alteridad, elaborada por la Carrera de Gestión para el Desarrollo Local Sostenible, recupera y presenta un conjunto de reflexiones y aportes de docentes de la Universidad Politécnica Salesiana e invitados especiales en torno al tema del desarrollo y soberanía alimentaria.

Varios son los retos asumidos en este número. En primer lugar, se busca visibilizar las nuevas teorías y conceptos que se han generado en los últimos años para explicar los cambios en curso. Las teorías y conceptos con los que se analizó la sociedad en períodos anteriores resultan cada vez más limitados e insuficientes para explicar los fenómenos actuales. Hoy en día existen iniciativas que buscan generar e incorporar nuevos enfoques para explicar la realidad y contribuir a la construcción de nuevas formas de poder. La revista incorpora precisamente esa búsqueda, y pretende, aunque en forma todavía limitada, delinear senderos por donde continuar con la reflexión.

Un segundo reto tiene que ver con el debate acerca del sentido del desarrollo y del desarrollo local en particular. Hasta hace poco, las propuestas alternativas de desarrollo eran reivindicadas por actores sociales y políticos que se oponían abiertamente al capitalismo y, en tal 
medida, llevaban implícitas una serie de elementos nuevos: la descentralización, la participación, el enfoque de género, el reconocimiento de la diversidad cultural, la sostenibilidad ambiental, entre otros. Estas nociones están perdiendo su sentido original y son cooptadas y resignificadas por el poder mundial. Esto explica por qué propuestas como la del desarrollo sostenible sean hoy fuertemente cuestionadas.

El tercer reto hace alusión a la viabilidad política y rendimientos del desarrollo. La tarea es abrir la discusión sobre las diversas experiencias de desarrollo llamadas alternativas. Al respecto, habría que preguntarse sobre el sentido y la orientación que han tenido y tienen las mismas, preguntarse dónde está lo alternativo de dichos procesos y si realmente están contribuyendo a mejorar las condiciones de vida de la población y crear nuevos poderes; o si, por el contrario, están contribuyendo a la reproducción de la inequidad social y la pobreza. Este es un debate todavía pendiente que es necesario impulsar entre la academia y los diferentes actores sociales que han protagonizado dichas experiencias.

Laurent Delcourt abre la sección relacionada con el Tema central proponiéndonos un análisis de las movilizaciones sociales -a las que ha denominado motines del hambre - de los países del sur, ocasionadas por las crisis alimentarias. El panorama es alarmante pues la crisis se presenta como un fenómeno global de tal amplitud y gravedad que sus consecuencias son difíciles de predecir. La contribución de Delcourt propone pautas para develar las raíces de la crisis alimentaria y el significado de las protestas urbanas y movilizaciones campesinas asociadas con ella. Finalmente, describe las respuestas gubernamentales y de los organismos internacionales al mismo tiempo que identifica los desafíos de la soberanía alimentaria cuyos rasgos son los siguientes: instauración de políticas audaces enfocadas en la protección, el apoyo y el fortalecimiento de la agricultura familiar y de subsistencia, la diversificación agrícola, el abastecimiento de mercados internos (rurales y urba- nos) con productos locales, y precios que aseguren la reproducción de las explotaciones campesinas. Estos desafíos implican, por último, la capacidad de movilización y organización de los movimientos sociales.

El artículo de Fernando Rosero trata el tema de la soberanía alimentaria como un elemento fundamental en la nueva propuesta de desarrollo y que se recoge en la Constitución aprobada en febrero del 2008. La soberanía alimentaria, plantea el autor, es un compromiso de todos los actores de las economías grandes y pequeñas. El sistema alimentario, nos dice, involucra a toda la población del campo y de las ciudades ya sea como productores de alimentos, como agentes de transformación, o simplemente como consumidores. Otro elemento central tratado por Rosero es que la soberanía alimentaria implica un cambio cuantitativo y cualitativo. Significa pasar de una agricultura y producción de alimentos centrados en los grandes negocios para la exportación o dirigida a las ciudades o centros de desarrollo a un desarrollo territorial endógeno en el cual el valor generado localmente se reinvierte localmente en la producción de bienes y servicios, mejorando la calidad de vida de los pequeños y medianos productores y asegurando la alimentación de toda la población ecuatoriana. Para garantizar aquello es fundamental el acceso a la tierra, al agua y al capital; es decir, a los factores de producción.

El mismo tema es tratado por Verónica Andino pero desde el derecho de los consumidores a una alimentación segura, garantizado por la nueva Constitución del Ecuador que, en su artículo 13 capítulo II, dice: "Las personas y colectividades tienen derecho al acceso seguro y permanente a alimentos sanos, suficientes y nutritivos; preferentemente producidos a nivel local y en correspondencia con sus diversas identidades y tradiciones culturales. El Estado Ecuatoriano promoverá la soberanía alimentaria”. En el artículo de Andino resulta interesante la diferenciación sobre cómo los derechos a la alimentación deben tener estrategias a corto y largo plazo. Para 
la autora la soberanía alimentaria implica una reducción progresiva y permanente del riesgo de perder los derechos de la población a la alimentación. Para ello, es necesario garantizar, un permanente aumento en la disponibilidad de alimentos sanos, recuperando los propios y priorizando la producción nacional; garantizar la capacidad de la población de acceder a dichos alimentos mediante el mejoramiento de los ingresos y el control de precios; $y$, finalmente, elevar el nivel educativo de la población en términos de nutrición para mejorar las prácticas culturales alimenticias. Su artículo incoŕpora el enfoque de la economía solidaria y plantea que uno de los roles de Estado es garantizar la disponibilidad de alimentos de calidad para el consumo interno promoviendo al máximo la producción local de alimentos orgánicos.

En su artículo Agrocombustibles en las llamadas tierras marginales, Elizabeth Bravo discute las políticas de promoción de cultivos energéticos en las llamadas tierras marginales. La autora sostiene que en la actualidad, desde varios círculos, se propone e impulsa el establecimiento de cultivos energéticos en "tierras marginales" con el argumento de que estos contribuyen a mejorar la economía de la población de dichas zonas, sin afectar su producción de alimentos, puesto que se trata de tierras improductivas. A partir del análisis de la propuesta de cultivo de piñón en las comunidades del sur de la Provincia de Manabí y de un diagnóstico social, económico y ambiental de la zona, Bravo concluye que estas iniciativas generan un cambio radical en el modelo de desarrollo de las comunidades, pues a la par que contribuyen a que dichas comunidades dejen de producir alimentos y pierdan soberanía alimentaria, les introducen en el gran mercado a través de la agricultura de contrato. Tal escenario es la causa para que autora afirme que estas iniciativas son incompatibles con el Sumak kausay.

Freddy Álvarez inicia la sección de Contribuciones especiales señalando que el mundo ya no es el mismo ante la catástrofe eco- lógica. Pero el tema es tratado desde las posturas antagónicas de defensores y detractores. El autor señala que la preocupación por el ambiente desde los países ricos surge de políticas proteccionistas, manteniendo prácticas de saqueo de los recursos del tercer mundo. Además, son estos mismos países los que pretenden dictar al mundo las políticas ambientales. En los países del Sur también existen contradicciones y distintas posturas que van desde procesos iniciales de oposición hasta los extremadamente radicales, que se mueven entre la paradoja del cuidado del ambiente y la necesidad de contar con recursos económicos para responder a las promesas políticas o a los planes de desarrollo. Entonces, se trata de "dejar intactos los recursos protegiendo la naturaleza; o arrancar las riquezas de la tierra para solucionar los problemas del hambre".

El autor afirma que los desarreglos ambientales colocan a la humanidad frente a la comprensión de un mundo diferente: el mundo está interrelacionado y es interdependiente, por ello lo que suceda en el sur afectará directamente al norte y viceversa. "La casa es de todos y lo que pase en uno de sus cuartos nos afecta a todos... Dependemos de lo que los otros hagan, así como los otros dependen de lo que nosotros hagamos en esta parte de la casa".

Pablo Ortiz desarrolla su propuesta desde el análisis del Sumak kawsay entendido como vida límpida y armónica que orienta el modo de vivir y determina las relaciones entre las personas en base a principios igualitarios, comunitarios y de reciprocidad, en relación con la naturaleza y sus formas de trascendencia. A partir del concepto del Sumak kawsay, como postura también filosófica, analiza las distintas concepciones sobre el significado del desarrollo, o de lo que se consideraría desarrollo en la modernidad y la posmodernidad. A la vez, cuestiona estos conceptos desde el punto de vista teórico y desde las implicaciones sociales, culturales y fundamentalmente políticas que han producido estas diferentes concepciones sobre desarrollo. 
Ortiz señala que el concepto del Sumak kawsay, recogido en la Constitución como "buen vivir", procura dar un giro cultural profundo cuando propone que no tienen que transformarse solamente los aspectos formales de las instituciones, o de las relaciones sociales y de poder, pues "Ya no cabe en un ámbito del Sumak kawsay la arrogancia y la indolencia de un burócrata ante el requerimiento de un/a ciudadano/a que demanda atención o un servicio, ni tampoco, en la práctica política cabe la privatización permanente de los instrumentos y espacios que son de dominio público". Los elegidos deben mandar obedeciendo. Su única obligación es cumplir los mandatos dados por el colectivo. "El buen vivir, en general comprende los derechos e instituciones que tienden a dotar a los habitantes del Ecuador las condiciones para gozar efectivamente de los derechos humanos, vivir en armonía con sus semejantes y con la naturaleza, para que esta sea el hábitat de las presentes y futuras generaciones".

Diego Obando discute el lugar de la economía solidaria y se interroga sobre si sus prác- ticas favorecen el desarrollo alternativo o un proyecto en última instancia neocapitalista. Al mismo tiempo, traza las condiciones para que la economía solidaría impulse la transformación social desde un nuevo paradigma de desarrollo: la solidaridad, la alteridad, la corresponsabilidad, la justicia, la reciprocidad, la cultura del consenso, la motivación y la proactividad.

Finalmente, en la tercera sección, incluimos un relato de las actividades académicas de las carreras y departamentos del Área de Ciencias Sociales y del Comportamiento Humano que evidencian la relación de nuestra universidad y propuestas académicas con la sociedad.

Lic. Sebastián Granda, M.Sc Director Área Ciencias Sociales y del Comportamiento Humano

Lic. Lola Vázquez, M.Sc Directora de Carrera Gestión para el Desarrollo Local Sostenible - Sede Quito Quito, 2 de abril del 2009 


\section{Tema central Desarrollo y \\ soberanía alimentaria}

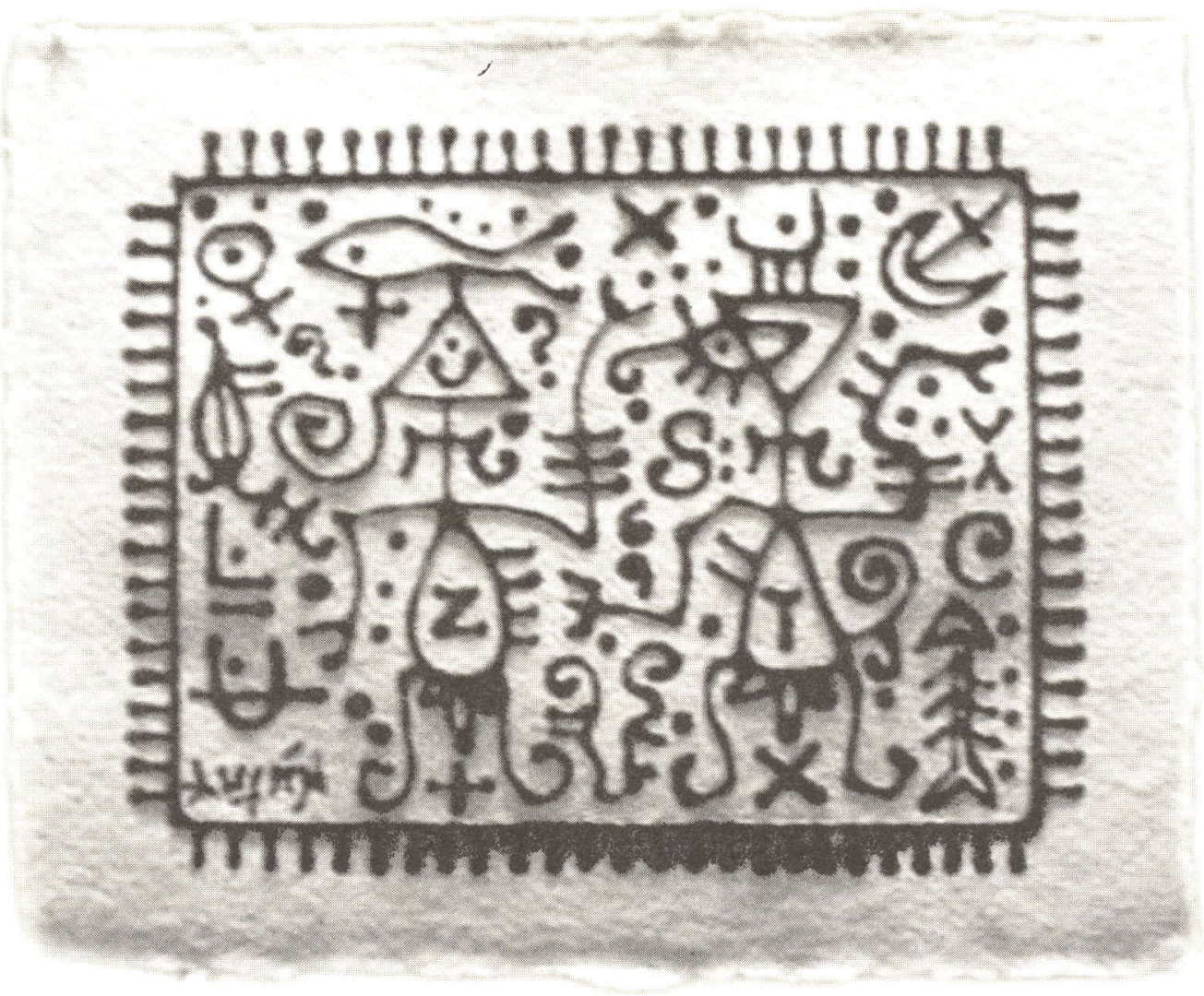




\title{
Movilizaciones del Sur frente a la crisis alimentaria
}

\author{
Laurent Delcourt*
}

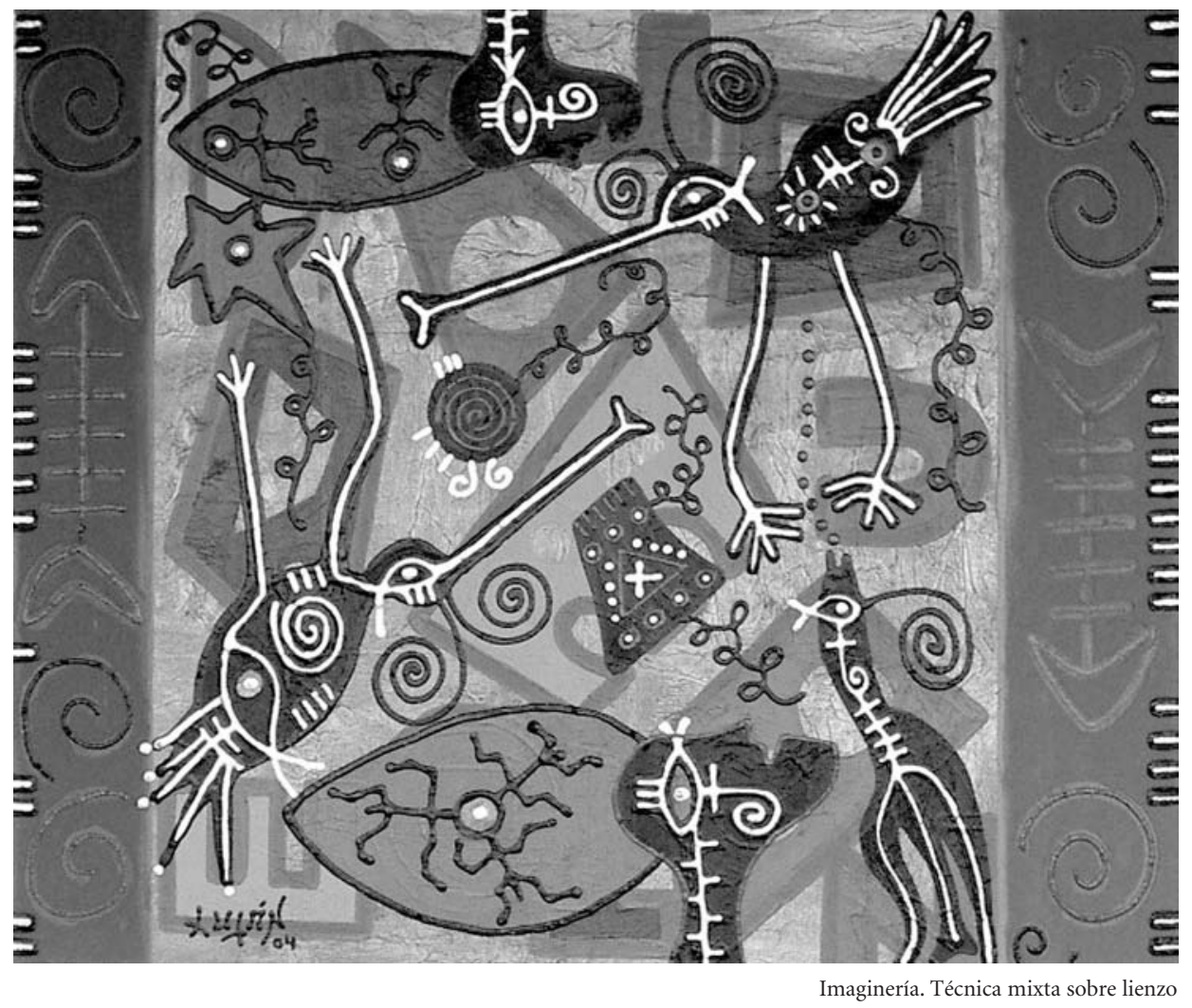

"Creemos que a esta crisis alimentaria hay que darle un nombre más exacto. Todavía no damos con ese nombre. Pero no es una crisis de alimentos, es una crisis de valores en las empresas transnacionales, en los gobiernos y en la cooperación internacional", Sinforiano Cáceres, presi- dente de la Federación nacional de cooperativas, Nicaragua (Envío, 2008).

Primer semestre 2008. El Sur es sacudido por una ola de manifestaciones populares violentas como consecuencia del alza espectacular de los precios de los alimentos. Ningún conti-

* Sociólogo e historiador, encargado de estudios en el CETRI (Centro tricontinental), Louvain-la-Neuve. 
nente se salva. Como un reguero de pólvora los disturbios urbanos estallan sucesivamente en Guinea, Burkina Faso, Camerún, Senegal, Haití, Costa de Marfil, Filipinas, Bangladesh, Pakistán, Indonesia, Malasia... Son casi simultáneos en Marruecos, en Túnez y en Egipto. Por todas partes el fenómeno parece repetirse de manera idéntica: alza súbita de los precios, expresiones de ira popular, saqueo de almacenes o de bodegas, proclamación del estado de emergencia por parte de las autoridades, enfrentamientos violentos con las fuerzas del orden que, en ciertos casos, no dudan en disparar contra la "masa".

El saldo humano es alto: en total, centenas de heridos y decenas de muertos, principalmente en África (Camerún, Costa de Marfil, Mauritania, Somalia, etc.). En algunos países, la presión en las calles es tal que los gobiernos nacionales se encuentran directamente amenazados. Haití lo experimenta dolorosamente: al cabo de tres días de disturbios donde mueren cinco personas, una de ellas un casco azul de la Minustah (Misión de Estabilización de las Naciones Unidas en Haití, uno de los blancos preferidos de los manifestantes), y el intento de tomar el Palacio nacional, el gobierno de Alexis se ve forzado a dimitir. En otros lugares, el hachazo de la represión cae: los arrestos son innumerables.

Muy rápido, un viento de pánico se apodera de la comunidad internacional. Ante esta multiplicación de "motines del hambre" algunos hablan ya de la "primera crisis alimentaria global desde la segunda guerra mundial". Otros destacan el carácter inédito de esta crisis que ahora afecta de lleno a las ciudades. Muchos temen un contagio amotinador. Con un discurso de tinte dramático, la prensa internacional se hace ampliamente eco de los eventos.

El Watan, el gran periódico argelino, predice una nueva "inflación de la pobreza" (Ali Benyahia, 13 de abril del 2008) ante la subida de los precios de los alimentos. El semanario británico The Observer da la alarma, advirtiendo que el "espectro de la catástrofe" estaría "azotando la tierra" (McKie, Steward, 13 de abril del 2008). Eric Le
Boucher, en Le Monde, anuncia el "regreso de los estómagos vacíos", y previene: "Para centenas de millones de pobres, la alimentación supera el 75\% de sus ingresos. La única alternativa que tienen es la de pasar hambre. La inflación alimentaria amenaza con anular la victoria histórica contra la pobreza y la desnutrición que el hombre estaba por conseguir." (13 de abril del 2008).

Al parecer, la amplitud y la gravedad de la crisis cogieron desprevenidas a las instituciones internacionales, a pesar de las repetidas advertencias hechas por la FAO desde varios meses ${ }^{2}$, y éstas suenan la alarma y dan los primeros diagnósticos. El tono es alarmista. El cuadro es pesimista: 100 millones de personas, señalan las Naciones Unidas, podrían caer en la pobreza por el alza de los precios de los productos alimenticios básicos si no se toma ninguna medida enérgica. Acumulando niveles elevados de subalimentación crónica, un alto crecimiento demográfico y una gran dependencia de las importaciones energéticas y alimentarias, unos cuarenta países son considerados particularmente vulnerables. Los países emergentes, advierte además la ONU, también podrían tener disturbios, o por lo menos fuertes tensiones sociales si el alza de los precios continúa.

Y las diferentes agencias Onusianas multiplican los llamados a la acción y a los planes de urgencia. Al mismo tiempo, la FAO convoca una cumbre extraordinaria en Roma (junio del 2008) y Robert Zoellick, presidente del Banco Mundial, para quien esta crisis es capaz de reducir a la nada cerca de siete años de esfuerzo en la lucha contra la pobreza, aboga por la ejecución de un "New Deal alimentario" en el cual se dé una nueva prioridad a las inversiones agrícolas. Por su lado, las grandes potencias -Estados Unidos y Europa a la cabeza- se comprometen en aumentar su ayuda alimentaria y su apoyo al desarrollo agrícola. La inquietud es palpable a nivel de los dirigentes mundiales, algunos estiman que en lo sucesivo la inseguridad alimentaria constituye una amenaza aún mayor que el terrorismo para la estabilidad internacional. 
En el Sur, varios son los Estados que no esperaron para actuar. Temiendo la ira de las calles, se tomaron medidas de urgencia para luchar contra la espiral inflacionista: bloqueo de los precios de los alimentos, uso de las reservas estratégicas, supresión temporal de los impuestos sobre las importaciones, aumento de los subsidios alimentarios, alza selectiva de salarios, limitación, hasta bloqueo, de las exportaciones, etc. En Egipto se pide ayuda al ejército para poder hornear el pan en las panaderías del Estado. En Filipinas, se lo ve distribuyendo sacos de arroz en los suburbios, y, como en Tailandia, primer exportador mundial de arroz, vigilando arma en mano los campos y las bodegas. El gobierno filipino va más allá aún al ampliar la pena de muerte para los individuos que almacenan arroz en secreto con el fin manipular su precio (Weaver, 2008).

\section{Más allá de los "motines del hambre"}

Ya que el humo de los recientes disturbios se ha disipado, nos parece útil, en esta edición 2009 de "Estado de las resistencias en el Sur", rever estos acontecimientos con una mirada a la vez objetiva, crítica y lúcida sobre la "crisis". Sobre sus motivos y su significado por supuesto. Pero también sobre la diversidad de las reacciones causadas, las tensiones abiertas o latentes engendradas por el alza de los precios, las respuestas dadas por los gobiernos nacionales, $y$ finalmente su actitud frente a las movilizaciones populares.

Muy rápido, un viento de pánico se apodera de la comunidad internacional. Ante esta multiplicación de "motines del hambre" algunos hablan ya de la "primera crisis alimentaria global desde la segunda guerra mundial"
Antes de nada, se requiere hacer un análisis, que se refiera a la vez a consideraciones teóricas y a una preocupación de representatividad, puesto que no puede ser exhaustivo. El término "motín del hambre" es un término engañoso, con una connotación muy fuerte. Sugiere una reacción violenta, espontánea, emotiva, imprevisible, irracional e incontrolable de un conglomerado de individuos sin vínculo aparente, sino sólo su pertenencia a las clases más desfavorecidas de la población, sin más proyecto que la satisfacción de una necesidad inmediata y sin más motivos que una profunda frustración. Al encontrarse en una situación límite, estos "estómagos vacíos" no tendrían más alternativa que el recurso a la violencia a falta de otros canales de expresión.

Un análisis más detallado y contextualizado de los últimos episodios de los disturbios del Sur invita sin embargo a matizar este concepto. En efecto, los disturbios no siempre tienen el carácter espontáneo e irracional que se les quisiera dar. Al observarlos más de cerca, éstos a menudo esconden, entre ruido y furor, formas iniciales de movilizaciones netamente más organizadas y estructuradas, duplicándolas o desbordándolas. Esto explica que el límite entre disturbios y formas de acción colectivas más convencionales sea impreciso.

La comprensión de los disturbios no puede reducirse a un solo eje de la confrontación. En realidad, como lo recalca Didier Le Scout refiriéndose al Magreb, los disturbios contienen una pluralidad de significados (1999). No son una muestra de una cultura específica, y tampoco pueden ser considerados bajo el ángulo de una causalidad única, en este caso el "hambre". Evitemos en efecto caer en el error de un análisis determinista de la "crisis" que presupone un vínculo mecánico entre una situación de carencia y su concreción en revuelta más o menos abierta.

La expresión "motín del hambre" puede ser engañosa. Por una parte porque, en los medios más pobres, estas formas de protesta colectiva constituyen mucho más la excepción que la regla. Por otra, porque las metas de estas explo- 
siones urbanas son generalmente múltiples, sus participantes no siempre vienen de la parte baja de la escala social y los motivos que conducen a la acción reflejan una realidad mucho más amplia que la sola satisfacción inmediata de una necesidad.

A lo largo de estos episodios de disturbios, a menudo se asocian a la emoción o a la frustración auténticas reivindicaciones sociales y políticas cuyo alcance y significado van más allá de las motivaciones más aparentes. Reflejos de las tensiones que atraviesan las sociedades del Sur, estos "motines" no deben ser tomados e interpretados como simples accidentes coyunturales, aislables en el tiempo y en el espacio, sino considerados dentro de un continuum o una genealogía de luchas y de resistencias afianzadas en contextos sociales, políticos, culturales específicos y variados.

Finalmente, para completar el cuadro, teníamos que hacer justicia a los demás tipos de reacciones populares causadas por el alza súbita de los precios. Y para ello, ampliar la perspectiva. Es decir, pasar de una geografía del disturbio a una geografía de la protesta, esto a fin de poner en evidencia la gran diversidad de las resistencias, de los métodos de acción colectiva y de los lugares de expresión de la insatisfacción en el Sur.

Si bien los medios de comunicación internacionales se interesaron esencialmente en los disturbios urbanos por el hecho de su simultaneidad y de su carácter espectacular, obviaron ampliamente los otros tipos de movilizaciones, sobre todo en el medio rural y fuera de este famoso "cinturón de pobreza" definido por la FAO. De hecho más convencionales, sin duda menos ruidosas, estas luchas son igualmente significativas para comprender los múltiples desafíos vinculados con el tema alimentario, tanto en el plano nacional como en el plano internacional. Establecer un panorama de estas movilizaciones colectivas en su diversidad y su complejidad, ubicarlas en las realidades nacionales, comprenderlas con respecto a las tendencias mundiales, tal es la apuesta de esta edición 2009 de Estado de las resistencias en el Sur.

\section{Raíces de la crisis}

En caso de un concurso de circunstancias, de un efecto de coyuntura, de una combinación no propicia e inopinada de factores agravantes, atribuyendo a cada cual un papel más o menos determinante según la apreciación de la crisis, éstas son las explicaciones más evocadas por los expertos y los medios de comunicación para dar cuenta de la actual problemática alimentaria: alza de los costos de la energía; cambio climático; explosión de la demanda debido a las nuevas costumbres en los países emergentes; reducción de la oferta por las malas cosechas en algunos grandes países exportadores (Australia, Brasil, Ucrania, etc.); agotamiento de stocks internacionales, en los niveles más bajos desde la Segunda Guerra Mundial; anticipación en los precios y especulación de los productos alimenticios, convertidos en valores refugios en un clima económico y financiero moroso; voluntad de ciertos países exportadores de reservar su producción para el mercado interno; caída del dólar; y sobre todo, carrera para la elaboración de combustibles biológicos, presentados en otros tiempos como recetas milagrosas contra el cambio climático ${ }^{3}$.

En verdad estos factores intervinieron en diferentes niveles con relación al alza súbita de los precios de los alimentos, pero, como en el caso de los factores endógenos (sequía, guerra civil en Kenia, bloqueo de los territorios palestinos, etc.) no son suficientes para explicar la crisis alimentaria.

No nos dejemos engañar por el carácter espectacular del alza de los precios que alimenta los miedos neomalthusianos de una penuria generalizada de bienes alimenticios frente a una demografía galopante. Estos últimos cincuenta años, la producción alimentaria y agrícola mundial en realidad aumentó con la misma rapidez, e incluso más rápido que el crecimiento demográfico 4 . En el caso actual, aunque desde hace varios años se hayan registrado niveles récord de producción y se logrará hacerlo de nuevo en el futuro, una pequeñez habrá bastado -disminu- 


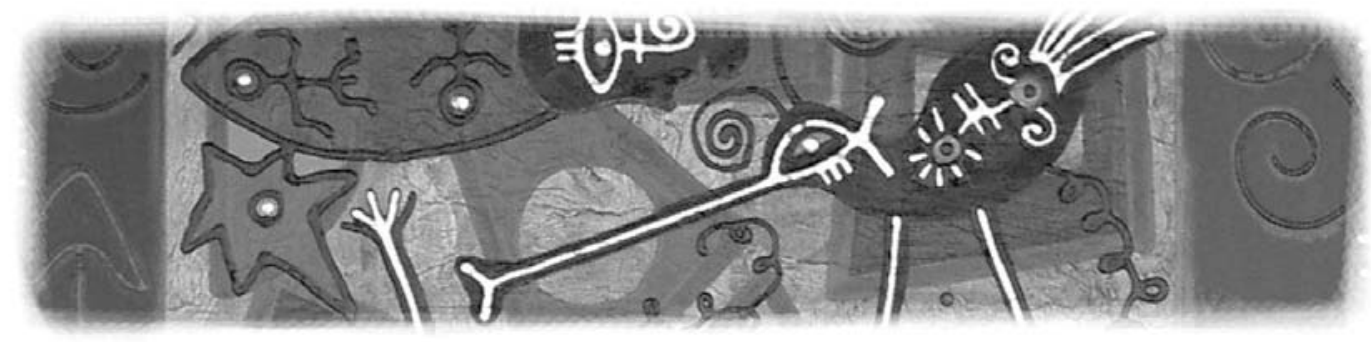

Imaginería. Detalle

ción relativamente escasa de la producción en algunos grandes países exportadores conjugada a fenómenos de anticipación- para provocar un alza desproporcionada de precios en los mercados internacionales.

Pero aún así, esta subida no tiene nada de excepcional, sólo tal vez su rapidez, más aún porque sucede después de un largo período de baja tendencial de los precios agrícolas y alimenticios: "Esta situación, explica Sylvie Brunel, nos recuerda los precedentes de 1973-1974 y de 1996, que también son periodos de tensiones en los precios." Y añade la economista: "Lo nuevo es que ésta pone en evidencia la extrema vulnerabilidad y la dependencia de muchos países en vías de desarrollo hacia sus importaciones alimentarias" (2008).

Es obvio que si la coyuntura tuvo consecuencias tan desastrosas en el Sur, es porque el terreno se prestaba para ello. La memoria mediática es corta. Ya, en los años 1980 - 1990, los países en desarrollo fueron la escena de numerosos disturbios urbanos... casi unos cincuenta. Más recientemente, Níger (2005), Bangladesh (2006), Mauritania, Guinea o también México y Marruecos (2007) tuvieron revueltas similares, aunque estos dos últimos países no consten en la lista de países considerados "vulnerables" de la FAO.

Otra manera de preguntar es: ¿Cómo se llegó a esto? ¿Cómo ciertos países, en otros tiempos autosuficientes, cayeron en una tal dependencia? Si bien la metáfora naturalista utilizada por el Comisario europeo para el desarrollo
Louis Michel, quien habla de un "tsunami económico y humanitario" para calificar los recientes acontecimientos, expresa realmente la gravedad de la situación, no impide que sea falaz. Ya que esta "crisis alimentaria" era perfectamente previsible. Sus raíces son profundas. Y su amplitud en los países del Sur es más bien la consecuencia de opciones políticas y económicas que fueron tomadas, reforzando una vulnerabilidad que se volvió poco a poco estructural, y no de un efecto coyuntural o un simple imprevisto. Crisis no tanto de escasez, sino de acceso a los alimentos para los países y los grupos más pobres, cuyo origen se debe principalmente a la transformación de los sectores agrícolas nacionales a lo largo de las últimas décadas.

Par comprender bien esta evolución es necesario echar una breve mirada hacia atrás. A principios de 1980 estalla la crisis de la deuda. A fin de disminuir un presupuesto bastante maltratado por el "servicio" de ésta última, las instituciones financieras internacionales obligan a la mayoría de los Estados del Sur a ajustar su economía. Las recetas son conocidas: austeridad presupuestaria, privatización de los servicios públicos, recortes netos en los gastos sociales, apertura a los intercambios y a los capitales extranjeros, etc.

Considerado costoso y poco productivo, el sector agrícola también es objeto de reformas de fondo. Se invita a los países en desarrollo a desregular sus mercados agrícolas, a abrir totalmente sus fronteras para las importaciones (sobre todo alimentarias) y a desmantelar sus políticas de 
asistencia para este sector, incluso las instituciones públicas encargadas de monitorear a los productores. Paralelamente, se les pide enfocarse en la producción y la exportación de productos con mayor valor añadido (fuentes de divisas en los mercados internacionales) y para los cuales disponen de ventajas comparativas innegables (mano de obra abundante y barata, condiciones de explotación favorables, facilidades de acceso a los recursos, etc.), perjudicando a los cultivos de plantas comestibles.

Para los autores de estas políticas neoliberales, la seguridad alimentaria realmente no estaba en peligro, en la medida en que los mercados internacionales se encargarían, en teoría, de abastecer a los mercados locales -particularmente urbanos- de productos alimenticios a bajos precios, en particular los provenientes de las agriculturas del Norte (Estados Unidos y Europa principalmente) con situaciones de sobreproducción, y mucho más competitivas puesto que se benefician de una política de ayuda pública generosa (primero subsidios para la exportación, y luego éstos son remplazados por ayudas directas a sus productores).

Así, John Block, Secretario de Estado de Agricultura en el gobierno de Ronald Reagan, declaraba en los años 1980: "La idea de que los países en desarrollo deberían alimentarse ellos mismos es un anacronismo de otros tiempos. Podrían asegurar mucho mejor su seguridad alimentaria contando con los productos estadounidenses, disponibles a menor costo" (citado por Bello, 2008).

En otras palabras, todo el mundo debía sacar provecho de la apertura y de la desregulación de los mercados agrícolas: el Norte lograría vender sus excedentes, mientras que los países del Sur mejorarían su situación económica sin tener que preocuparse por su seguridad alimentaria, puesto que a partir de ese momento ésta iba a ser asegurada por los mercados. Dentro de este mismo contexto serán firmados los diversos acuerdos de libre comercio regionales, bilaterales y birregionales, así como los acuerdos de Marra- kech (1995) que establecerán, con la creación de la OMC, un marco global para la liberación de los intercambios agrícolas.

Esta "actitud pasiva" tendrá consecuencias devastadoras para los países del Sur. Llevando los precios a un nivel artificialmente bajo, sin relación alguna con los costos de producción, la competencia internacional alterará profundamente las economías rurales locales y acabará con los pequeños campesinos, que ya no podrán obtener un ingreso suficiente por su actividad, al punto de afectar la seguridad alimentaria de muchos países.

El caso de Haití es emblemático. A fines de los años 1980, en el marco del plan Caribe minuciosamente elaborado por las instituciones internacionales y la administración Reagan, el país abandona casi totalmente su agricultura de subsistencia cuyos costos de producción eran considerados en esa época como "prohibitivos". Conminado a abrir totalmente sus fronteras para integrarse mejor en la economía mundial, el gobierno haitiano suprime en sólo algunos años los derechos de aduana de varios productos alimenticios (entre otros los cereales y las leguminosas), para concentrar sus esfuerzos en el desarrollo de cultivos más fácilmente exportables hacia Estados Unidos o Europa (árboles frutales principalmente). En cuanto a las fábricas y talleres de ensamblaje que supuestamente iban a implantarse en el país - promesa de los autores del plan atraídos por las "condiciones favorables", éstos se encargarían de absorber la mano de obra rural excedentaria.

Las consecuencias de esta política rápidamente resultaron ser catastróficas:

\footnotetext{
De la noche a la mañana, los campesinos haitianos, peso pluma de la agricultura mundial, tuvieron que boxear en el mismo ring que los pesos pesados americanos, cuya agricultura es muy subvencionada. Las importaciones se dispararon y los precios cayeron tan rápido como los ingresos de los campesinos. El resultado es que, mientras en el pasado la agricultura haitiana satisfacía más o menos las necesidades de la población, ahora el país importa cerca del $60 \%$ de sus alimentos. No es una sorpresa, en esas condiciones,
} 
que a la menor evolución de los cursos en los mercados mundiales, los "motines del hambre" se desencadenen como un fuego de paja (Husson, 2008).

Incapaces de competir con importaciones baratas que tenían costos de producción muy inferiores a los suyos, los campesinos haitianos, pero también filipinos, egipcios, nigerianos, indios, senegaleses, mexicanos, etc. vieron en pocos años cómo su ingreso se fundía como nieve al sol. Y se encontraron bloqueados en una espiral de endeudamiento y de empobrecimiento. Presionados por los mercados internacionales, menos canalizados y ayudados que en el pasado, muchos no tuvieron más alternativa que vender su fuerza de trabajo a los grandes terratenientes y a las empresas agroindustriales que supieron aprovechar plenamente la apertura y la liberalización de los intercambios agrícolas (acceso a nuevos mercados, disponibilidad de mano de obra, posibilidad de concentrar nuevas tierras y comprar las mejores por una bicoca a los campesinos empobrecidos, etc.) o de migrar hacia las aglomeraciones urbanas agrandando los suburbios que al campo se le hacía cada vez más difícil alimentar.

Asimismo, la apertura del mercado mexicano al maíz importado de Estados Unidos habría obligado a cerca de 1,3 millones de campesinos a dejar el campo entre 1994, fecha de la firma del TLCAN (Tratado de Libre Comercio de América del Norte), y 2003. El país, en otros tiempos autosuficiente, importa desde entonces cerca del 30\% del maíz necesario para su consumo desde Estados Unidos. En este caso, la decisión de Estados Unidos de producir masivamente combustibles biológicos a base de maíz, junto con las prácticas especulativas de las principales empresas importadoras en situación de casi monopolio, provocó en pocos meses un aumento de cerca del $60 \%$ del precio de la tortilla, causa de los disturbios del 2007.

La entrada de Filipinas a la OMC tuvo consecuencias igualmente catastróficas en el campesinado local. La supresión de cuotas en las importaciones de arroz y la decisión del gobierno de Aquino de reducir drásticamente las ayu- das a los productores para recortar el presupuesto nacional, produjeron una disminución de 400.000 personas en la población activa campesina entre 1994 y 2001. Esto sucedía mientras que el gobierno prometía que las eventuales pérdidas de empleo se compensarían mucho más con la creación de 500.000 puestos suplementarios en el campo, gracias al surgimiento de una industria agro-exportadora basada en producciones con "mayor valor agregado" (coliflor, brócoli, espárrago, etc.). Exportador neto de arroz bajo el régimen autoritario de Marcos (19651986), Filipinas importa ahora grandes cantidades de Tailandia para el consumo doméstico (Be1lo, 2008). Si sobreviene, en esas condiciones, una brusca alza de los cursos internacionales del arroz, las poblaciones de las ciudades, engrosadas por la llegada masiva de los campesinos empobrecidos, serán las primeras en sufrir las consecuencias.

Dicho esto, como lo recalca con razón Sylvie Brunel, "acusar a los países del Norte y a las instituciones financieras internacionales de haber querido hacer padecer hambre a los países en desarrollo, [...], refleja más el oportunismo de las circunstancias que la realidad" (2008). Los países industrializados y las instituciones internacionales no son los únicos responsables de la erosión del paisaje agrícola en los países del Sur. Interesados en maximizar sus intereses económicos y políticos a corto plazo, "los países en desarrollo, mucho antes de la crisis de la deuda, fueron los primeros en sacrificar a sus campesinos en el altar de la urbanización, de la industrialización y de la paz social" (ibíd.).

Desde los años 1960 en efecto, la mayoría de los gobiernos del Sur descuidaron intencionalmente el desarrollo y el fortalecimiento de la agricultura familiar y de subsistencia, considerada poco importante desde un punto de vista estratégico, para concentrar sus inversiones y sus esfuerzos en programas de industrialización a marcha forzada. Con el riesgo de afectar a un sector que representaba en ese entonces la gran mayoría de la población activa y de acrecentar 
su dependencia alimentaria, esta modernización desde arriba se apoyó en la importación masiva de productos alimenticios a bajo pre$\mathrm{cio}^{5}$, como medio, en una lógica clientelista, de comprar la paz social en la ciudad y contener los salarios para facilitar el proceso de industrialización.

La importación de productos alimenticios tenía además la ventaja de producir impuestos providenciales para esos gobiernos pobretones $y$ en busca de legitimidad. En muchos casos (Brasil, Argentina, Indonesia, Tailandia, Egipto, Costa de Marfil, Kenia, etc.), este proceso estuvo también acompañado por una política orientada hacia el desarrollo de monocultivos de exportación heredados de la época colonial, a costa de los cultivos de subsistencia (Friedmann, 2008; Mazoyer y Roudart, 2002). Más tarde, durante la fase neoliberal, varios fueron los gobiernos que además tomaron ellos mismos la iniciativa de desregular su mercado agrícola, sin esperar las directivas de las instituciones internacionales. No ver las responsabilidades locales en la deterioración de la situación, es no poder comprender el significado y el "alcance" reales de las movilizaciones sociales y populares del Sur.

\section{Movilizaciones: actores, formas, desafíos...}

Si el origen de la "crisis alimentaria" debe principalmente buscarse en la restructuración del paisaje agrícola y en la erosión de la agricultura familiar a lo largo de los veinte, treinta, incluso cincuenta últimos años, es en cambio en las ciudades que se sintieron los efectos más inmediatos del alza de los precios. Ahí también es donde las reacciones populares frente al alza desmesurada de los precios fueron más enérgicas. No sin razón. A medida en que se produjo el triple proceso de éxodo rural, urbanización y extraversión económica, las ciudades del Sur acabaron dependiendo casi exclusivamente de las importaciones de los productos alimenticios para
Más que simples reacciones defensivas, estas marchas cristalizaron también la aspiración a cambios políticos de fondo.

alimentar una población cada vez más numerosa, y ahora a merced de la mínima oscilación de los cursos internacionales.

Amplificadas por la caja de resonancia mediática, las protestas urbanas no deben, sin embargo, hacer olvidar que la problemática alimentaria afecta más al campo que, se debe recalcar, representa la mayor parte de la población en situación de extrema pobreza ${ }^{6}$. Pero enfoquémonos primero en las protestas urbanas.

\section{Protestas urbanas}

Digámoslo desde un principio, es casi imposible entender de un solo golpe las numerosas expresiones de descontento en medio urbano ante el alza de los precios. Ya que, en este asunto, la diversidad domina: diversidad de los lugares, de las situaciones y de los contextos de movilización, diversidad de las formas y de los repertorios de acción, diversidad de los participantes y de los actores presentes, diversidad de los motivos, etc. Qué tienen en común, en efecto, los disturbios de Puerto Príncipe, los estallidos esporádicos de violencia en Abiyán o en Karachi; los enfrentamientos mortales entre jóvenes desempleados y fuerzas del orden en las pequeñas ciudades de Sidi Ifni en Túnez y Gafsa en Marruecos; la prolongada huelga de los camioneros en Managua para obtener una disminución de los precios de la gasolina; la de los obreros textiles en Bangladesh y en Egipto, o las generales e intersectoriales organizadas en El Salvador, en Guatemala, en India o en África del Sur, sino su concomitancia. 
A veces reactivas, otras veces reivindicativas; a veces espontáneas, otras veces estructuradas; a veces dispersas, otras veces canalizadas; agitaciones de superficie o mar de fondo, estas protestas urbanas encajan difícilmente en un esquema interpretativo único. Primeramente porque su naturaleza y su alcance dependen mucho -sin por ello reducirse totalmente a esto- de los contextos nacionales en los cuales se encuentran, caracterizadas por lógicas conflictuales propias. Luego, porque los motivos de su aparición las alejan a menudo de la problemática alimentaria en sí.

En este contexto de alza de precios, varias categorías sociales en efecto se movilizaron por temas variados y causas diversas. Prolongando a menudo luchas mucho más viejas, estas movilizaciones reflejan sobre todo fuertes tensiones (sociales, económicas, políticas, culturales, étnicas, etc.) que atraviesan los universos urbanos extremadamente fragmentados y cada vez más desiguales.

Obviamente, la coyuntura actual no es necesariamente percibida como un fenómeno exclusivo o excepcional en las ciudades del Sur. A lo sumo aumenta la presión sobre las poblaciones urbanas que viven un proceso de informalización acelerada y una deterioración creciente de sus condiciones de vida, sobre todo después del ajuste sectorial de las ciudades en los años 1980 y 1990, que ya fue causa de "motines del hambre" (Delcourt, 2007).

Como lo señala en este libro Michel Luntumbue refiriéndose a la República democrática del Congo, con un comentario que se podría utilizar para varios países y ciudades del Sur, esta crisis "se inscribe en el contexto de una crisis anterior amoldándose a ella. Los efectos prolongados de la primera crisis ocultan la segunda y la vuelven difícil de entender". Esta crisis, usando las palabras del autor, solo se inserta en otra, mucho más profunda, remplazándola.

Una tendencia puede, sin embargo, desprenderse de esta constelación de movilizaciones urbanas, y merece ser tomada en cuenta: el sur- gimiento y la multiplicación de "coaliciones contra la vida cara” en África negra, en Egipto y en el Magreb, generalmente fuera de los habituales canales de expresión y de los movimientos políticos tradicionales. Heteróclitas en su composición -hay asociaciones de consumidores, estudiantes, desempleados, organizaciones confesionales y de pequeños comerciantes, ONG, grupos de defensa de los derechos humanos, representantes de las comunidades de base, partidos de oposición y sindicatos-, estas "coaliciones" revelan la aparición en la escena pública de un nuevo actor colectivo cuya única alternativa es utilizar la calle como lugar de expresión. Activas ciertas veces a nivel local alrededor de motivos específicos, otras veces a escala nacional, estas coaliciones son prueba también, más allá de las reivindicaciones materiales inmediatas, del descontento creciente de amplios sectores de la población con los sistemas políticos nacionales.

En efecto, en varios casos (Senegal, Costa de Marfil, Guinea, Níger, Camerún, Burkina Faso, etc.) las marchas contra la vida cara organizadas por iniciativa de estas coaliciones, en vínculo estrecho con las fuerzas de oposición más tradicionales (sindicatos, partidos políticos, etc.) se volvieron verdaderas manifestaciones antigubernamentales, donde se denunciaban indistintamente la incuria, la corrupción, la falta de gobernabilidad, la ausencia de diálogo, la falta de libertad individual y colectiva, el autoritarismo o también la indiferencia de las autoridades públicas, consideradas como ampliamente responsables de la situación.

Más que simples reacciones defensivas, estas marchas cristalizaron también la aspiración a cambios políticos de fondo ${ }^{7}$. Seguramente no es una casualidad si la asociación estrecha entre reivindicaciones económicas y políticas era todavía más aparente ahí donde las riendas del poder habían sido confiscadas desde hace varios años.

Ante estas movilizaciones, los gobiernos quisieron enmendarse invocando factores externos independientes de su voluntad (alza internacional de los precios, catástrofes naturales, injus- 
ticia del sistema económico internacional, etc.). Sin embargo la calle apuntaba directamente a ellos mismos (Harsch, 2008). Lo que explica además la rapidez y la brutalidad de la respuesta gubernamental y los enfrentamientos violentos que subsiguieron. Las experiencias nigeriana y guineana estaban sin duda presentes en la memoria. Coaliciones similares lograron, respectivamente en el 2005 y el 2007, conseguir cambios políticos significativos (Estados de las resistencias en el Sur, 2007).

\section{Movilizaciones de campesinos}

Sin embargo, esta crisis alimentaria también fue buena para algunos: las empresas agroexportadoras y la agroindustria sacaron plenamente provecho del alza de los cursos. La coyuntura de los precios altos, desde principios de los años 2000, les permitió no solamente acumular beneficios sustanciales, sino también fortalecer su posición económica. No sucedió lo mismo con las pequeñas explotaciones familiares para las cuales los beneficios potenciales de la coyuntura se anularon debido al alza desmesurada de los costos de producción (alza de los precios del combustible, de la tierra, del arrendamiento de las fincas, de los insumos agrícolas como las semillas, etc.), de los transportes, y a las prácticas abusivas de los negociantes en situación de casi monopolio en zonas apartadas o también debido a una situación dramática de endeudamiento.

Más allá de los efectos coyunturales, recordemos una vez más la doble tendencia histórica, generalizable en los tres continentes (África, América Latina, Asia), que empobreció profundamente y desarticuló las sociedades campesinas: la disminución tendencial de los ingresos agrícolas, agravada por la apertura de los mercados, y el fortalecimiento concomitante de un modelo productivista enfocado a los monocultivos de exportación y a los grandes proyectos industriales y de infraestructura que aumentan la presión sobre la tierra y los recursos naturales (agua, bosques, etc.). Es en contra de esta doble

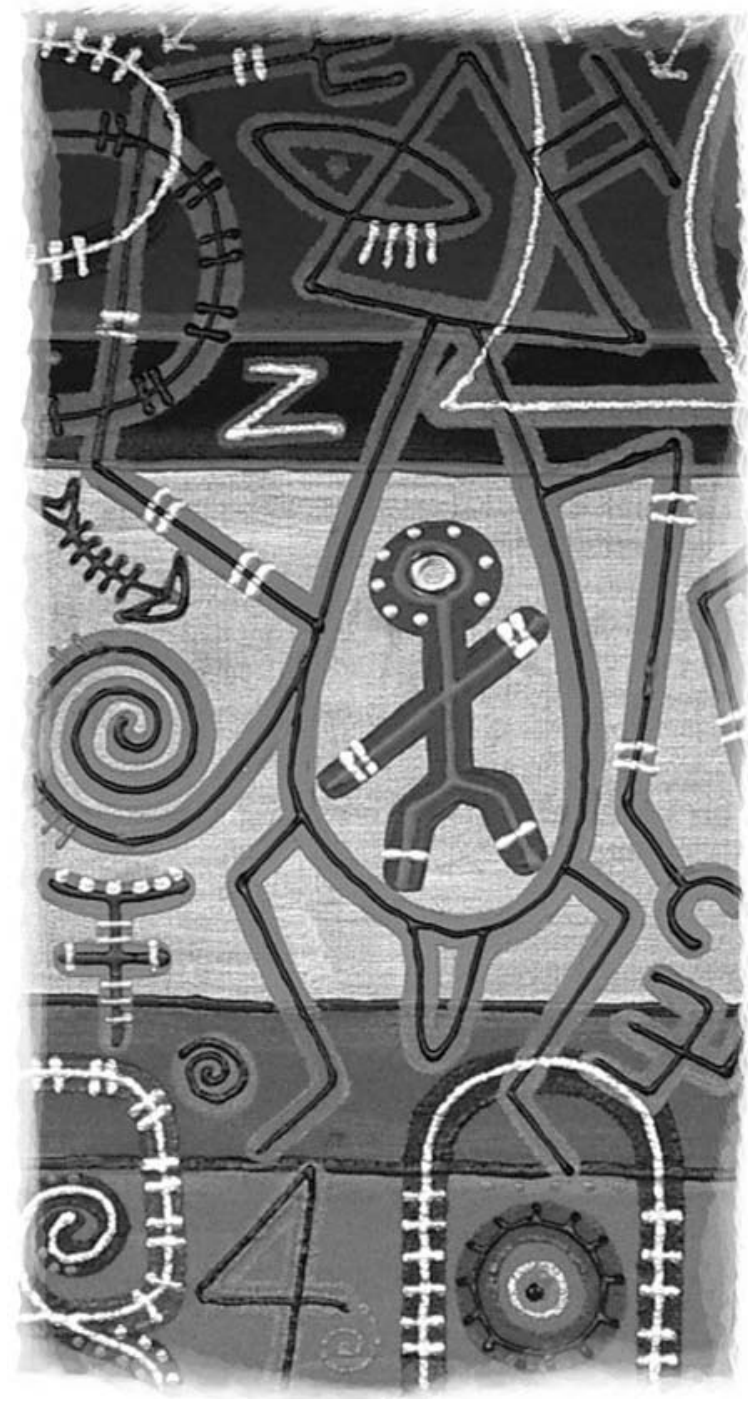

Reminiscencias. Detalle

tendencia deletérea para el mundo del pequeño y mediano campesinado que los movimientos sociales rurales, campesinos e indígenas se movilizan desde hace varios años, utilizando una gama de acciones ya sea defensiva, ya sea ofensiva, ya sea reivindicativa.

En los países emergentes, los proyectos de modernización económica (concesiones mineras y petroleras, construcción de presas, creación de 
zonas francas, etc.) y sus corolarios (expulsión, espoliación, etc.) son la causa de una multiplicación de resistencias en el mundo rural, unas espontáneas, otras enmarcadas por organizaciones asentadas a nivel local o nacional. En India, en China, en Indonesia o en Filipinas por ejemplo, las zonas francas o zonas económicas especiales, creadas por iniciativa de los gobiernos para atraer inversiones extranjeras e impulsar la expansión económica, son actualmente el teatro de una serie de conflictos entre las poblaciones rurales (indígenas y campesinas) por una parte, obligadas a ceder su tierra a un precio irrisorio o a cambio de vagas promesas de reinstalación, y las autoridades públicas y los grandes grupos privados $^{8}$ por otra.

Este tipo de conflicto se intensifica igualmente en América Latina, donde la lucha contra el modelo agrícola neoliberal y sus avatares tomó en varios países (México, Paraguay, Brasil, etc.) una nueva fuerza en el contexto de crisis. Así, las organizaciones campesinas brasileñas, asociadas en esa ocasión a las principales coordinaciones urbanas, lanzaron en junio del 2008 una serie de movilizaciones en aproximadamente trece Estados. Luchando contra proyectos de infraestructura (puertos, centrales hidroeléctricas, etc.), supermercados, multinacionales agroalimentarias, grandes explotaciones agrícolas (de caña de azúcar u otras), etc., incluían entre otros repertorios de acción, marchas, bloqueos de carreteras o también invasiones de tierra.

Con este conjunto coordinado de acciones, los movimientos y organizaciones movilizadas (MST, MAB, CPT, etc. ${ }^{9}$ ) trataban de denun-

\section{La "crisis" fue la oportunidad para} las organizaciones campesinas de desarrollar en la opinión pública el tema de la "soberanía alimentaria". ciar la orientación de las políticas agrícolas del gobierno de Lula (política de apoyo a la agroindustria y a los sectores agro-exportadores, promoción de los transgénicos y de los combustibles biológicos, etc.), de reclamar una reforma agraria efectiva, así como programas de apoyo a la agricultura familiar y de subsistencia. Políticas públicas de apoyo a la pequeña agricultura familiar que son reivindicadas igualmente por la mayoría de las coaliciones campesinas africanas. A semejanza de sus homólogas asiáticas y latinoamericanas, tampoco dejan de denunciar el abandono y la falta de inversión del Estado en este sector, la política de liberalización y las subvenciones que reducen dramáticamente los ingresos. Signo de los tiempos, en lo más fuerte de la crisis, estas coaliciones crearon en Addis-Abeba una plataforma panafricana común para defender los intereses de las explotaciones familiares agrícolas y de los productores ${ }^{10}$.

La "crisis" finalmente fue la oportunidad para las organizaciones campesinas de desarrollar en la opinión pública el tema de la "soberanía alimentaria", concepto movilizador clave de la red internacional Vía Campesina. Concebida como solución global para la crisis actual y para las crisis venideras, la soberanía alimentaria defiende exactamente lo contrario a las teorías fundadas en las ventajas comparativas. Considerada como un derecho internacional, ésta representa la posibilidad para un país o un grupo de Estados de definir democráticamente y de manera autónoma las políticas mejor adaptadas a las necesidades de sus poblaciones.

A la noción de "seguridad alimentaria", que corresponde a la cantidad de alimentos producidos en el plano nacional y a su disponibilidad, añade una dimensión social y medioambiental: mejor repartición de la tierra, si es necesario por medio de una reforma agraria, protección y fortalecimiento de las explotaciones familiares y de subsistencia, preservación de los entornos, reflexión sobre el tipo de producción y la manera como se producen los alimentos, privile- 
giando principalmente la agricultura orgánica y la utilización de semillas locales, en oposición a los transgénicos.

\section{Respuestas gubernamentales a la crisis}

Las reacciones de las autoridades públicas ante la crisis deben ser analizadas según la naturaleza de las relaciones entre Estados y sociedades civiles. Por una parte, porque el tipo de respuestas concretas generalmente depende de la capacidad que tiene la sociedad civil de influir en las decisiones públicas. Por otra parte, porque las respuestas gubernamentales se inscriben generalmente dentro de estrategias políticas que buscan canalizar o a anular las razones del descontento popular.

Relatando el alza de los precios alimentarios y los "motines del hambre" que se produjeron por su causa en Marruecos, Yemen, Uzbekistán, Mauritania, Guinea y Senegal, el representante de un gran organismo internacional señalaba durante el Foro económico de Davos en enero del 2008: "Estos fenómenos preocupan a los gobiernos mucho más que el aumento del precio de la gasolina" (Lemaître, 9 de febrero del 2008). Mucho más que el impacto económico directo del alza de los precios de la energía, muchos temían en efecto los conflictos sociales y los riesgos políticos asociados que podían resultar del alza extrema de los precios alimentarios, en particular en los países donde los gobiernos se caracterizan por un déficit de legitimidad.

En términos generales, es esta aprensión, mucho más que una verdadera voluntad de remediar la situación de las poblaciones directamente más afectadas, que llevó a las autoridades a reaccionar inmediatamente, adoptando con apremio un conjunto de medidas para evitar que el descontento creciente de la población se convierta en manifestaciones de masa, políticamente peligrosas.
En Asia, los gobiernos, en su mayoría, anticiparon los acontecimientos. Atentos a los primeros signos de insatisfacción, Tailandia, Vietnam, India, o también China optaron desde el principio por una estrategia de repliegue sobre sí mismo, ya sea restringiendo los contingentes exportados, ya sea aumentando los impuestos sobre las exportaciones, para asegurar el abastecimiento de los mercados internos. En Filipinas, para calmar las calles ya ampliamente movilizadas, las autoridades procedieron a distribuir masivamente arroz en los barrios populares.

Ahí, como en otros países asiáticos que se volvieron importadores netos, una política de estabilización y de control de precios alimentarios fue lanzada: supresión temporal de los impuestos sobre las importaciones, utilización de los stocks estratégicos, adquisiciones costosas de productos en los mercados internacionales, imposición de precios máximos para la venta hasta en los supermercados, etc. Estas iniciativas parecen haber alcanzado en parte su objetivo. Con excepción de algunos países (Filipinas, Malasia, Bangladesh, Indonesia), donde las movilizaciones fueron de todas maneras rápidamente circunscritas, Asia no fue realmente el teatro de una ola masiva de protestas populares directamente vinculadas con el alza súbita de los precios.

Tomados por sorpresa por los acontecimientos y -es cierto- menos armados para enfrentar la crisis, los gobiernos africanos, con raras excepciones (Etiopía, por ejemplo), actuaron mucho menos al principio. Frente a las reivindicaciones de la calle, prefirieron mayoritariamente la opción represiva. En los lugares donde las sociedades civiles son más débiles y menos organizadas, las pocas tentativas de movilizaciones sobre el tema alimentario fueron directamente cortadas de raíz. En otras partes, el Estado no dudó en desplegar todo su poder represivo, iniciando así un nuevo ciclo de violencia-represión.

Frente a la determinación de los protestantes y conscientes de los riesgos políticos a los que estaban expuestos, varios gobiernos final- 
mente decidieron abrir el diálogo, principalmente con las organizaciones de la sociedad civil "oficial”, y adoptar algunas medidas de urgencia especialmente dirigidas a las poblaciones urbanas (eliminación de impuestos en los productos de primera necesidad, alza sectorial de salarios, en particular los de los funcionarios, indemnizaciones para los jóvenes graduados, etc.), a veces con razones puramente simbólicas, como en Senegal, donde se tomó la decisión de limitar el salario de los parlamentarios.

En un puñado de países (Nigeria, República democrática del Congo, Senegal) también se anunciaron con energía y rapidez ambiciosos planes de desarrollo agrícola para garantizar en el futuro una mejor seguridad alimentaria, incluso, como en Burkina Faso, la ejecución de una verdadera política social contra la vida cara. Sin embargo, surge la pregunta sobre los medios de una tal ambición, puesto que la vulnerabilidad de los países africanos a los choques externos es muy grande y sus capacidades presupuestarias son débiles.

En los países del Magreb y en Egipto, los gobiernos actuaron por su parte a varios niveles, usando alternativamente la represión, la apertura y las medidas de apaciguamiento. Luego de haber amenazado con reprimir cualquier movilización, las autoridades tunicinas, marroquíes o también egipcias, temiendo un contagio de protestas, maniobraron con mucho tino, tratando de adaptar sus repuestas en función del giro que tomaban los acontecimientos.
En Egipto por ejemplo, donde la huelga sectorial y localizada de los obreros textiles de la ciudad de Mahalla se transformó poco a poco en huelga general contra la vida cara, a la que se aliaron amplios sectores de la clase media sobre todo a través del llamado del movimiento Kifaya. Ante esta unión inesperada, el gobierno que en un principio mostró una rígida firmeza ante las reivindicaciones obreras, terminó por ceder y decidió aumentar los salarios de los obreros en un $50 \%$, y los de la función pública en un $30 \%$. Una concesión inhabitual, destinada principalmente a preservar, tras una aparente apertura, el statu quo social y político.

Como lo explica Sarah Ben Nefissa en este libro, "estas decisiones son el reflejo de la nueva actitud de los poderes públicos egipcios ante las movilizaciones de tipo social: una voluntad de "apaciguar la situación" tratando de responder de manera parcial a los reclamos y procurando vigilar cualquier politización de estas acciones colectivas y cualquier unión posible entre los activistas sociales y los activistas políticos". Así como en Marruecos o en Túnez, las autoridades egipcias también tomaron medidas temporales para reforzar el acceso a los alimentos: aumento de los cupos de harina subvencionada, multiplicación de la cantidad de puntos de distribución de pan en las grandes ciudades, incremento de la producción de las panaderías del Estado, ampliación de la categoría de los "derechohabientes", etc.

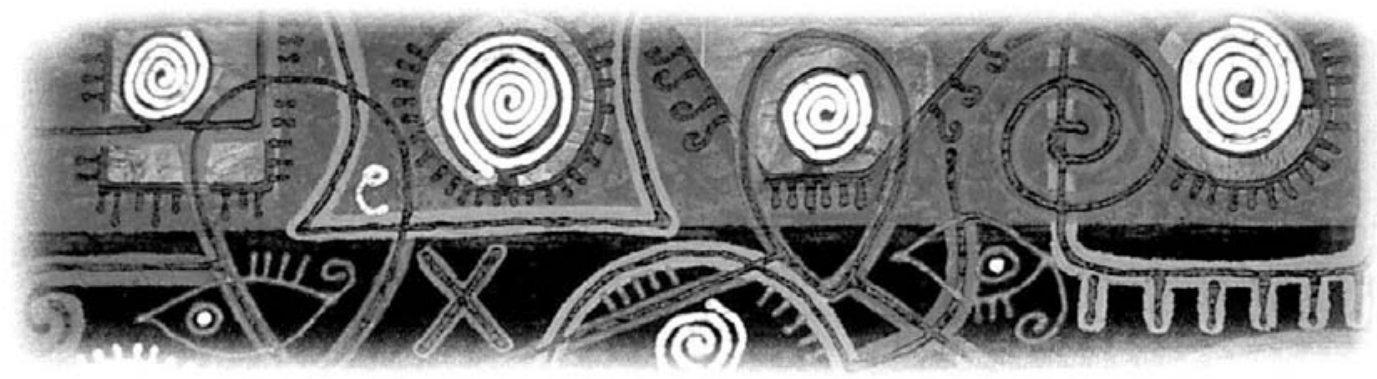

Omnipresencia. Detalle 
El caso de América Latina también merece una atención especial. Con notable excepción de Haití y de México, la mayoría de los países latinoamericanos no tuvieron movilizaciones de gran importancia. Manifestaciones intersectoriales y huelgas generales se dieron en varios países de América Central (El Salvador, Guatemala, Honduras), pero la temática alimentaria sólo aparecía de manera indirecta, incorporada en un amplio panel de diversas reivindicaciones. En otras partes, hubo movilizaciones sectoriales pidiendo una revalorización de salarios.

Es un hecho significativo, que en los lugares donde los gobiernos subieron al poder gracias a la movilización de amplios sectores populares, la sociedad civil y los movimientos sociales se mostraron más discretos, absteniéndose de movilizar masivamente por el tema de la crisis alimentaria. Una reserva que se explica esencialmente por las grandes esperanzas puestas en estos gobiernos. Así, según Marielle Palau, "el clima post-electoral y las esperanzas para con el nuevo gobierno contribuyeron a la moderación de las interpelaciones". Es verdad que Fernando Lugo, recientemente electo, enfocó su campaña en los temas de la seguridad y de la soberanía alimentaria, en la participación del conjunto de los sectores sociales para la elaboración de políticas públicas, en la reforma agraria o también en el apoyo y el fortalecimiento de la agricultura familiar y de subsistencia, medidas reivindicadas desde hace mucho tiempo por los movimientos sociales paraguayos.

Asimismo, en Bolivia, en un contexto político extremamente tenso y polarizado, los movimientos populares parecen haber privilegiado ampliamente los retos políticos del momento antes que las preocupaciones materiales inmediatas, aportando masivamente su apoyo al gobierno de Morales que atraviesa dificultades debido a la rebelión de los gobernadores del Este del país. Sólo los partidarios de éstos últimos trataron de aprovechar la situación para adherir la población a su causa... sin alcanzar su objetivo hasta ahora.
Pero los países latinoamericanos que sin duda estuvieron más protegidos de la crisis y de sus consecuencias sociales son aquellos en donde las políticas públicas establecidas por los gobiernos progresistas funcionaron plenamente, impidiendo que el alza de los precios golpee duramente a las poblaciones más expuestas. Por más limitado que sea, no hay duda alguna de que el programa "Bolsa Familia", adoptado por el gobierno de Lula, que prevé el otorgamiento bajo ciertas condiciones de un ingreso complementario para las familias más pobres, permitió disminuir sustancialmente la factura de los alimentos $^{11}$. Alza de precios igualmente amortiguada en Venezuela donde una red muy densa de almacenes subsidiados y el otorgamiento de bonos alimentarios a los asalariados, financiados gracias a los ingresos petroleros, permiten ahora a las categorías sociales más pobres gozar del beneficio de una alimentación variada y barata.

En estos países extremadamente dependientes de las importaciones y que ya vivieron en el pasado disturbios (el famoso Caracazo en 1989), la cuestión de la soberanía alimentaria, de la reforma agraria y de la agricultura familiar y de subsistencia también está en el centro de la agenda política del gobierno. Pero el discurso oficial que convierte la "lucha contra los latifundios" en uno de sus caballos de batalla no debe ocultar una realidad netamente más prosaica, que resalta la dificultad de conciliar renta petrolera y autosuficiencia alimentaria.

El boom petrolero, combinado con una estricta política de control de cambios que trata de moderar la inflación y evitar la fuga de capitales, hace en efecto que las importaciones alimentarias sean relativamente baratas, con el riesgo de afectar la competitividad de los pequeños productores, de acrecentar el éxodo rural y de reforzar la dependencia alimentaria del país -éste importa en efecto cerca del 75\% de los alimentos para su mercado doméstico-, esto a pesar de las tentativas del gobierno de Chávez para remediar esta situación con una política voluntarista de diversificación agrícola y económica. 
En estos últimos cincuenta años, la producción alimentaria y agrícola mundial aumentó con la misma rapidez, e incluso más rápido, que el crecimiento demográfico.

En cuanto a la reforma agraria, su realización no estuvo exenta de errores y de extravíos. Así, como lo explica un agrónomo de la Universidad central de Venezuela, "se asignaron tierras y se distribuyeron recursos, pero en un clima de improvisación, sin comprender dimensiones técnicas de las decisiones, sin integrar la inversión económica a la necesidad del mercado" (citado por Saint-Upéry, 2007).

Dicho esto, sin juzgar de antemano su éxito o su fracaso a largo plazo, estas medidas demuestran sin embargo una verdadera voluntad de modificar radicalmente la orientación de las políticas agrícolas y alimentarias, al contrario de la mayoría de los países del Sur cuyas iniciativas no combaten las causas sino las consecuencias del problema: no hay proyectos de gran importancia, no hay reformas de envergadura, no hay iniciativas que lleven hacia un verdadero cambio estructural. Singularmente, la agricultura familiar y de subsistencia, eterno pariente pobre de las políticas públicas, se encontró nuevamente fuera del alcance de estas medidas enfocadas principalmente a las necesidades urbanas. Y el gobierno tailandés, por ejemplo, justifica el statu quo declarando sin discernimiento que el alza de los precios solo podía resultar positiva para el sector rural.

\section{Desafío de la soberanía alimentaria}

La cumbre de la FAO, celebrada en Roma en junio del 2008 a fin de encontrar soluciones comunes a la crisis alimentaria, fue sobre todo la ocasión para los participantes de exponer sus profundas divergencias: divergencias de puntos de vista prácticamente inconciliables sobre los combustibles biológicos, sobre los subsidios y las ayudas agrícolas, sobre el tipo de política alimentaria que debe instituirse, etc. Además, las esperanzas puestas en esta cumbre dieron rápidamente paso a la desilusión.

A su favor, una serie de promesas de los Estados del Norte de aumentar su ayuda alimentaria de urgencia y su apoyo al desarrollo agríco$\mathrm{la}^{12}$, varios llamados a una mayor responsabilidad por parte de los Estados en la gestión de sus políticas alimentaria y agrícola, una nueva preocupación en cuanto al futuro de la agricultura familiar y de subsistencia y, finalmente, una declaración intrascendente que, al mismo tiempo que allana los numerosos conflictos de intereses -económicos y políticos- entre los países, compromete a estos últimos a "eliminar el hambre y garantizar la seguridad alimentaria para todos, hoy día y mañana”. Objetivo sin duda alguna audaz, pero que no hace más que retomar compromisos antiguos y varias veces reiterados desde entonces.

Adoptada por unanimidad por el conjunto de los Estados presentes - menos la abstención notoria de Venezuela, de Cuba y de Argentina -, la declaración es evasiva en la problemática sobre la ayuda de los países del Norte a su sector agrícola, se abstiene de cuestionar el modelo agroexportador vigente y permanece callada ante el tema de la "soberanía alimentaria". Luego de una letanía de buenas intenciones y de peticiones de principios, la orientación liberal de las políticas agrícolas mundiales se reafirma, en cambio, sin rodeos: "Alentamos a la comunidad internacional a continuar con sus esfuerzos en materia de liberalización de intercambios internacionales de productos agrícolas, reduciendo los obstáculos para el comercio y las políticas que son la causa de distorsiones de los mercados" (FAO, 2008).

Este unanimismo aparente no puede ocultar el hecho de que el consenso liberal que prevalecía en el sector agrícola en los años 1990 se res- 
quebrajó. Consecuencia de la crisis, los reflejos proteccionistas se multiplicaron a pesar de las repetidas advertencias de las instituciones internacionales, dado que estas reacciones amenazan -es cierto- con agravar la situación de los países importadores. El fracaso de la reunión de la OMC, organizada un mes después de la Cumbre de la FAO y que se supone permitiría concluir el ciclo de Doha en lo referente a la liberalización, revela igualmente la ausencia de un verdadero consenso internacional. Seis meses antes, los acuerdos de cooperación económica (APE) propuestos por la Comisión europea a los países ACP para liberalizar los intercambios interregionales eran rechazados por varios países africanos, argumentando que representan una amenaza para su economía rural.

Propuesto algunos años antes por los Estados Unidos a los países de la región, el proyecto de integración económica del continente (Alca) corrió la misma suerte. Considerados como estrategias de remplazo del Alca, los acuerdos bilaterales de libre comercio tienen dificultad en imponerse o son cada vez más abiertamente cuestionados. No solamente por una población que se moviliza contra este tipo de acuerdo, sino también por los gobiernos de la ola izquierdista que se expandió en un continente escarmentado por cerca de treinta años de liberalismo desenfrenado. Iniciativa venezolana, el Alba (Alternativa bolivariana para las Américas) pretende desde ya imponerse, usando a gran escala una diplomacia de la seducción, como solución alterna a los acuerdos de libre comercio, especialmente promocionando una cooperación interestatal orientada hacia los temas de seguridad y de soberanía alimentaria ${ }^{13}$.

Sin embargo, falta mucho para ganar la apuesta alimentaria. La instauración de políticas audaces enfocadas en la protección, el apoyo y el fortalecimiento de la agricultura familiar y de subsistencia, la diversificación agrícola, el abastecimiento de los mercados internos (rurales y urbanos) con productos de calidad producidos localmente y a precios que aseguran la reproduc- ción de las pequeñas explotaciones campesinas, dependerá ante todo de la capacidad de las organizaciones y movimientos sociales a superar sus numerosas divisiones, a converger hacia acciones comunes para imponer una verdadera relación de fuerza, y a encontrar finalmente soluciones políticas a sus reivindicaciones. Son muchos los obstáculos.

En el sector militante, en efecto, los intereses particulares y corporatistas subyugan a menudo la acción común y la coordinación necesaria. Como lo muestra en este libro Maristella Svampa en el caso de Argentina, en una coyuntura de precios altos provechosa para los sectores agrícolas nacionales, los proyectos gubernamentales encaminados a gravar las exportaciones desembocaron en un conflicto abierto con el mundo rural y generaron una "falsa polarización". De esta manera, muchos pequeños y medianos productores, pero también amplios sectores urbanos, hartos por el aumento de los precios, se unieron al "frente agrario" dirigido esencialmente por una oligarquía agraria despreocupada del

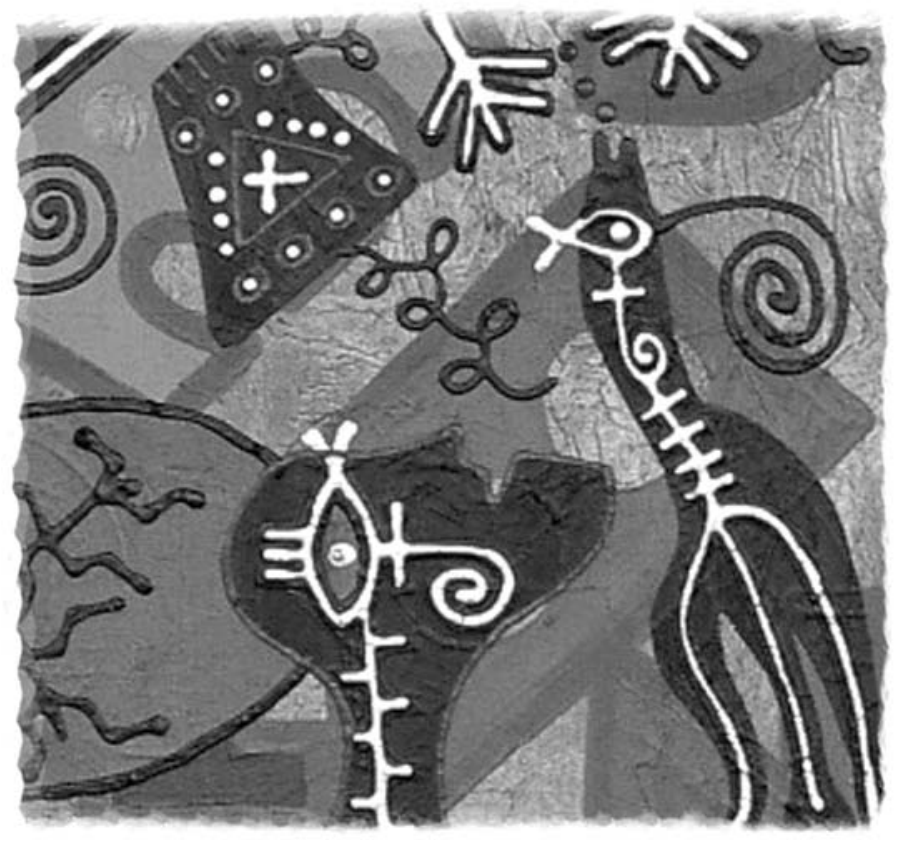

Imaginería. Detalle 
interés general. Una falsa polarización que también existe en Bolivia y en India, donde el tema de la vida cara es utilizado para fines políticos, incluso religiosos en el segundo caso.

Es verdad que la percepción diferenciada de los retos no facilita el proceso de convergencia, especialmente entre los movimientos sociales urbanos y rurales, los unos movilizando generalmente a favor del poder de compra y por el empleo, los otros reclamando precios de venta suficientemente altos para asegurarse un mejor ingreso. Contradictorios en apariencia, y a menudo factor de tensiones entre sindicatos y movimientos campesinos en las zonas de desarrollo económico, estos intereses sólo se conciliarán con la construcción de un marco común de percepción que establezca la relación entre los problemas particulares y los diferentes retos ${ }^{14}$.

$\mathrm{Al}$ permitir esa generalización, el concepto de "soberanía alimentaria", que sintetiza los diferentes retos ligados a los temas agrícolas y alimentarios y define un proyecto alternativo a las políticas de liberalización, puede servir de base a tales convergencias, como lo muestra la experiencia exitosa de Vía Campesina.

Pero este proyecto sólo podrá llegar a un resultado si encuentra sólidos apoyos en las esferas políticas institucionales nacionales e internacionales, únicas capaces de transformar las reivindicaciones en políticas concretas. Ahora bien, aun ahí donde los dos universos, social y político, no están muy separados, ahí donde existe entre ellos un cierto "parecido de familia", la presión de los grupos de interés, en este caso los de la agroindustria, se mantiene fuerte y continúa a influir en la definición de las políticas nacionales.

Esto sucede en Brasil. Aunque llegó al poder gracias a la movilización de numerosos sectores populares, el gobierno de Lula, motivado por intereses económicos a corto y a mediano plazo, poco se alejó de la política económica y agrícola ortodoxa de sus predecesores. A semejanza de otros países emergentes, el país hasta se volvió uno de los principales promotores de la liberalización de los intercambios agrícolas y - con Estados Unidos - el gran defensor de los combustibles biológicos.

Lo que demuestra sobre todo el caso brasileño, es que el debate sobre los temas agrícolas y alimentarios no coincide para nada con las líneas del debate Norte-Sur. Es ante todo un debate entre dos modelos, dos visiones radicalmente diferentes sobre el devenir agrícola, que opone, como lo resumía con ironía un comentarista del Guardian: "Por un lado [...] gobiernos y grandes multinacionales que sostienen que necesitamos más mercado y globalización. Por otro [...], un número creciente de personas que piensan que hemos tocado fondo, y que sería mejor -en esas condiciones- dejar de cavar".

Por una parte, los que, a la manera del primer ministro británico Gordon Brown, "hacen creer que el mejor medio de enfrentar la crisis alimentaria mundial es concluir lo más rápido el ciclo actual de negociación en la OMC para liberalizar más el comercio y abrir todavía más ampliamente los mercados mundiales a las exportaciones de las multinacionales". Por otra, los que reclaman una reorientación radical de las políticas agrícolas para superar el caos que la globalización ayudó a crear, recordando de paso que las políticas de libre comercio desorganizaron la estructura de las sociedades rurales y "empujaron a millones de trabajadores rurales y urbanos hacia la economía informal, ahí donde el hambre es una realidad cotidiana incluso cuando todo va bien" (Hilary, 2008).

\section{Bibliografía}

- BELLO, W.: "How to manufacture a global food crisis: lessons from the World Bank, IMF, and WTO", Focus on Trade, $\mathrm{N}^{\circ} 140$, mayo, 2008.

- BRUNEL, S. : "Les émeutes de la faim, une opportunité historique pour les paysans", Le Mensuel de l'Université, 2008. <www.lemensuel.net>

- CÁCERES, S.: "Ante la crisis alimentaria: 'Ne- 
cesitamos más acciones y menos discursos", Envío, $\mathrm{N}^{\circ} 315$, junio, 2008.

- DELCOURT, L. : "Editorial: Explosion urbaine et mondialisation", Alternatives Sud, vol. 14-2, 2007.

- DE SCHUTTER, O. : "Il faut suspendre les programmes d'investissement dans les agrocarburants", Le Soir, 6-7 de septiembre de 2008.

- Etats des résistances dans le Sud-2008 (2007), CETRIS/Syllepse, Louvain-la-Neuve/Paris.

- FAO: Declaración de la Conferencia de alto nivel sobre la seguridad alimentaria mundial: los desafíos del cambio climático y la bioenergía, 5 de junio, 2008. <www.fao.org $>$.

- FRIEDMAN, H.: "The origins of Third Word food dependence", Third World Resurgence, $\mathrm{N}^{\circ}$ 212. Versión tomada del libro, The Food Question: Profits Versus People, (1990), Bernstein Henry, Crow Ben, Mackintosh Maureen, Martin Charlotte (ed.), New York, Monthly Review Press, 2008.

- HARSCH, E.: "Manifestations contre la vie chère. Emeutes et répression témoignent des problèmes de grouvernance en Afrique", Afrique Renouveau, vol. 22 - 2 de julio, 2008.

- HILARY, J.: "Food crisis: stop digging!", The Guardian, 4 de junio, 2008.

- HUSSON, S. : "Crise alimentaire. Soigner le mal par les racines", Faim et Développement magazine, $\mathrm{N}^{\circ} 232$, junio-julio, 2008.

- LEMAITRE, F. : "Une crise alimentaire majeure se profile", Le Monde, 9 de febrero, 2008.

- LE SAOUT, D. : "Les émeutes en perspective", in Didier Le Saout, MargueriteRollinde (dir.), Emeutes et mouvements sociaux au Maghreb. Perspective comparée, Paris, Karthala/Institut Maghreb-Europe, 1999.

- MAZOYER, M. : "L'origine de la crise alimentaire mondiale", Entrevista, 2008. <www.cite-sciences.fr $>$.

- MAZOYER, M. y L. Roudart : Histoire des agricultures dans le monde. Du néolithique à la crise contemporaine, Paris, Le Seuil, col. Point Histoire, s.l., 2002.

- MCKIE, R. y H. Steward: "Riots, The food crisis bits", The Observer, 13 de abril, 2008.

- DE RAVIGNAN, A. : "Au Sud, plus dur est le choc", Alternatives économiques, $\mathrm{N}^{\circ} 269$, mayo, 2008.

- RIVELLI, Ph. : “Les Philippins regretteraient presque... Ferdinand Marcos", Le Monde Diplomatique, $\mathrm{N}^{\circ} 651$, junio, 2008.

- SAINT-UPERY, M. : Le rêve de Bolivar. Le défis des gauches sud-américaines, Paris, La Découverte, 2007.

- WEAVER, M.: "Q\&A, Food crisis", The Guardian, 29 de abril, 2008.

1 Artículo traducido de Alternatives Sud, No. 4 (2008)

2 Desde julio del 2007, la FAO propuso, sin éxito, la organización de una Conferencia de alto nivel sobre la seguridad alimentaria y, en diciembre del mismo año, previendo la inminencia y la naturaleza de la crisis - especialmente una multiplicación de motines del hambre -, lanzó una iniciativa, tampoco muy tomada en cuenta, contra el alza desmesurada de los precios de los alimentos y a favor del aumento de la producción agrícola mundial.

3 Varios especialistas estiman que el 75\% del aumento de los precios desde el 2006 se debe a la producción de combustibles biológicos, teniendo en cuenta las políticas (programas de inversión, subsidios, etc.) y los efectos especulativos asociados (De Schutter, 2008).

4 Según Marcel Mazoyer (economista e ingeniero agrónomo, profesor emérito del Instituto nacional agronómico Paris-Grignon, presidente del comité del programa de la FAO de 1983 a 1993), habrían suficientes tierras explotables para alimentar sosteniblemente a toda la población incluso hasta el 2050, cuando ésta haya alcanzado su apogeo demográfico, inclusive sin tomar en cuenta bosques y tierras reservadas para otros cultivos (combustibles biológicos, por ejemplo). Pero el autor aclara, sin embargo, que este obje- 
tivo solo podrá ser alcanzado si se aceptan inversiones substanciales en el sector de los cultivos de subsistencia a fin de mejorar la productividad (Mazoyer, 2008).

5 Se trataba esencialmente de excedentes de producción donados por Estados Unidos como ayuda alimentaria o vendidos a precios concesionales. En el periodo de la Guerra fría, esa ayuda tenía un objetivo estratégico, tanto los Estados Unidos como la URSS utilizaron el instrumento de la ayuda alimentaria para fortalecer alianzas.

6 Según Marcel Mazoyer, de los 852 millones de personas que sufren hambre en el mundo, las tres cuartas partes son rurales. Los campesinos representan aproximadamente dos tercios de los 3 mil millones de personas que viven con menos de 2 dólares por día (2008).

7 En Burkina Faso, la coalición lleva el nombre de "Coalición nacional de lucha contra la vida cara, la corrupción, el fraude, la impunidad y por las libertades”. En mayo del 2008, se realizó una huelga general de 72 horas por iniciativa de ella.

8 En ciertas regiones, estos últimos no dudan además en utilizar la intimidación, incluso el asesinato de militantes para conseguir sus fines. En Filipinas, opuesto al North Luzon Super Economic Planship (vasto plan de desarrollo económico elaborado por las autoridades locales que prevé la construcción de un puerto al norte de la isla de Luzón, la creación de zonas francas y el desarrollo de los cultivos de exportación), el movimiento campesino regional Kagimungan vio precisamente a varios de sus líderes asesinados por grupos paramilitares. Considerada como el principal obstáculo para la realización del plan, esta organización había impulsado la lucha contra la aparcería en la región y obtuvo algunas victorias decisivas (Cancelación del pago de $50 \%$ de las cosechas a los "señores de la tierra" e imposición a los comerciantes de condiciones de compra de las cosechas más favorables para los pequeños productores) (Rivelli, 2008).

9 Movimiento de campesinos sin tierra, Movimientos de las víctimas de las presas, Comisión pastoral de la tierra.

10 Esta plataforma agrupa las cuatro grandes redes subregionales africanas: Redes de las organizaciones campesinas de Africa austral (Sacau), de Africa central (Propac), de Africa del Este (Eaff) y del Oeste (Roppa).

11 Actualmente el programa abarca más o menos 11 millones de familias, o sea aproximadamente el cuarto de la población brasileña.

12 Cabe indicar que el monto total de las ayudas para el desarrollo de la agricultura no ha dejado de disminuir desde fines de los años 1970, pasando de más de 7 mil millones de dólares a menos de 2 mil millones en el 2005. En el mismo periodo, la proporción de esta ayuda con respecto a la totalidad de ayudas públicas pasó de más del 16\% a menos del 4\% (de Ravignan, 2008).

13 El Alba fue oficialmente celebrado en abril del 2005 con la firma de un tratado "comercial de los pueblos" entre Venezuela y Cuba. Posteriormente, Bolivia, Nicaragua, República Dominicana y Honduras se unieron a esta iniciativa.

14 Se pudo ver en varios países convergencias inéditas: en México, por ejemplo, durante la crisis de la tortilla, los sindicatos campesinos se aliaron a los sindicatos obreros para organizar las movilizaciones; en varios países de África donde ciertas organizaciones rurales integraron las coaliciones contra la vida cara, o también en Egipto donde los campesinos movilizados contra un proyecto de desarrollo económico en la ciudad de Maniet recibieron el apoyo importante por parte de las poblaciones urbanas. 


\section{La construcción del sistema de soberanía alimentaria y nutrición del Ecuador}

\section{Fernando Rosero*}

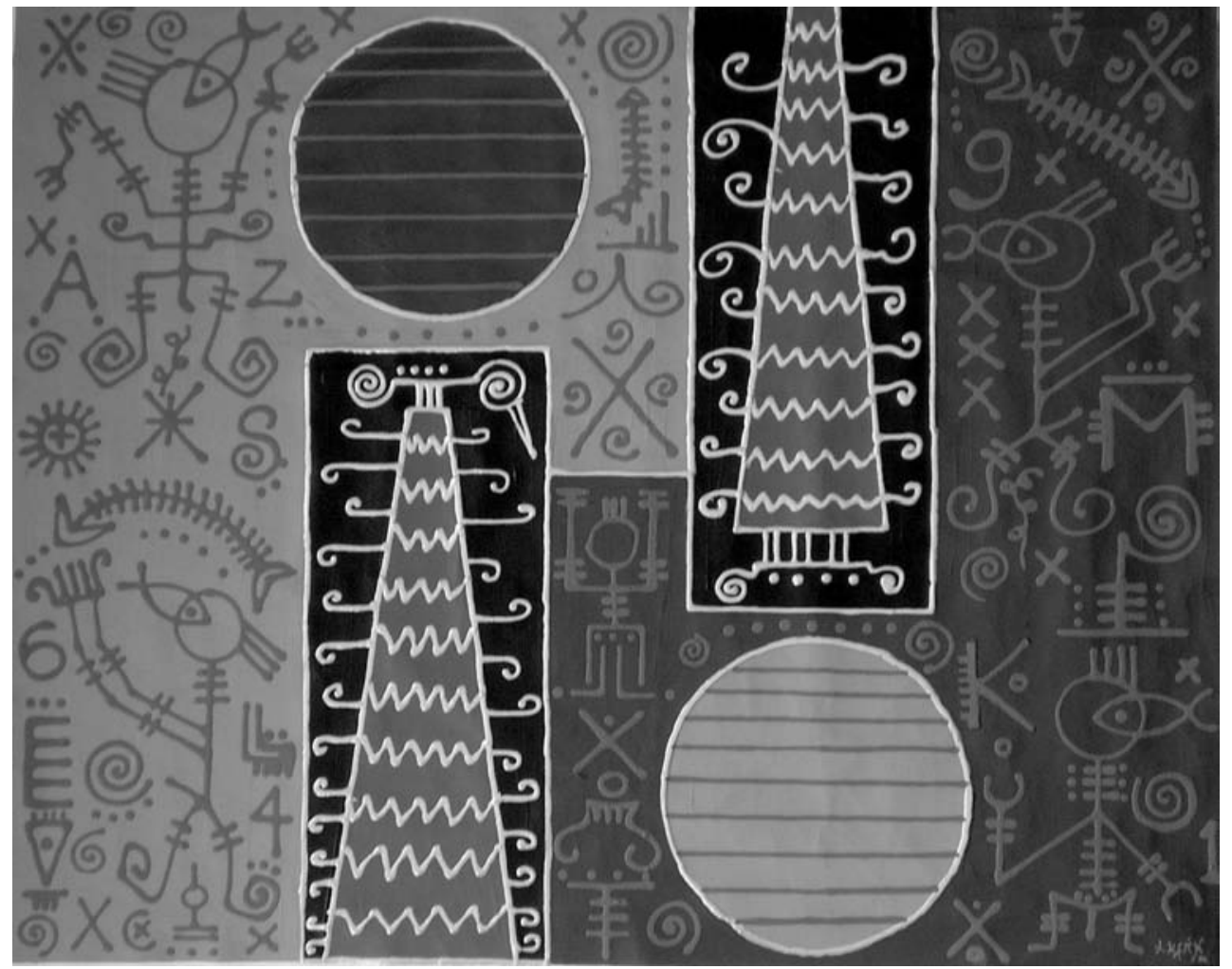

Fusiones. Técnica mixta sobre lienzo

El nuevo paradigma de la soberanía alimentaria surgió a mediados de la década de los noventa como propuesta de las organizaciones campesinas de América Central ante el proceso de desestructuración de las agriculturas familiares de la región. Si bien este proceso se profundi-

* El autor es sociólogo rural graduado en la Universidad de París III, profesor de la Escuela de Gestión para el Desarrollo Local Sostenible de la UPS-Q. Actualmente se desempeña como coordinador del Centro Andino para la Formación de Líderes Sociales (CAFOLIS). 
zó con la ayuda alimentaria de la cooperación internacional ante los huracanes y la violencia generados por la naturaleza y los humanos, ya se había dado por la presencia de productos alimentarios subsidiados provenientes de los países industrializados y vendidos localmente a bajos precios, configurando verdaderas estrategias de dumping.

La nueva propuesta de soberanía alimentaria tiene antecedentes en las políticas de seguridad alimentaria surgidas después de la Segunda Guerra Mundial, en Europa, frente al hambre desencadenada por esa gran conflagración. Se planteó, entonces, la necesidad de reconocer la universalidad del derecho a la alimentación, es decir, que todas las personas, de todos los sectores sociales puedan acceder, de manera permanente, a los alimentos necesarios. Con la creación de la Unión Europea en 1957, se consolidó la idea de que estos productos debían ser preferentemente nacionales o europeos para desarrollar las economías nacionales y para asegurar la soberanía del Estado, considerando a los alimentos como arma estratégica para la independencia de los Estados.

\section{Complejidad y multidimensiona- lidad de la soberanía alimentaria}

El nuevo paradigma de la soberanía alimentaria es complejo y multidimensional porque se plantea como una estrategia y una obligación del Estado, como lo reconoce el Art. 281 de la nueva Constitución Política de la República. Se trata de una de las estrategias clave del nuevo modelo de desarrollo económico, ambiental, social y cultural, junto con la propuesta de economía popular solidaria.

Desde esta perspectiva, la soberanía alimentaria involucra a todos los sectores de la economía, el primario, el industrial y el de servicios, pero también concierne a la producción de alimentos en la agricultura, la ganadería, la pesca artesanal, el procesamiento de alimentos, el intercambio, la comercialización, la distribución y el consumo de alimentos. Es decir que los sistemas alimentarios involucran a toda la población del campo y de las ciudades ya sea como productores de alimentos, como agentes de transformación, transporte, comercialización o simplemente como consumidores.

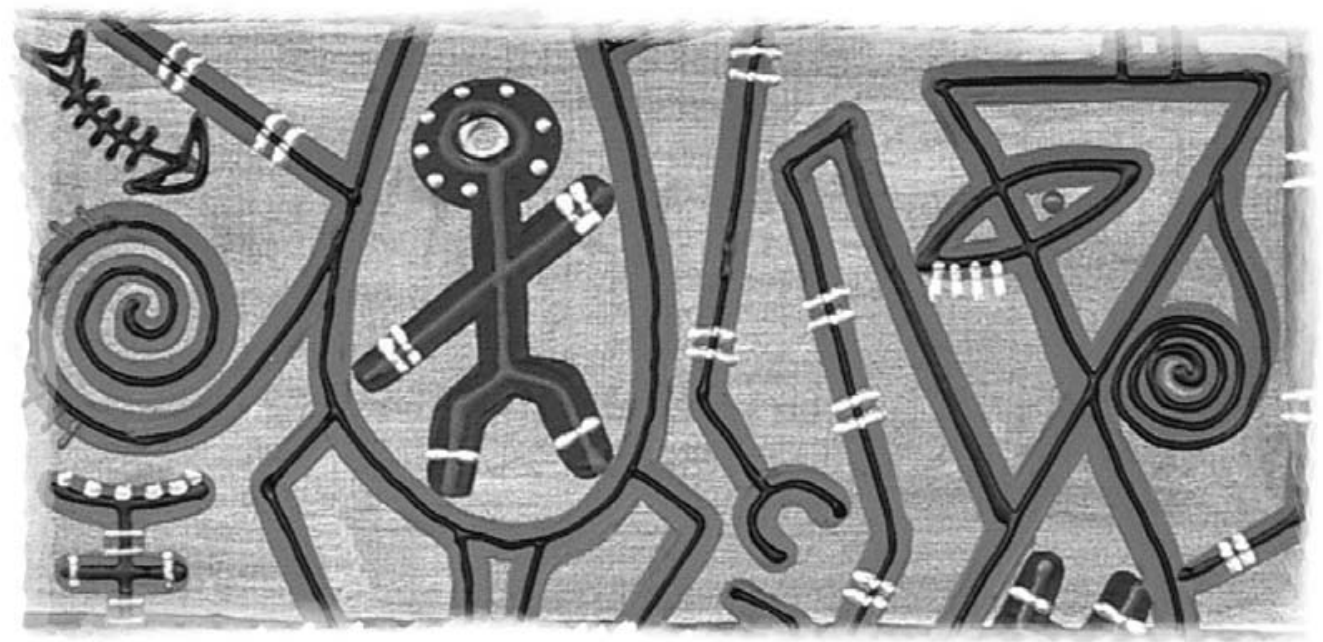

Reminiscencias. Detalle 
Por su carácter comprensivo la soberanía alimentaria en su dimensión institucional no puede ser competencia o coto de caza de un solo ministerio, sino que tiene naturaleza supra-ministerial, pues involucra la nutrición, la salud, la educación, el ambiente y por supuesto los diversos sectores de la economía. Brasil creó, en septiembre de 2006, la Cámara Interministerial a nivel del Estado Federal y las Cámaras Intersecretariales en los Estados de la federación para responder a este enfoque, pero sobre todo para dar salida a los celos institucionales y a las tendencias corporativas presentes en el sector público y en las culturas políticas latinoamericanas.

El médico y sociólogo brasileño Josué de Castro mostró el carácter engañoso de la idea que el hambre es un sino, un destino preestablecido o fatum, al poner en evidencia que es una construcción social generada por modelos de desarrollo de carácter inequitativo, como el modelo brasileño de industrialización de mediados del siglo pasado. Pero además, Josué de Castro tuvo el mérito de hacer visibles las interrelaciones entre las deficiencias en la nutrición, la salud de las personas, su desarrollo físico e intelectual, y el desarrollo de las naciones (Maluf, 2008). Por ello, de Castro prefirió hablar de la seguridad alimentaria y nutricional, calificativo posteriormente recogido por la FAO y por el sistema brasileño de seguridad alimentaria.

\section{La centralidad de la agricultura familiar}

La diversidad de modelos de crecimiento hacia afuera se sustentó en la explotación de grandes extensiones de tierra para la exportación, primero del cacao, y posteriormente de banano. Las reformas agrarias de 1964 y 1973 distribuyeron tierras marginales, no afectaron el monopolio de la tierra y re-funcionalizaron los sistemas productivos rurales a las nuevas demandas del mercado. La ley agraria de 1994 cerró definitivamente el ciclo de la reforma agraria y creó las condiciones para el desarrollo de la agroindustria moderna de flores, brócoli, espárragos, etc., orientada hacia la exportación.

Los modelos de crecimiento hacia afuera sometieron a las economías campesinas a los intereses del capital financiero de las empresas importadoras de agroquímicos, de los exportadores y de los comerciantes locales y nacionales. La relación con la parcela y las comunidades locales permitieron la venta de sus productos alimentarios y de la fuerza de trabajo por debajo de su costo de producción. En los últimos años, las grandes empresas de alimentos orientadas hacia el mercado interno y hacia la exportación han controlado a las agriculturas familiares y a las economías campesinas a través de lo que se ha dado en llamar la agricultura por contrato. Este es el sistema productivo por el cual las pequeñas y medianas unidades producen alimentos que posteriormente son procesados por las grandes empresas de alimentos, como PRONACA, la cual se abastece del maíz vendido a bajo precio por las economías campesinas controladas a través del aprovisionamiento de créditos, semillas, fitosanitarios y asistencia técnica.

El nuevo modelo de desarrollo propone mudar del predominio del agro-negocio para la exportación a la centralidad de la agricultura familiar y de la economía popular solidaria. Es decir, pasar del crecimiento hacia afuera, en el cual el valor generado localmente se traslada a las grandes empresas de bienes y servicios, a las ciudades, hacia los centros de desarrollo y de éstos hacia las grandes metrópolis de los países industrializados, hacia un desarrollo territorial endógeno en el cual el valor generado localmente se

El nuevo paradigma de la soberanía alimentaria es complejo y multidimensional porque se plantea como una estrategia y una obligación del Estado. 
reinvierta localmente en la producción de bienes y servicios, mejorando la calidad de vida de los pequeños y medianos productores y del conjunto de la población ecuatoriana.

En esta perspectiva, el Art. 281 de la nueva Constitución Política de la República, CPR, vincula el derecho de los pueblos a alimentarse, es decir, al autoabastecimiento, a la producción de las pequeñas y medianas unidades agrícolas, pecuarias y pesqueras, en las cuales predomina la mano de obra familiar, el uso de tecnologías amigables con el ambiente, y la satisfacción de las necesidades de la familia y de las comunidades locales. Este enfoque se sustenta en el rol histórico de abastecimiento del mercado interno jugado por este tipo de unidades de producción. Si bien ha caído en los últimos años la participación de las pequeñas y medianas unidades de producción en el abastecimiento de granos, carnes, frutas y legumbres, en la actualidad representa todavía alrededor del 40\% contra el 65\% en los años sesenta.

Pero esta no es la única función de las economías campesinas, ellas también se caracterizan por su enorme capacidad de absorción de mano de obra, es decir por la generación de empleo e ingresos. En la actualidad se afirma con insistencia la multifuncionalidad de la economía campesina y se pone énfasis en la utilización de tecnologías amigables con el medio ambiente en el contexto de una creciente preocupación por el calentamiento global y los impactos de los agrotóxicos en la salud humana.

Así por ejemplo, el Art. 104 de la Constitución de la Confederación Helvética afirma que:

“1. La Confederación vela para que la agricultura, por medio de una producción que responda a la vez a las exigencias del desarrollo sostenible y a las del mercado, contribuya sustancialmente a:

a. la seguridad del aprovisionamiento de la población;

b. la conservación de los recursos naturales y al mantenimiento del paisaje rural; c. la ocupación descentralizada del territorio.

2. Como complemento a las medidas de ayuda mutua que razonablemente se puede exigir de la agricultura y si fuere necesario derogando el principio de libertad económica, la Confederación promueve las unidades de producción campesinas que cultivan el suelo.

3. Ella concibe las medidas de manera que la agricultura responda a sus múltiples funciones. Sus competencias y tareas son sobre todo las siguientes:

a. ella complementa el ingreso campesino por medio de pagos directos a fin de remunerar equitativamente los servicios prestados, con la condición de que el productor presente la prueba de que satisface las exigencias de carácter ecológico;

b. ella promueve, por medio de iniciativas de carácter económico, las formas de producción, particularmente, amigables a la naturaleza y respetuosas del ambiente y de los animales;

c. ella legisla sobre la declaración del origen, de la calidad, de los métodos de producción y de los procedimientos de transformación de los productos alimenticios;

d. ella protege el ambiente contra los atentados vinculados a la utilización abusiva de abonos, de productos químicos y de otros productos auxiliares;

e. ella puede promover la investigación, la difusión y la formación agrícola y otorgar ayudas a las inversiones;

f. ella puede legislar sobre la consolidación de la propiedad rústica rural.

4. Para estos fines ella se obliga a orientar especialmente los créditos agrícolas, así como también los recursos generales de la Confederación"2.

Los campesinos y productores familiares ecuatorianos insisten, con razón, en la necesidad de que el Estado les de un tratamiento diferenciado en créditos, pero también en aranceles y en asesoría técnica. 


\section{Acceso a los factores de producción}

Uno de los pilares fundamentales de la nueva política de soberanía alimentaria es el acceso a la tierra, al agua y al capital, es decir a los factores de producción.

La nueva ley marco de soberanía alimentaria prevé la elaboración y publicación posterior de seis leyes conexas, entre ellas una ley de tierras y territorios, la ley de aguas y la ley de la banca pública.

La CPR y la ley marco ya contemplan créditos para los pequeños y medianos productores en condiciones especiales, pero sin duda se requiere de un nuevo instrumento legal en el cual se defina las reglas de juego para que este tipo de unidades de producción accedan al crédito para capital de operación, pero también para activos fijos.

La herencia colonial de monopolio de las tierras no fue substancialmente modificada ni por la llamada ley de manos muertas de la Revolución Liberal -la cual facilitó la transferencia de dominio de algunos terratenientes al Estado y de éste a arrendatarios vinculados al sector- ni por las reformas agrarias de los años sesenta y setenta. El tímido proceso de democratización de las tierras empujado por las reformas agrarias fue rápidamente parado a fines de la dictadura militar (1979), y con la ley agraria decretada en el período del Arq. Sixto Durán Ballén. Las reglas de juego neoliberales permitieron una rápida reconcentración de la tierra bajo la figura de empresas agrícolas, la mayoría de ellas dedicadas a la exportación. En la actualidad, el coeficiente de Gini indica que el grado de concentración de las tierras en Ecuador es de 0,80; es decir, uno de los más altos de América Latina y por ello la CPR tiene fundamentos sólidos para plantear el tema de la redistribución de la tierra mediante la conformación de un Fondo de Tierras. La nueva ley de soberanía alimentaria proporciona nuevos detalles sobre la función ambiental y social de las tierras, pero envía su tratamiento a la nueva
Asamblea Nacional, pues prevé un plazo de 365 días para su tratamiento.

De igual forma, la nueva ley de soberanía alimentaria prevé la elaboración de una nueva ley de aguas sustentada en la gestión social y en las prelaciones preescritas en la nueva constitución.

\section{La agroecología, una opción de vida}

La opción por la agricultura familiar está vinculada estrechamente a la opción por la agroecología, no sólo como tecnología sino sistema de vida, en el cual se articulan las dimensiones: económica, ambiental, socio-cultural y técnica.

La agroecología se sustenta en el reconocimiento de la persona y de los grupos humanos como parte del cosmos y de la naturaleza, no para dominarla y explotarla sino para interactuar con ella en un repetido proceso de re-alimentación del suelo (de los micronutrientes), de la agrobiodiversidad, pero también de las identidades personales, familiares y colectivas.

Partiendo de los suelos desgastados, legados por la "revolución verde", la producción agroecológica es rentable a partir de los cuatro o cinco años en los que se logra recuperar la fertilidad de los suelos por medio del abonamiento con materia orgánica y la optimización del uso del agua a través del riego por aspersión o del riego por goteo.

Como lo muestra la experiencia de los granjeros de Toacaso, Cotopaxi, la producción rotativa y permanente de legumbres en camas de $0,80 \mathrm{~cm}$ de ancho por $20 \mathrm{~m}$ de largo, genera un ingreso bruto de 2.000 dólares mensuales y un ingreso neto de alrededor de 1.000 dólares mensuales. Esto ha permitido el mejoramiento de la calidad de vida de las familias de estos granjeros en cuanto a la alimentación, la vivienda, la educación y los medios de transporte propio.

La producción agroecológica, como lo afirman sus actores, permite la reintegración familiar y evita la emigración interna e internacional. 


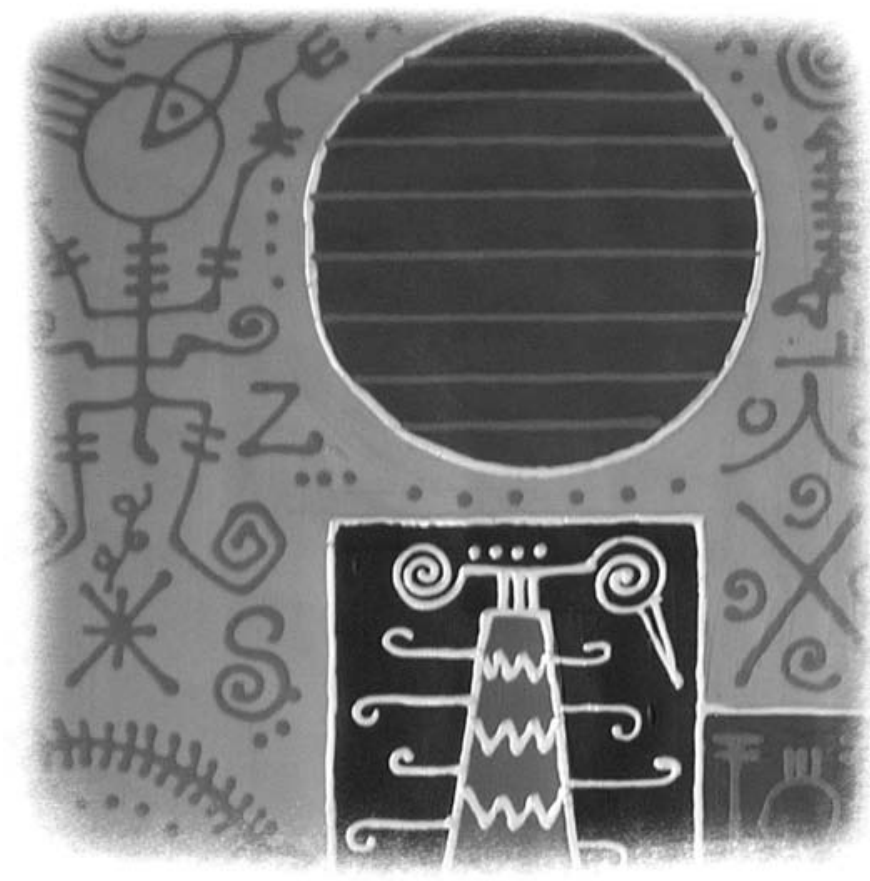

Fusiones. Detalle

En la actualidad hay en el país alrededor de tres mil unidades de producción agroecológicas y muy pocas orgánicas, en sentido estricto, porque la mayoría de ellas utilizan semillas provenientes de grandes empresas agro-alimentarias de Europa, Estados Unidos y Canadá. Lo ideal sería dar el paso a la producción de semillas y plántulas a nivel local a partir de la agro-biodiversidad local.

La difusión de la agro-ecología, la multiplicación de estas experiencias locales y la construcción de la política de Estado respectiva demandan el intercambio de experiencias; la articulación de las redes locales y regionales en una gran red nacional; el cambio institucional y la elaboración y ejecución de programas estratégicos que articulen proyectos y programas de tipo sectorial.

\section{El desafío de los transgénicos}

Las empresas transnacionales de alimentos pregonan las bondades de los transgénicos en relación al incremento de la productividad y de las utilidades, la inocuidad de los productos y la irrelevancia de sus impactos sobre el suelo y los sistemas de vida. En realidad, investigaciones realizadas en Argentina y Brasil muestran que los beneficios económicos altos se dan en los periodos de introducción de los cultivos de soja, pero que estos tienden a desaparecer una vez consolidado el paquete tecnológico y el control ex ante y ex pos por parte de las empresas transnacionales. Más todavía los estudios realizados en Canadá muestran los impactos contaminantes de los transgénicos en la biodiversidad y en la salud humana.

Detrás del negocio de los transgénicos está el interés por el control de la vida por parte de los grandes grupos agroalimentarios que buscan apoderarse de los genomas de plantas, animales e inclusive humanos, por medio de las patentes y otras formas de propiedad intelectual, a fin de utilizarlos en combinaciones genéticas a ser vendidas en el mercado, en paquetes tecnológicos que incluyen semillas, fertilizantes, fitosanitarios y asistencia técnica.

En este contexto se entiende la importancia estratégica del Art. 401 de la nueva CPR en que "Se declara al Ecuador libre de cultivos y semillas transgénicas". Sin embargo, y por presión de un grupo de empresarios en el mismo artículo se afirma que "Excepcionalmente y sólo en caso de interés nacional debidamente fundamentado por la Presidencia de la República y aprobado por la Asamblea Nacional, se podrá introducir semillas y cultivos genéticamente modificados".

\section{En busca de una nueva institucionalidad}

En su estudio sobre la gobernanza, Pierre Calame afirma que a menudo se quiere cambiar el 
Estado y las sociedades con ideas de ayer e instituciones de anteayer (Calame, 2008). Esta idea me ha rondado en la mente a lo largo del proceso de formulación de la norma constitucional y de la elaboración de la ley marco de soberanía alimentaria, pues el nuevo paradigma es poco conocido en el país, pero sobre todo por la dificultad de pensar los alimentos más allá de la producción agropecuaria y pesquera, a la luz del enfoque de la complejidad en el cual se articulan varios sectores y dimensiones, como ya se vio más arriba.

Este tipo de dificultad también está presente en el proceso de elaboración de la institucionalidad de la soberanía alimentaria pues hay quienes piensan que las nuevas demandas pueden ser atendidas por el Ministerio de Agricultura, Ganadería y Pesca, MAGAP re-estructurado o por un Comité creado especialmente para el caso, en el cual estén presentes representantes del Estado y de la sociedad civil, y cumpla las funciones de planificación participativa de la política pública, de ejecución y de seguimiento y evaluación. En los últimos meses ya se ha visto la posición de algunos dirigentes de las organizaciones sociales que conciben la soberanía alimentaria como una política intersectorial y supra-ministerial a funcionar a través de un Consejo Nacional, de la Conferencia Nacional y de un Gabinete interministerial.

Este debate se refleja en las diferentes versiones de la ley de soberanía alimentaria, especialmente en las elaboradas por la Comisión especializada de salud y ambiente de la Comisión Nacional de Legislación y Fiscalización.

Para precisar la nueva institucionalidad es necesario definir el Sistema de soberanía alimen- taria, sus componentes y funciones, confirmando los avances institucionales respecto del Consejo consultivo, como el responsable de la formulación, seguimiento y evaluación de la política pública de soberanía alimentaria, y de la Conferencia, como un espacio de deliberación pública con la participación de amplios sectores sociales. Pero también es indispensable definir claramente el Gabinete interministerial como espacio de coordinación de programas y políticas al interior del ejecutivo para la construcción del nuevo sistema de soberanía alimentaria, y como medio para superar los celos institucionales y las visiones corporativas propias de las culturas políticas latinoamericanas.

\section{Bibliografía}

- ASAMBLEA NACIONAL CONSTITUYENTE: Constitución Política de la República del Ecuador, aprobada el 24 de julio 2008 y publicada el 20 de octubre 2008.

- CALAME, Pierre: Hacia una revolución de la gobernanza. Reinventar la democracia, CEN, UASB, CAFOLIS, Quito, 2008.

- COMISIÓN ESPECIALIZADA DE SALUD Y AMBIENTE DE LA COMISIÓN NACIONAL DE LEGISLACIÓN Y FISCALIZACIÓN: Ley orgánica del régimen de soberanía alimentaria, Quito, febrero, 2009.

- CONFEDERACIÓNi HELVÉTICA: Constitution, janvier, 2008

- MALUF, Renato: La seguridad alimentaria y nutricional. Un enfoque de derecho y de soberanía, Quito, Editorial Silva, CAFOLIS, diciembre, 2008.

1 Este artículo fue escrito en febrero 2009, entre el primero y el segundo debate de la Comisión Nacional de Legislación y Fiscalización sobre la ley marco del régimen de soberanía alimentaria.

2 Ver la sección de sistemas alimentarios sostenibles del portal CAFOLIS: www.cafolis.org 


\section{Soberanía alimentaria y derecho a la alimentación:}

elección de políticas públicas desde el enfoque de la economía solidaria

Verónica Andino*

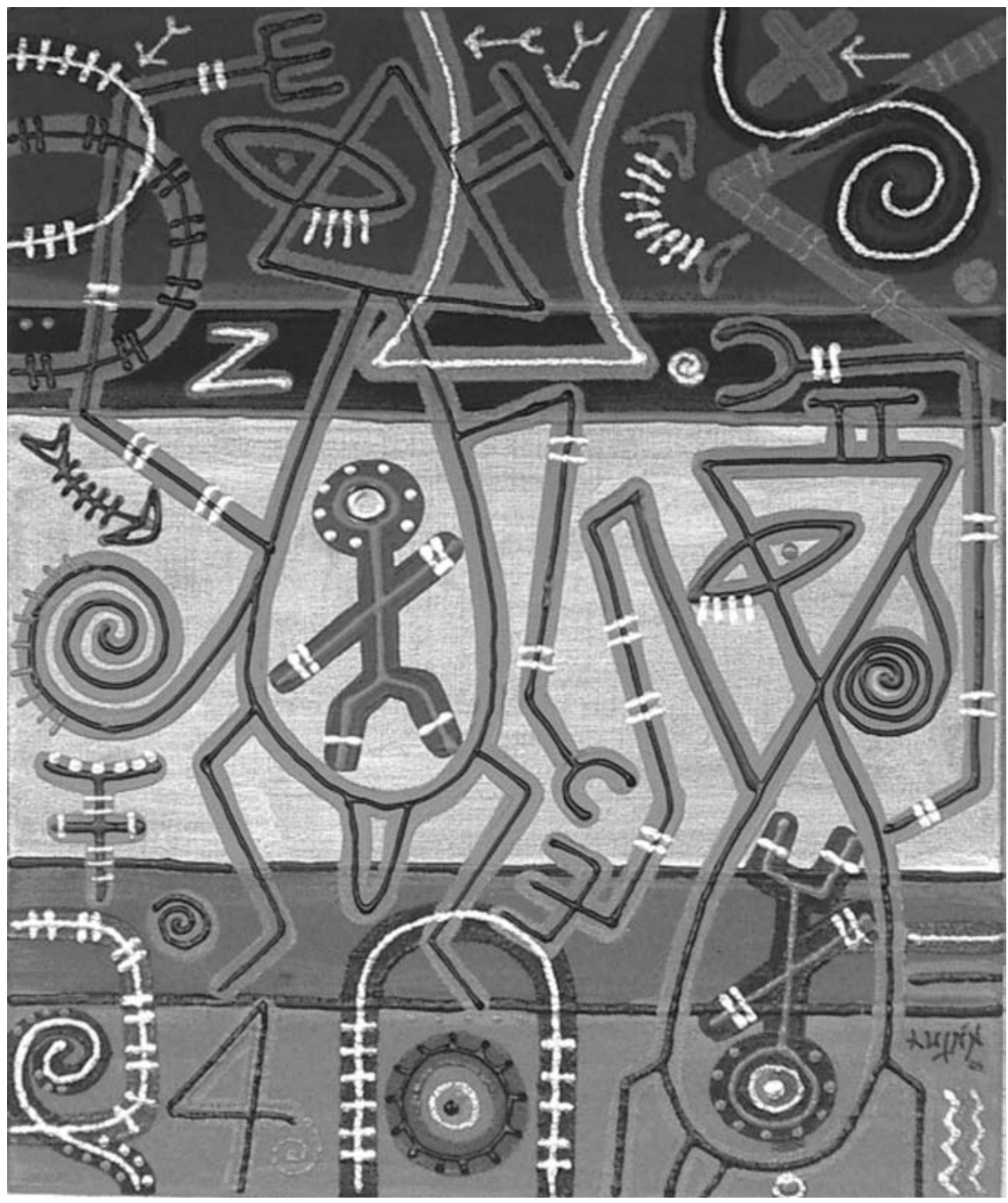

Reminiscencias. Técnica mixta sobre lienzo

* Docente de la carrera de Gestión para el Desarrollo local Sostenible. Consultora Internacional experta en Economía Solidaria. 
Este estudio parte del reconocimiento que toda la población tiene un derecho inalienable e incondicional a la provisión de una ración mínima de alimentación que permita su supervivencia. El Estado tiene por lo tanto, la responsabilidad de hacer valer este derecho asegurando a todos 20sus ciudadanos una dotación mínima de alimentos que le permita funcionar biológicamente. Este derecho está garantizado por la nueva Constitución del Ecuador que, en su Art. 13, capítulo II, indica lo siguiente: "Las personas y colectividades tienen derecho al acceso seguro y permanente a alimentos sanos, suficientes y nutritivos; preferentemente producidos a nivel local y en correspondencia con sus diversas identidades y tradiciones culturales. El Estado ecuatoriano promoverá la soberanía alimentaria”.

La protección de los derechos a la alimentación debe tener estrategias a corto y a largo plazo. En el corto plazo muchas veces se trata de buscar una solución inmediata a la amenaza de pérdida repentina de estos derechos por parte de los grupos más vulnerables, que requieren de políticas para la distribución inmediata de alimentos tanto en casos de desnutrición crónica como en casos de emergencias y desastres naturales. En el largo plazo, se trata de una reducción progresiva del riesgo de pérdida de los derechos a la ali- mentación que requiere: garantizar la disponibilidad de alimentos sanos en la economía nacional; garantizar la capacidad de la población de acceder a dichos alimentos, especialmente, vía la protección y diversificación de los ingresos de la población más vulnerable y el control de la especulación de precios de los alimentos; y finalmente, elevar el nivel educativo de la población en términos de nutrición, de tal manera que tengan la libertad de escoger alimentos que sean más beneficiosos para su salud.

\section{Estrategias a largo plazo: ga- rantizar la capacidad de una so- ciedad de consumir alimentos de calidad}

En la selección de estrategias a largo plazo para garantizar la capacidad de una sociedad para consumir alimentos de calidad, es importante identificar tres factores distintos que pueden poner en riesgo esta capacidad: 1) la falta de disponibilidad de alimentos en la economía nacional (o en ciertas regiones del país) para solventar las necesidades de la población; 2) la incapacidad de ciertos grupos de la población de acceder a los alimentos que están disponibles en la economía nacional; y 3 ) cambios cultura-

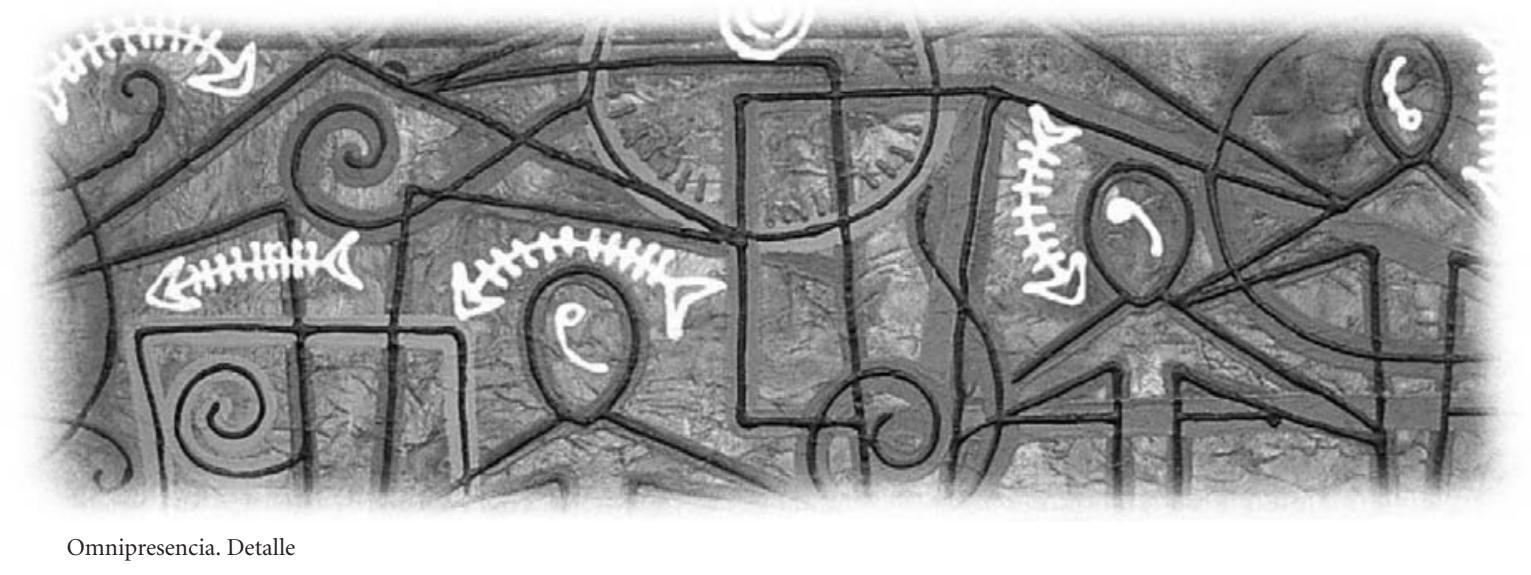


les que generen malos hábitos alimenticios. Dentro del enfoque de la Economía Solidaria, las políticas públicas a largo plazo que debe implementar el Estado para evitar la pérdida de los derechos a una alimentación de calidad de la población deben considerar conjuntamente estos tres factores, evitando poner en marcha estrategias parciales que permitan solucionar uno de ellos a expensas del otro. De igual manera, el enfoque de la Economía Solidaria privilegia estrategias que permitan la autodeterminación de los pueblos, el fortalecimiento de las prácticas democráticas y participativas y el respeto y revalorización de la identidad cultural y las prácticas solidarias de los pueblos.

\subsection{Políticas públicas para garantizar la disponibilidad de alimentos en la economía nacional}

El aumento de la disponibilidad de alimentos en la economía de un país puede ser un factor importante para favorecer la seguridad alimentaria ya que permite que los precios de los alimentos bajen y, por lo tanto, que sea más fácil para la población adquirirlos en cantidades adecuadas. Sin embargo, la aplicación de estrategias de importación y la obtención de alimentos donados del extranjero para incrementar la disponibilidad de alimentos en la sociedad pone en serio riesgo los otros dos factores claves para garantizar los derechos a la alimentación de calidad de la población y la capacidad de autodeterminación de los pueblos. Como se puede ver en el Cuadro 1, estas estrategias no son únicamente negativas desde el punto de vista del productor nacional, sino que además ponen en serio riesgo la capacidad de amplios sectores de la población rural del Ecuador de satisfacer sus necesidades alimentarias, generan cambios culturales que deterioran la calidad de alimentos seleccionados por la población y generan la pérdida de identidad cultural, y por último ponen al país en situación de dependencia y sumisión a los dictámenes de naciones extranjeras.

Cuadro 1. Efectos negativos de las donaciones de alimentos en la soberanía alimentaria

- Muchos alimentos donados/importados a bajos precios, no se adaptan a las necesidades y a la cultura alimenticia de los receptores, provocando trastornos gastrointestinales en los consumidores.

- El consumo de algunos productos donados/importados a bajos precios, por ejemplo enlatados, es consumido preferentemente por adultos y no por los niños (estudio de Bolivia sobre los alimentos donados).

- El análisis en términos de nutrientes de los alimentos donados muchas veces impacta más en términos proteicos que en calóricos, por lo que no contribuyen a tener una dieta balanceada.

- Algunos alimentos donados/importados a bajo precio suponen la intromisión en la canasta de consumo alimentario de los beneficiarios, de productos totalmente nuevos, de producción extranjera y de alto costo. Al generar una sustitución de las preferencias de los grupos vulnerables por este tipo de alimentos, disminuye el consumo de productos locales (ricos en proteínas y calorías ) que se producen internamente y a precios más bajos (Ej. Quinua, chochos, habas, mellocos, etc.) . Esto genera también una tendencia a la baja de los precios de estos productos $y$, por lo tanto, se ocasiona un desincentivo a seguir produciéndolos.

- Los alimentos donados/importados cambian el modelo de consumo de la población, lo que ocasiona un cambio de importancia creciente en la canasta alimentaria de los beneficiarios hacia una canasta alimentaria más cara, además de la incorporación de nuevos productos no consumidos tradicionalmente.

- Una vez habituados al consumo de alimentos donados/importados a bajo precio, los beneficiarios buscan volver a consumirlos lo más pronto posible, haciendo que compren en los mercados productos parecidos, 
sustitutos a los donados/importados a bajo precio, que son tradicionalmente más costosos que los productos locales. Por lo tanto, se crean requerimientos de la población que no pueden ser satisfechos más que con importaciones y genera tensiones en la balanza comercial.

- Las donaciones o importaciones de alimentos a bajos precios, están generando una no correspondencia entre lo que se consume y los que se produce nacionalmente. Es decir, que las donaciones están orientando la estructura productiva nacional hacia una estructura de consumo de productos elaborados con materia prima importada (Ej.: la importación de trigo que ha generado la producción de galletas, fideos, pan que se producen con harina importada).

- La ayuda alimentaria norteamericana obedece más a preocupaciones de orden político y comercial que a preocupaciones humanitarias. La ayuda humanitaria disminuye en gobiernos que no tienen una orientación favorable a sus intereses políticos y económicos, lo que indica su manejo como medio de presión.

- Las donaciones alimentarias tienen también una serie de efectos sociales y económicos. Desde el punto de vista social, desarticulan organizaciones de base, las deforman en sus objetivos y propósitos y las hacen dependientes de su funcionamiento. Así mismo inculcan el individualismo y el paternalismo.

Fuente: Arrieta (1993)

Por otro lado, el fomento a la producción nacional, no debe hacerse a expensas de la salud del consumidor. Las políticas que promueven la importación de paquetes tecnológicos que contienen agroquímicos peligrosos para la salud, no son coherentes con el mandato constitucional que tiene el Estado de promover el acceso a alimentos sanos.

Desde el enfoque de la Economía Solidaria, el rol del Estado en garantizar la disponibilidad de alimentos de calidad para el consumo interno debe hacerse promoviendo al máximo la producción local de alimentos orgánicos. Consideramos que es la mejor opción desde la perspectiva de los derechos a la alimentación por las siguientes razones: 1) un número importante de los pobres están en zonas rurales y dependen de las pequeñas parcelas productivas para su alimentación diaria; 2) Permite promover el consumo de alimentos sanos y nutritivos propios de la cultura local; y 3) Evita generar situaciones de dependencia y permite la autodeterminación de los pueblos.

Por esta razón, incluso desde la perspectiva del consumidor, la propuesta desde la economía solidaria pone especial énfasis en: 1) Privilegiar fuertemente el fomento a la producción nacional de alimentos de calidad (orgánicos) para garanti- zar su disponibilidad para el consumo interno; 2 ) Reducir progresivamente la importación y las donaciones de alimentos para el consumo interno, utilizando esta estrategia únicamente en casos de extrema necesidad, previo a un análisis caso por caso, con la participación activa de la sociedad civil organizada; 3) Evitar al máximo la importación de alimentos nocivos para la salud (incluidos alimentos transgénicos y alimentos con bajo contenido nutricional).

\section{La situación del acceso a alimentos en Ecuador}

De manera general, el abastecimiento de alimentos en América Latina, no es un problema. De acuerdo a un informe entregado por la FAO en agosto de 2008, "América Latina no tiene problemas de disponibilidad de alimentos, ya que su oferta supera en un $40 \%$ a la deman$\mathrm{da}$, aunque su encarecimiento ha provocado un deterioro para una gran proporción de sus habitantes" (...) "Por esta razón "no hay ni se prevé que habrá una crisis de desabastecimiento en América Latina, a excepción del caso específico de Haití" (Nota de prensa, Opción final 29 Agosto, 2008). 
De acuerdo al Informe del Ecuador Cumbre Mundial Sobre La Alimentación Cinco Años Después, el Ecuador, con una población de 12'646.095, de los cuales el 77\% corresponde a una población menor de 40 años y una extensión territorial de $256.370 \mathrm{~km}^{2}$, es uno de los países megadiversos del mundo, lo atraviesa la Cordillera de los Andes y la Línea Ecuatorial, que le da características especiales para la producción agropecuaria. Según el mismo informe, el suministro de energía alimentaria, a nivel nacional, satisface los requerimientos de la población promedio; la disponibilidad para 1998, fue de 2.532 kcal/día, frente a una necesidad estimada de $2.188 \mathrm{kcal} /$ día. La energía para 1998-2000 proviene de: cereales, azúcares y tubérculos (50\%); oleaginosas (15\%), frutas ( $15 \%$ al $20 \%)$, carne, leche y huevos cerca de $20 \%{ }^{3}$. La capacidad del Ecuador de producción agropecuaria sobrepasa la demanda necesaria para abastecer su demanda interna de alimentos. En el libro Ecuador su rea-

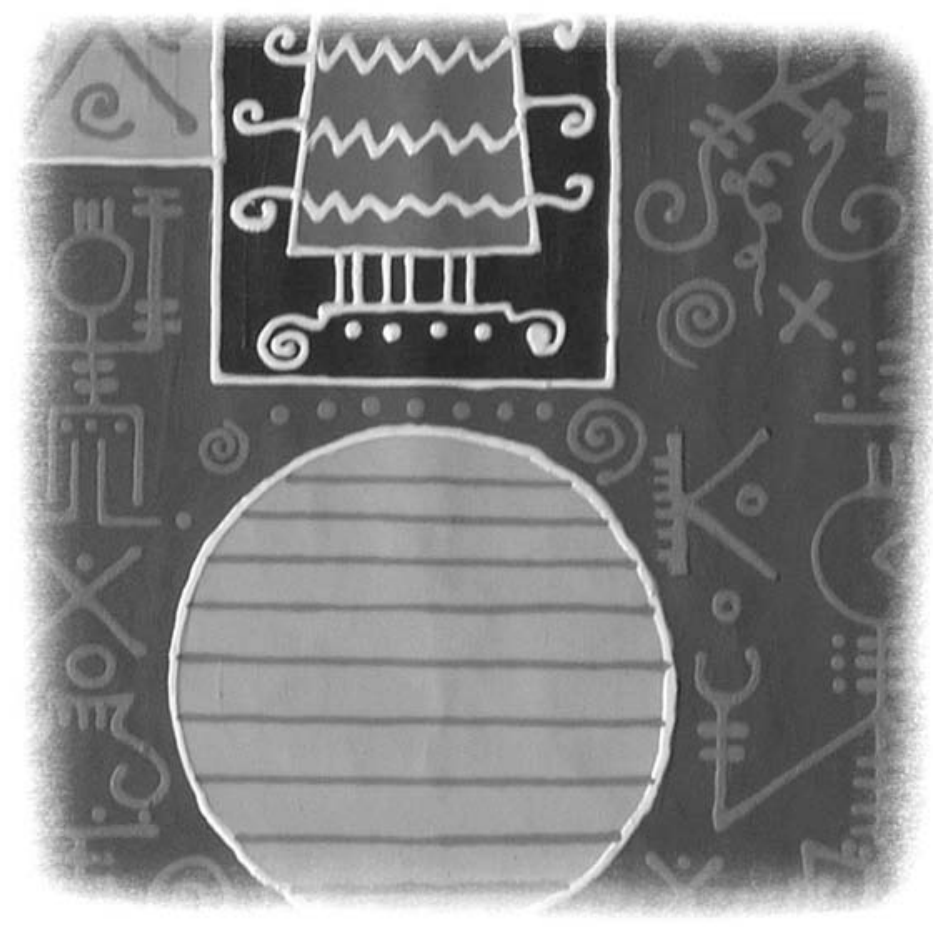

Fusiones. Detalle lidad se indica que, de acuerdo a la FAO, sólo la cuenca del río Guayas abastecería a 40 millones de habitantes con su producción (Vásquez y Saltos, 2008).

Sin embargo, existen algunas regiones que, por sus condiciones geográficas o por su tipo de producción, son vulnerables a una falta de abastecimiento de alimentos. Éstas son:

- Península de Santa Elena y la zona costera de frontera con el Perú, por constituir formaciones secas con condiciones climáticas muy desfavorables, no son patas para la producción agrícola.

- Archipiélago de Galápagos por ser zona protegida y poco apta para cultivar.

- Amazonía por ser terrenos muy poco fértiles.

- Sierra todas las zonas superiores a 3.800 msnm.

- Zonas de monocultivos destinados a la exportación como Los Ríos y El Oro (Banano).

Sin embargo, la capacidad de abastecimiento en alimentos se ha visto sistemáticamente afectada por las políticas públicas del Estado que han favorecido el cambio hacia sistemas de producción para la exportación. Se estima que 8,5 millones de hectáreas conforman el área con uso agropecuario lo que representa el 32\% de la superficie total. La mayor área cultivada es destinada a la producción de exportación, en tanto que el consumo interno proviene fundamentalmente de pequeños y medianos agricultores (Cumbre Mundial Sobre la Alimentación Cinco Años Después, 2001). Es importante notar que desde un punto de vista histórico, se puede ver muy claramente esta tendencia. De 1980 a 1991 las producciones agrícolas - bienes de uso agroindustrial relacionados con la industria de alimentos balanceados tienen un crecimiento sostenido: maíz duro crece en un $108 \%$, soya en $412 \%$, palma africana $256 \%$ y arroz en $126 \%$; lo que contrasta con las variaciones de trigo, cebada, papa, caña de azúcar y algodón que son casi insignificantes (Jordán, 1996). De igual manera, el es- 
tudio de Jordán (1996) muestra que el incremento de la producción pecuaria en la costa ha venido en detrimento de la producción de cereales y tubérculos de clima templado A la luz de las cifras disponibles, es muy probable que el desarrollo ganadero se haya hecho en parte al menos a expensas de las tierras dedicadas a esos productos. Actualmente, el $70 \%$ de la tierra cultivable en Ecuador, está dedicada al cultivo de pastos. El restante $30 \%$ a cultivos (Vásquez y Saltos, 2008).

Esto se ha acompañado por un sistemático desinterés por promover la producción para el consumo interno. De 1970 a 1982, la tasa promedio anual de crecimiento de la producción para consumo interno sólo alanzó un $0,4 \%$, valor muy inferior al crecimiento poblacional para esa década que fue de 2,9\% (Jordán, 1996). De acuerdo a Vásquez y Saltos (2008), desde 1970 la producción de trigo se redujo en más del $60 \%$, cebada y maíz en un $50 \%$ y tubérculos en un $12 \%$.

Tradicionalmente, la producción para consumo interno ha sido producida por pequeñas unidades productivas (entre 0,1 y 20 ha) como lo muestra este cuadro presentado como parte del estudio de Jordán (1996).

Porcentaje de la producción nacional de alimentos de consumo interno producido por unidades familiares de producción (de 0,1 ha a 20 ha).

\begin{tabular}{|r|c|c|c|c|c|}
\hline $\begin{array}{r}\text { Maíz } \\
\text { suave }\end{array}$ & Arroz & Habas & Cebada & Papas & Trigo \\
\hline $89,1 \%$ & $63 \%$ & $85,6 \%$ & $71 \%$ & $60,9 \%$ & $58,6 \%$ \\
\hline
\end{tabular}

MAG-ORSTOM (1978)

La política agropecuaria del Estado ecuatoriano que margina a la producción para el consumo interno es evidente por la estructura de las importaciones del Ecuador, que han dejado de lado la importación de bienes de capital para la agricultura. De acuerdo al estudio de Jordán, las importaciones de bienes y productos agropecuarios se han mantenido en alrededor del $11 \%$ del total importado, aunque se registran cambios importantes en su composición: mientras los bienes de consumo no duradero suben de 94 a 166 millones de dólares entre 1985 y 1991 las materias primas para la agricultura -principalmente agroquímicos- lo hacen en un $60 \%$ y los bienes de capital para la agricultura disminuyen en un 33\% entre esos años.

Esta orientación de la política agropecuaria ha generado una constante migración del campo hacia la ciudad. Vásquez y Saltos (2008) indican que "el Ecuador ha dejado desde hace mucho tiempo de ser un país rural. En 1950 la población rural representaba el 72\%, en el 2001 fue apenas del $38 \% "$.

Esto demuestra que la producción nacional no está creciendo al mismo ritmo que el incremento de la demanda y que puede resultar en una mayor dependencia de alimentos provenientes del extranjero. Por ello, el Ecuador, a pesar de ser un país agrícola, debe importar productos básicos como, el $98,4 \%$ del trigo y el $86 \%$ de la lenteja que consumimos (Vásquez y Saltos, 2008).

Los efectos negativos de la política agroalimentaria del Ecuador en las décadas de los setenta y de ochenta han sido descritos en el estudio de Jordán (1996) que muestran que, "En los setentas la estructura de la demanda cambió sustancialmente como resultado de los cambios de los niveles de ingreso, especialmente en la clase media, paralelo a un crecimiento sustancial de su volumen poblacional. El cambio favoreció la demanda de alimentos "superiores" como los que se originan en le sector pecuario o de alimentos que se basan en materia prima importada, que es el caso del pan y el trigo". Por otra parte indica que "el arroz se ha constituido en componente decisivo de la dieta de los sectores de bajos ingresos y de los sectores medios pauperizados, desplazando a otros productos tradicionales de la canasta popular como guineos, habas, otros...".

Estos datos demuestran que es necesario promover activamente la producción para el consumo interno en las pequeñas unidades productivas si se quiere evitar una tendencia hacia 
situaciones que ponen en severo riesgo la disponibilidad de alimentos para consumo de la población ecuatoriana.

\subsection{Políticas Públicas para incrementar la capacidad de la población de tener acceso a alimentos de calidad}

La pérdida de los derechos a la alimentación de calidad puede también verse afectada por la incapacidad de ciertos grupos poblacionales de acceder a alimentos que están disponibles en el mercado. Esta situación puede darse por dos factores esenciales en los cuáles el Estado puede intervenir: 1) altos niveles de especulación en los precios de los alimentos; y 2) bajos y variables ingresos en algunos segmentos de la población.

\section{El control de los niveles de especulación en los precios de los alimentos}

En países como el nuestro en los que existe un poder alto de los grupos de intermediación, así como malas condiciones para el transporte de alimentos a ciertos sectores del país, la especulación con el precio de los alimentos puede ser alta, incrementando la vulnerabilidad de ciertos grupos de la población. Incluso, si las zonas donde más déficit nutricional hay en un país son también las zonas donde el precio de los alimentos es el más bajo, el comercio tenderá a exportar alimentos de esas zonas hacia zonas donde se paga mejor, incrementando así el problema.

\section{El Estado puede jugar un rol activo} en la soberanía alimentaria impidiendo la especulación excesiva con relación al precio de los alimentos.
En el caso del Ecuador el problema de la existencia de oligopolios es evidente. Cómo se puede ver en los siguientes cuadros, del precio del producto en la finca al precio de venta al público hay variaciones de más del 100\%, aunque es justo considerar que una parte de estas variaciones puede estar explicada por los costos de intermediación.

El Estado puede jugar un rol activo en la soberanía alimentaria impidiendo la especulación excesiva con relación al precio de los alimentos. Existen tres tipos de políticas que generalmente han sido utilizadas para este fin: 1) la fijación de precios de los alimentos; 2) la interdicción de exportación interna y externa de alimentos; y 3 ) la participación del Estado en el mercado de alimentos. El problema con las dos primeras, al menos en lo que tiene que ver con la restricción de la movilidad interna de alimentos, es que requieren un alto nivel de control y complejos sistemas administrativos para hacerlas operar, lo que las hace también meas favorables a la aparición de prácticas de corrupción y contrabando. Por otro lado, la participación del Estado en la compra-venta de alimentos no sólo permite una regulación de los precios a nivel de las diferentes regiones sino además una regulación del precio a través del tiempo evitando especulaciones que conduzcan a retener alimentos en stock mientras hay necesidades inmediatas afuera.

Por otro lado, la participación del Estado en la compra-venta de alimentos, no sólo es una estrategia que permite contrarrestar al especulación sino que además puede servir para garantizar el derecho a la alimentación de los grupos vulnerables en el sector rural, en el caso de una repentina baja de los precios de los productos en casos de sobreproducción por ejemplo. La compra de alimentos por el Estado para mantener los precios a un nivel alto sólo puede darse en casos en los que los grupos más vulnerables sean los productores de estos alimentos. Sin embargo puede ser una política regresiva en el sentido que puede beneficiar más a quienes más alimentos tienen en venta y que son además quienes están 
en situación de menor vulnerabilidad. En ese sentido, debe haber una política para favorecer en especial a los pequeños productores.

Desde esta perspectiva, es fundamental para la protección del derecho a la alimentación de calidad, recuperar la capacidad del Estado de participar en el mercado de alimentos gracias a la construcción de la infraestructura adecuada y de los sistemas administrativos necesarios.

\section{La protección de los niveles de ingresos de los grupos más vulnerables}

En el caso del Ecuador, este es uno de los factores fundamentales de privación de los derechos a la alimentación. De hecho, el Informe del Ecuador Cumbre Mundial sobre la Alimentación Cinco Años Después, muestra que el acceso económico a los alimentos se ha limitado por la reducción del poder adquisitivo hasta el punto que, para el año 2001 se estima que el consumo en familias de bajos ingresos se ha reducido de tres comidas diarias a dos.

Por otro lado, es importante notar que justamente los cultivos que ocupan mayor mano de obra han sido los que se han visto severamente reducidos en estas dos últimas décadas, como se mostró en la sección anterior. En efecto, según INEM los cultivos que ocupan más mano de obra son el maíz suave y el fréjol con 15\% de la PEA agrícola, arroz con 12\%, maíz duro con el $11 \%$ y café con el $10 \%$.

Esta tendencia a la reducción de la importancia de la producción para el consumo interno en la economía nacional ha ocasionado un fuerte cambio en la estructura económica de los hogares en las zonas rurales. De acuerdo al estudio de la Cumbre Mundial sobre la Alimentación muestra que en el Ecuador, sólo el 60\% de la PEA rural trabaja en agricultura, lo cual es inferior al promedio de América Latina y da cuenta de la relevancia del trabajo no agrícola en el campo. Por otra parte, los estudios de la realidad rural en Ecuador muestran

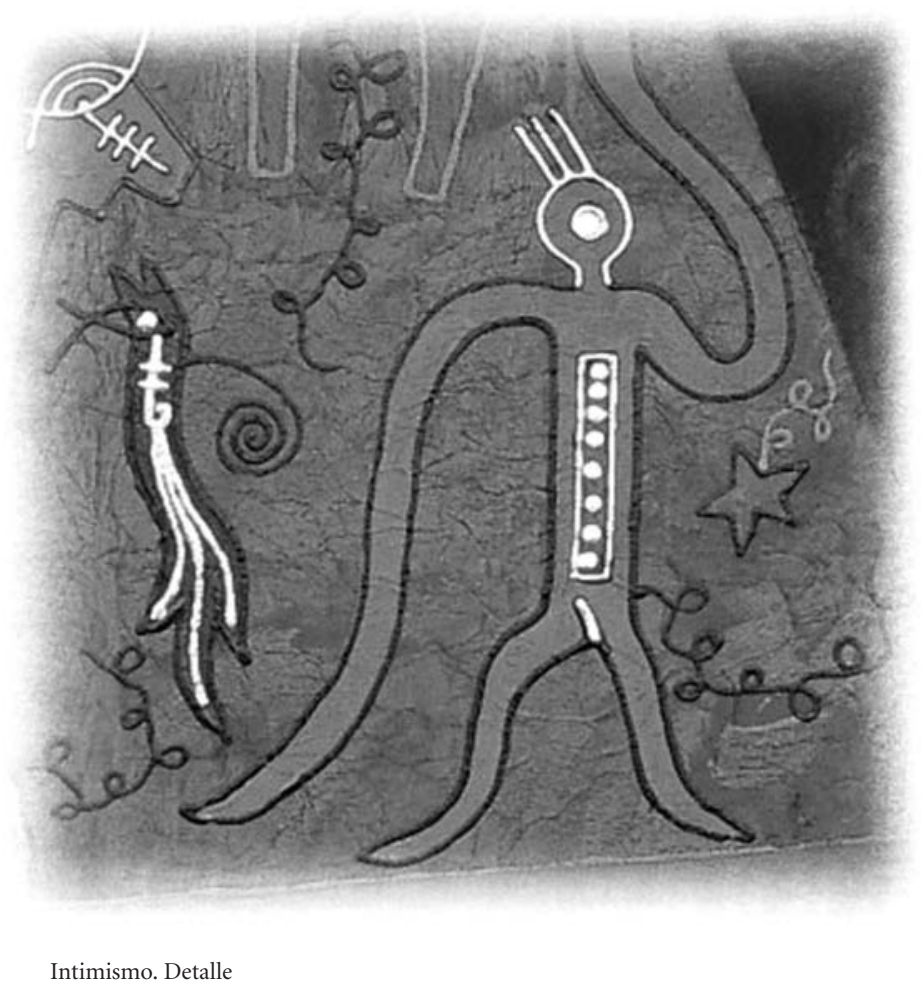

que el empleo remunerado en actividades agroindustriales y cultivos de exportación es generalmente muy vulnerable ya que no cuentan con contratos estables, trabajan más horas de las establecidas por la ley y no se les paga horas extras.

Este mismo estudio indíca que "los agricultores pobres destinan alrededor de un $60 \%$ de su producción al consumo familiar y el resto de sus alimentos lo compran en el mercado local. Con la pobreza e indigencia en aumento este problema es más serio y se traduce en riesgos de vulnerabilidad o inseguridad alimentaria, especialmente en agricultores que poseen minifundios poco diversificados. Esta situación determina flujos migratorios que agudizan el problema urbano marginal, donde el consumo depende básicamente de los ingresos familiares".

Con el incremento de los precios de los alimentos alrededor del mundo, se ha deteriorado en mayor medida la capacidad de los consu- 


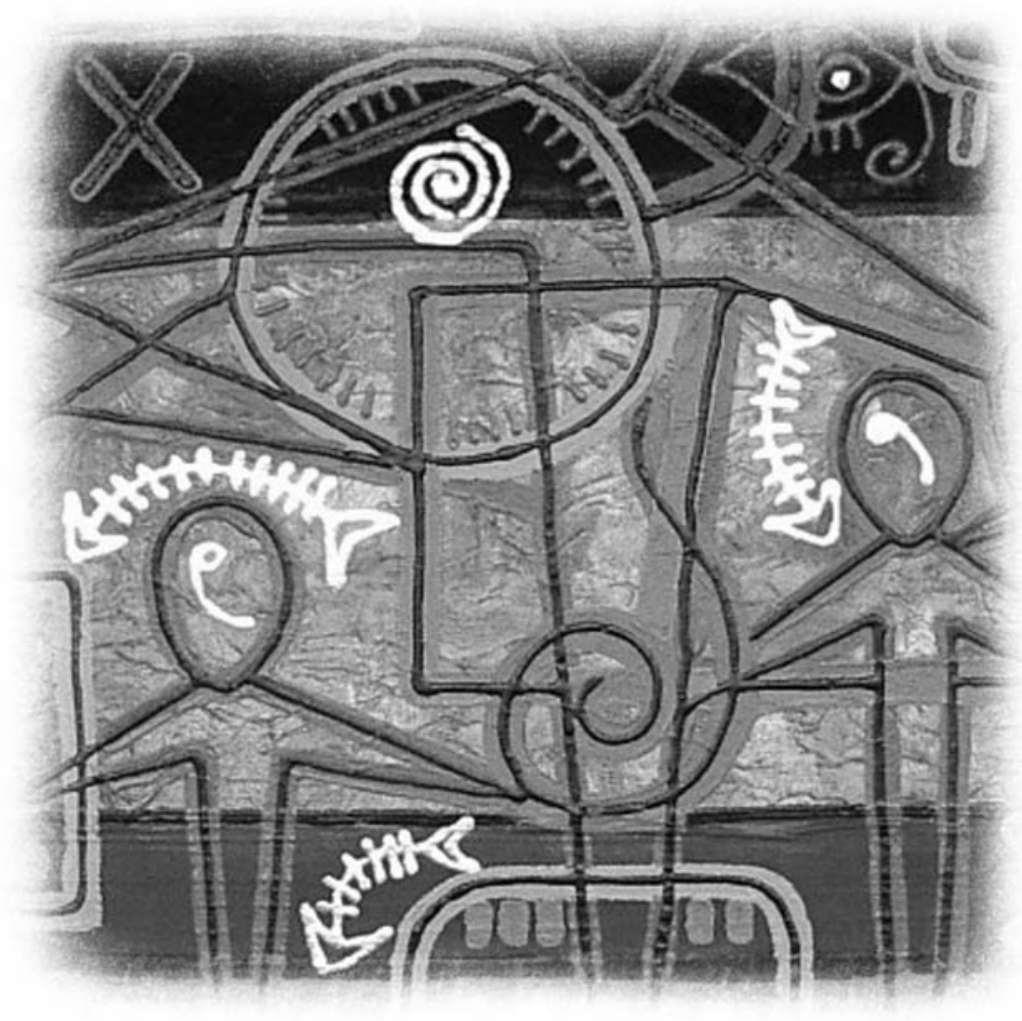

Omnipresencia. Detalle

midores urbanos de los estratos medios y bajos de la población para acceder a los alimentos.

Para la protección de los niveles de ingresos de los grupos más vulnerables, se requieren varias tipos de políticas que dependen de la actividad socioeconómica de los grupos vulnerables. En el caso de los consumidores de alimentos de la ciudad, se requiere especialmente de una política de empleo que garantice que el salario mínimo sea suficiente para cubrir las necesidades de alimentación de calidad por parte de una familia tipo. Por otro lado se requiere la implementación de un seguro de desempleo que permita a la familia mantener un nivel de ingreso que le permita asegurar su derecho a la alimentación. De igual manera, se puede promover formas de agricultura urbana que permitan el auto-abaste- cimiento de alimentos por parte de grupos vulnerables de la población. Desde el enfoque de la economía solidaria, este tipo de políticas son fundamentales ya que permiten asegurar que las personas y colectividades no caigan en situaciones de dependencia ni de extrema vulnerabilidad que pongan en riesgo su dignidad.

En el caso de las zonas rurales, es necesario que las políticas del Estado permi$\tan$ que las pequeñas unidades familiares de producción puedan autoabastecerse de alimentos con su propia producción y que sus ingresos no caigan a niveles que no les permita adquirir los alimentos que necesitan para complementar su nutrición. En este sentido, se debe proteger la economía de las pequeñas parcelas productivas. Como se vio anteriormente, la compra-venta de alimentos por parte del Estado es una solución para evitar que los precios de ciertos productos de los cuales depende la economía de las familias más empobrecidas de las zonas rurales caigan demasiado. De igual manera, es fundamental proteger y promover la producción de productos para el consumo interno por sobre la producción de productos alimentarios para la exportación puesto que su expansión tiende a limitar los derechos a la alimentación de los grupos más vulnerables, por dos razones fundamentales:

Incrementa las desigualdades en el medio rural favoreciendo el enriquecimiento de ciertos actores en detrimento de otros, principalmente privando a los pequeños campesinos de sus tierras y convirtiéndolos en trabajadores agrícolas con salarios bajos e inestables.

En economías en las que la mayoría de los más pobres no tienen tierra, un cambio hacia cultivos de exportación genera un incremento en el precio de los alimentos y los hace más vulnerables

Finalmente, es importante que el Estado implemente políticas que permitan diversificación de los ingresos de los grupos más vulnerables, pa- 
ra evitar que el acceso a la alimentación de calidad dependa de una sola fuente y que la gente se vea obligada a migrar fuera de su territorio, con las graves consecuencias en términos de perdida del tejido social, la solidaridad y la identidad cultural.

\section{Estrategia a corto plazo: la protección inmediata a los grupos en riesgo}

Es probable que, pese a que exista una estrategia a largo plazo que garantice la soberanía alimentaria, existan situaciones en las que el Estado deba garantizar, al menos a los grupos más vulnerables, la provisión de una cantidad mínima de alimentos que permitan su supervivencia. En estos casos, se justifican estrategias en las que el Estado provee el alimento a la población. Estas estrategias pueden ser diversas y con diferentes ventajas o desventajas. Lo que es importante es que la estrategia escogida sea coherente con la estrategia a largo plazo y con el modelo económico basado en la economía social y solidaria elegido por el Ecuador.

\subsection{La prevención y la intervención temprana}

La aplicación de políticas públicas que permitan garantizar de la manera más adecuada el derecho a la alimentación de calidad a toda la población del país requiere en primer lugar el establecimiento de un sistema de prevención temprana de situaciones de crisis alimentaria. Efectivamente, la intervención oportuna en casos de riesgo es fundamental, desde un el enfoque de la Economía Solidaria, no sólo porque es la manera más efectiva de contener los niveles de mortalidad, prevenir daños psíquicos irreversibles y evitar consecuencias en los niveles de empleo y/o productividad sino principalmente porque permite preservar una cierta normalidad en la calidad vida (psicológica y física) de los individuos y permi- te realizar intervenciones desde el Estado que no debiliten los sistemas de solidaridad que tradicionalmente existen en la sociedad para evitar crisis de mayor impacto (ayuda entre vecinos, redistribución de los alimentos a nivel intra-familiar, mejor utilización de los alimentos y reutilización de alimentos tradicionales, etc.). De igual manera, la prevención temprana de crisis, permite realizar acciones públicas que respeten los espacios de convivencia alrededor de la alimentación, que son fundamentales para la unidad familiar y muchas veces comunitario, ya que no requiere del desplazamiento de la población en riesgo fuera de sus espacios naturales de convivencia.

En este sentido, el Estado debe garantizar que exista la adecuada preparación, alerta y respuesta en caso de síntomas de crisis alimentarias. Dentro del enfoque de la Economía Solidaria, es fundamental que el Estado garantice la implementación de un Sistema de Información sobre acceso a la alimentación de calidad de la población, que prevea un conjunto de indicadores y un sistema de alertas tempranas para casos en los que está en riesgo la seguridad alimentaria. Este sistema de información no solo debe servir para informar las políticas públicas del gobierno sino que debe estar acompañado de un proceso ámplio de difusión de la información que pueda ser utilizada para que la ciudadanía ejerza una presión en sus gobernantes a favor de una intervención oportuna en caso de riesgo y que permita que las intervenciones del Estado sean diseñadas de tal manera que no pongan en riesgo los sistemas tradicionales de solidaridad para la seguridad alimentaria ya existentes, acordes con la cultura de cada nacionalidad del Ecuador.

Es fundamental que el Estado garantice la implementación de un Sistema de Información sobre acceso a la alimentación de calidad de la población. 


\subsection{Análisis de alternativas de politicas públicas para la provisión de alimentos a grupos en situación de crisis alimentaria}

Si bien existe un acuerdo con relación a la necesidad, en ciertos casos críticos, de asegurar a los grupos vulnerables en situación de crisis alimentaria la capacidad para proveerse de una cantidad mínima de alimentos que permita ase- gurar su supervivencia y evitar lesiones físicas y Psicológicas irreversibles, la forma de provisión de este soporte está en discusión. El Cuadro 2 muestra algunas alternativas con diferentes consecuencias positivas y negativas en el bienestar del individuo y de la colectividad que es importante analizar antes de seleccionar la alternativa que corresponde mejor, desde el enfoque de la economía solidaria.

Cuadro 2. Alternativas de políticas públicas para la protección inmediata a los grupos vulnerables en situación de crisis alimentaria

\begin{tabular}{|c|c|c|}
\hline Estrategias & Ventajas & Desventajas \\
\hline $\begin{array}{l}\text { Al. Entrega directa y } \\
\text { centralizada de ali- } \\
\text { mentos } \\
\text { Entrega directa al beneficia- } \\
\text { rio en lugares específicos y } \\
\text { en los que consume el ali- } \\
\text { mento. } \\
\text { (Ej. programas de comedo- } \\
\text { res populares, de desayuno } \\
\text { escolar, etc.) }\end{array}$ & $\begin{array}{l}\text { - Se logra focalizar la ayuda } \\
\text { a las personas que más lo } \\
\text { necesitan. } \\
\text { - Se evita que haya discri- } \\
\text { minaciones en el reparto } \\
\text { del alimento al interior } \\
\text { de los hogares. Es parti- } \\
\text { cularmente relevante pa- } \\
\text { ra las personas de la ter- } \\
\text { cera edad puesto que es- } \\
\text { tudios empíricos han de- } \\
\text { mostrado que son discri- } \\
\text { minados al interior de los } \\
\text { hogares en momentos de } \\
\text { crisis alimentarias. }\end{array}$ & $\begin{array}{l}\text { - Tiene inherente algunos problemas en tér- } \\
\text { minos administrativos y logísticos. Requiere } \\
\text { de muchos recursos en administración, lo- } \\
\text { gística y personal. } \\
\text { - Los comedores populares sólo permiten } \\
\text { atender a personas que ya están en un ni- } \\
\text { vel alto de vulnerabilidad, lo cuál no per- } \\
\text { mite atender a personas vulnerables antes } \\
\text { de que lleguen a un estado avanzado de } \\
\text { necesidad. } \\
\text { - Requiere el desplazamiento de la población } \\
\text { fuera de sus lugares de vivienda. Genera una } \\
\text { relación de dependencia y puede vulnerar la } \\
\text { solidaridad interna de los grupos (De hecho } \\
\text { se han visto casos en que las familias no ali- } \\
\text { mentan al miembro de la familia que recibe } \\
\text { la ayuda, aún cuando esta no es suficiente } \\
\text { para garantizar la alimentación completa). }\end{array}$ \\
\hline $\begin{array}{l}\text { A2. Entrega descen- } \\
\text { tralizada de alimentos: } \\
\text { Se asigna a instituciones lo- } \\
\text { cales la responsabilidad de } \\
\text { entregar alimentos a las fami- } \\
\text { lias que más lo necesiten. } \\
\text { (Ej. Gobiernos locales entre- } \\
\text { gan fundas de comida, lideres } \\
\text { de las comunidades, etc). }\end{array}$ & $\begin{array}{l}\text { Puede llegar a más per- } \\
\text { sonas porque no requie- } \\
\text { re de desplazamiento de } \\
\text { población } \\
\text { - Tiene el potencial de ser } \\
\text { mejor focalizado porque } \\
\text { los líderes locales cono- } \\
\text { cen mejor a su población. }\end{array}$ & $\begin{array}{l}\text { - Pueden generarse condiciones de corrup- } \\
\text { ción con mucha facilidad. SE puede evitar al } \\
\text { asignar la ayuda a todos los habitantes de } \\
\text { una comunidad si es que los niveles de ne- } \\
\text { cesidad no varían mucho dentro de la mis- } \\
\text { ma comunidad. Una manera de evitar esto } \\
\text { es ampliando la participación ciudadana en } \\
\text { este tipo de programas. } \\
\text { - Genera una relación vertical de dependen- } \\
\text { cia entre organismos receptores y agencias } \\
\text { donantes, transmisor de dependencia y su- } \\
\text { misión. }\end{array}$ \\
\hline
\end{tabular}




\begin{tabular}{|c|c|c|}
\hline Estrategias & Ventajas & Desventajas \\
\hline & & $\begin{array}{l}\text { - Muchos dirigentes de las organizaciones so- } \\
\text { ciales que reciben estos alimentos se con- } \\
\text { vierten en portavoces de las agencias y no } \\
\text { de sus bases. }\end{array}$ \\
\hline $\begin{array}{l}\text { A3. Transferencia de } \\
\text { dinero hacia los gru- } \\
\text { pos vulnerables: } \\
\text { Transferencia de dinero a los } \\
\text { beneficiarios. } \\
\text { (Ej. Bonos, cash transfers, vou- } \\
\text { chers). }\end{array}$ & $\begin{array}{l}\text { - Genera una cierta redis- } \\
\text { tribución del acceso a la } \\
\text { alimentación ya que, con } \\
\text { el incremento de precios } \\
\text { que se genera por el in- } \\
\text { cremento de la demanda, } \\
\text { los grupos con mayores } \\
\text { ingresos, que no reciben } \\
\text { el bono, pueden reducir } \\
\text { su consumo. } \\
\text { Genera un incentivo a la } \\
\text { producción de más ali- } \\
\text { mentos. } \\
\text { Hay un flujo positivo de } \\
\text { alimentos hacia las zonas } \\
\text { que más lo necesitan. }\end{array}$ & $\begin{array}{l}\text { - Si la focalización no está bien hecha, es de- } \\
\text { cir, si hay personas de grupos vulnerables } \\
\text { que quedan fuera del grupo de beneficia- } \\
\text { rios, su vulnerabilidad incrementa con el in- } \\
\text { cremento de los precios de los alimentos. } \\
\text { Una forma de contrarrestar este efecto es } \\
\text { la de complementar esta política con una } \\
\text { que promueva el aumento de la cantidad de } \\
\text { producción local. }\end{array}$ \\
\hline $\begin{array}{l}\text { A4. Provisión de ali- } \\
\text { mentos o dinero a } \\
\text { cambio de trabajo: } \\
\text { Contratación de personas } \\
\text { de grupos vulnerables en si- } \\
\text { tuación de crisis para la rea- } \\
\text { lización de obras públicas } \\
\text { y/o para la participación en } \\
\text { la producción y entrega de } \\
\text { bienes y servicios públicos } \\
\text { (Ej. Construcción masiva de } \\
\text { obras de infraestructura con } \\
\text { un proceso de selección cui- } \\
\text { dadoso de los empleados de } \\
\text { acuerdo a criterios de vulne- } \\
\text { rabilidad) }\end{array}$ & $\begin{array}{l}\text { - Selección espontánea de } \\
\text { la gente que quiere tener } \\
\text { acceso a este apoyo (lo } \\
\text { que permite evitar los } \\
\text { problemas de exclusión } \\
\text { que genera la focaliza- } \\
\text { ción). } \\
\text { Genera una presión posi- } \\
\text { tiva a incrementar los sa- } \\
\text { larios de la mano de obra } \\
\text { no calificada. } \\
\text { Permite mantener la dig- } \\
\text { nidad del receptor al evi- } \\
\text { tar el sentimiento de ser } \\
\text { un mendigo. } \\
\text { Puede focalizarse en el } \\
\text { empleo femenino para } \\
\text { permitir un refuerzo en } \\
\text { la alimentación del miem- } \\
\text { bro de la familia usual- } \\
\text { mente más discriminado } \\
\text { en situaciones de crisis } \\
\text { alimentaria. }\end{array}$ & $\begin{array}{l}\text { - Si el empleo requiere el desplazamiento de } \\
\text { la población, puede afectar las relaciones fa- } \\
\text { miliares. } \\
\text { - Puede generar una disminución del volu- } \\
\text { men de producción agrícola si es que gene- } \\
\text { ra una masiva migración campo-ciudad. } \\
\text { - No incluye a aquellos que no son físicamen- } \\
\text { te aptos para trabajar. Se debe complemen- } \\
\text { tar con apoyos específicos para grupos de } \\
\text { población con esta características (ancia- } \\
\text { nos, personas con capacidades especiales, } \\
\text { huérfanos, etc.). }\end{array}$ \\
\hline
\end{tabular}


Desde el enfoque de la Economía Solidaria, la selección de la mejor alternativa para garantizar el acceso a alimentos de calidad por parte de grupos en situación de crisis alimentaria, requiere considerar una intervención que no afecte de manera permanente los vínculos de solidaridad al interior de la comunidad y de la familia y que no genere una situación permanente de dependencia que ponga en riesgo la autonomía de las organizaciones sociales ni la dignidad de la persona. Por esta razón, de acuerdo a este enfoque, se debe privilegiar un paulatino cambio hacia la alternativa 4: Provisión de alimentos/dinero a cambio de trabajo, velando por que el acceso al trabajo privilegie principalmente a los segmentos de la población que más lo necesitan (por ejemplo a las mujeres, a los padres de fami-

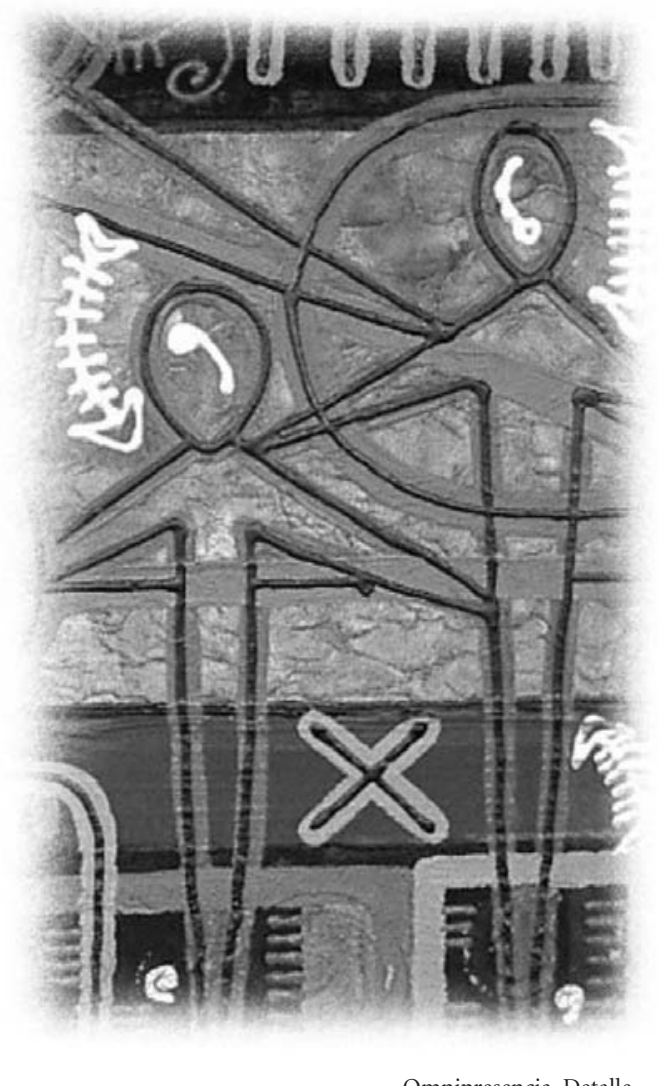

Omnipresencia. Detalle lias numerosas, etc.) y que la localización del trabajo no requiera una desmembración de la familia y de la comunidad. Esta alternativa deberá ser combinada con la alternativa 1. Entrega directa y centralizada de alimentos para los grupos vulnerables que no están en condiciones de trabajar (por ejemplo, ancianos, personas con capacidades especiales, niños huérfanos, etc.) y que no tienen el soporte de una persona hábil para el trabajo. En este sentido, es fundamental que las diferentes instituciones encargadas de la provisión de alimentos coordinen sus esfuerzos, para evitar duplicar beneficiarios y dejar a otros desatendidos.

\subsection{La Compra Pública Ética: Una forma de conectar la estrategia a largo plazo con la estrategia a corto plazo}

Más allá de la estrategia de distribución seleccionada, el Estado debe garantizar que las políticas públicas implementadas a corto plazo para paliar los efectos de la crisis alimentaria en ciertos grupos de la población, no pongan en riesgo la estrategia de soberanía alimentaria en el largo plazo. En este punto, es fundamental hacer un análisis sobre la forma en que las compras de alimentos por parte de los programas del Estado pueden fortalecer la soberanía alimentaria a largo plazo del país.

Como se puede ver en el Cuadro 3, el concepto de compra pública sostenible, al incorporar criterios sociales, ambientales y culturales en el proceso de licitación y entrega de los bienes adquiridos por el Estado, permite efectivamente hacer el vínculo entre la estrategia de soberanía alimentaria a corto y a largo plazo, puesto que influye positivamente en los tres factores que determinan a largo plazo la garantía al derecho a la alimentación en una sociedad logrando: 1) generar incentivos positivos para una producción de alimentos de calidad en gran escala incrementando la disponibilidad de los mismos para la sociedad;2) permite mante- 
ner un nivel aceptable de los ingresos de las personas involucradas en la producción de estos alimentos y controlar las cadenas de comercia- lización para evitar la especulación; y 3) fomenta una cultura de consumo de alimentos locales sanos, especialmente en los niños.

Cuadro 3. Marco conceptual de la compra pública sostenible

La Compra Pública Sostenible hace referencia a los contratos públicos que introducen criterios éticos relativos al cumplimiento de convenciones internacionales y estándares sobre condiciones laborales dignas, salarios mínimos, derechos de los trabajadores, lucha contra el trabajo infantil, dando preferencia en sus compras a aquellos proveedores y productos que apuestan por criterios o estándares más exigentes, como son los estándares de Comercio Justo. La Compra Pública Responsable o Sostenible integra 3 dimensiones principales:

- Compra Verde: hace referencia a la minimización de impactos ambientales a través de la reducción de la producción de residuos, reducción del consumo de recursos, utilización de alternativas realizadas con productos monomateriales o reciclados o que provengan de recursos renovables gestionados de forma sostenible.

- Compra Social: fomento de la inserción sociolaboral de personas en riesgo de exclusión, fomento de la calidad y estabilidad en el empleo y cumplimiento de la legislación relativa a no discriminación, igualdad de oportunidades, accesibilidad y prevención de riesgos laborales. Apoyo a la economía social.

- Compra Ética: garantía de condiciones laborales dignas en toda la cadena de producción y suministro, especialmente en los casos de subcontratación y deslocalización en países en vías de desarrollo.Apoyo a las alternativas de Comercio Justo.

Cualquier cambio en los criterios de compra o selección de proveedores por parte del Estado implica un fuerte impacto en volúmenes de compra y consecuentemente es una herramienta eficaz para lograr cambios en el tipo de producción. Por otra parte, la apuesta del Estado por un consumo más responsable puede animar a que las empresas y a las familias a adoptar a su vez un mayor compromiso por la responsabilidad social y a los ciudadanos y ciudadanas a incorporar comportamientos más sostenibles en su vida diaria.

Fuente: www.comprapublicaetica.org

La incorporación de la compra pública ética en los programas de alimentación del Estado debe hacerse: 1) Remplazando de manera inmediata aquellos productos y servicios importados y/o producidos localmente fuera de los estándares de la compra pública sostenible en los que existe oferta suficiente por parte de las organizaciones de Comercio Justo; y 2) En los casos donde no existe alternativa de Comercio Justo disponible, promoviendo que las empresas fabri- cantes y proveedoras garanticen que en la elaboración de dichos productos o desempeño del servicio se han cumplido en una primera instancia unas condiciones laborales dignas y en una segunda instancia, todos los criterios de la compra pública sostenible.

Por otra parte, el sistema de compra del Estado, deberá garantizar los principios del procesos de la compra pública sostenible indicados en el Cuadro 4. 
Cuadro 4. Principios del proceso de la compra pública ética

- Principio de publicidad y transparencia. Todos los licitadores deben ser informados de la misma forma y a la vez, y los requerimientos deben ser especificados claramente para poder comparar objetivamente las ofertas.

- No discriminación. Los criterios sociales, éticos y ambientales no pueden ser introducidos de modo que se favorezca a los proveedores locales o nacionales.

- Relación con el objeto de contrato. Todos los requerimientos sociales, éticos y ambientales deben estar relacionados con el objeto de contrato.

- Criterios Objetivos. La adjudicación del contrato debe estar basado en criterios objetivos para asegurar el cumplimiento de los principios comunitarios. El criterio de adjudicación puede ser "el precio más bajo" o "la oferta más ventajosa". En el caso de que se opte por "la oferta más ventajosa", las autoridades contratantes deben evaluarlas en base a criterios objetivos que permitan determinar la calidad y eficiencia económica de la oferta en relación con el objeto del contrato. Por ello, es importante que las especificaciones técnicas establezcan parámetros medibles que puedan ser tomados como referencia para evaluar las ofertas (Art. 46 de la Directiva).

- Mutuo reconocimiento. Las entidades contratantes deben reconocer explícitamente y aceptar productos que cumplan las especificaciones sociales, éticas y ambientales mostrando certificaciones equivalentes. Si en la descripción de las especificaciones técnicas, la autoridad contratante hace referencia a estándares predefinidos, deben admitirse también ofertas que no se hayan sometido al estándar pero que demuestren, por cualquier medio de prueba, que su oferta es "equivalente" a las ofertas cubiertas por el estándar (art. 29 de la Directiva).

Fuente: www.comprapublicaetica.org

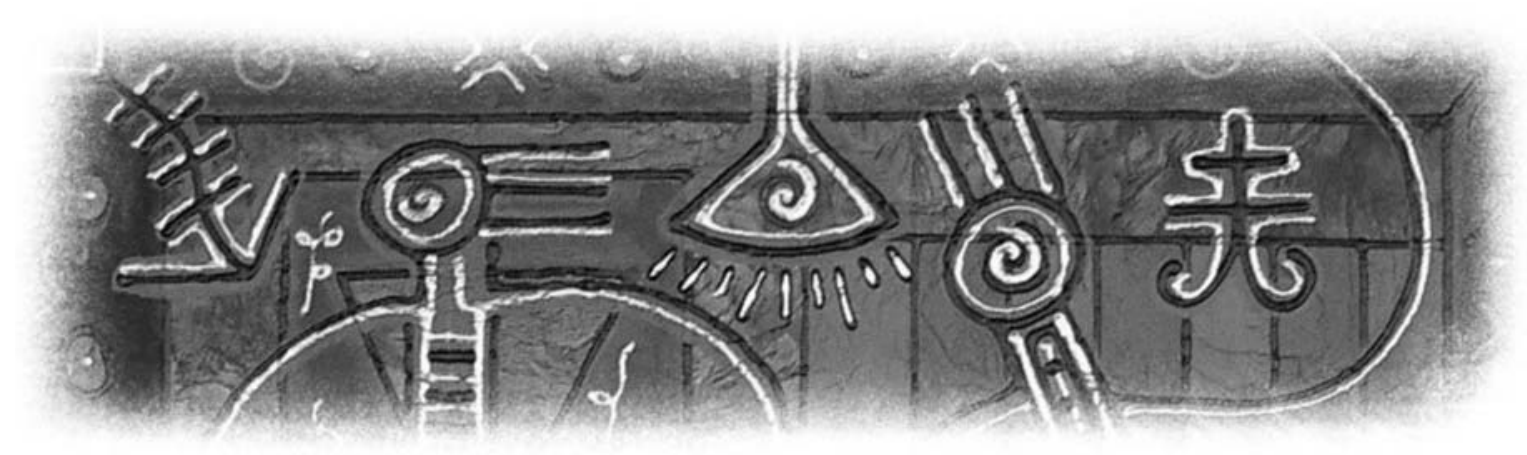

Detalle 


\section{Bibliografía:}

- SEN, Amartya y DREZE, J. 1991. Hunger and Public Action, Oxford University Press, USA.

- ARRIETA, M. (coordinación). 1993. Autosuficiencia o inseguridad alimentaria: el rol de los alimentos donados en Bolivia, ILDIS: La Paz.

- Cumbre Mundial Sobre La Alimentación Cinco Años Después (2001), Informe Del Ecuador, disponible en www.rdfs.net/linked-
docs/WFS-ECUADOR-notraducir.doc

- VÁSQUEZ L. y Saltos, E. 2008. Ecuador: su realidad, Fundación José Peralta: Quito.

- JORDÁN, R. H. 1996. Las mujeres productoras de alimentos en Ecuador: diagnóstico y politicas. San José, C. R.: Instituto Interamericano de Cooperación para la Agricultura.

- MAG-ORSTOM (1978), Diagnóstico socioeconómico del medio rural ecuatoriano. Doc. $4^{\mathrm{a}}$, Quito.

1 Este artículo fue elaborado en el marco de la construcción de una propuesta alternativa de Ley de Soberanía Alimentaria del Ecuador por parte de la Mesa de Comercialización y Consumo del Colectivo Agrario con el apoyo de VECO-Andino. Este documento fue parte de las contribuciones del Movimiento de Economía Social y Solidaria del Ecuador y del Colectivo Agroecológico a esta construcción colectiva de la propuesta de Ley.

2 INEC. Censo Nacional, Proyecciones de Población. La población urbana asciende a 8’098.436 y rural 4’547.659. A nivel nacional el 50,2\% son hombres y 49,8\% mujeres.

3 Datos provenientes de Hojas de Balance de Alimentos, procesados por FAO, FAOSTAT y ODEPLAN. 


\title{
Agrocombustibles en las llamadas tierras marginales
}

\author{
Elizabeth Bravo*
}

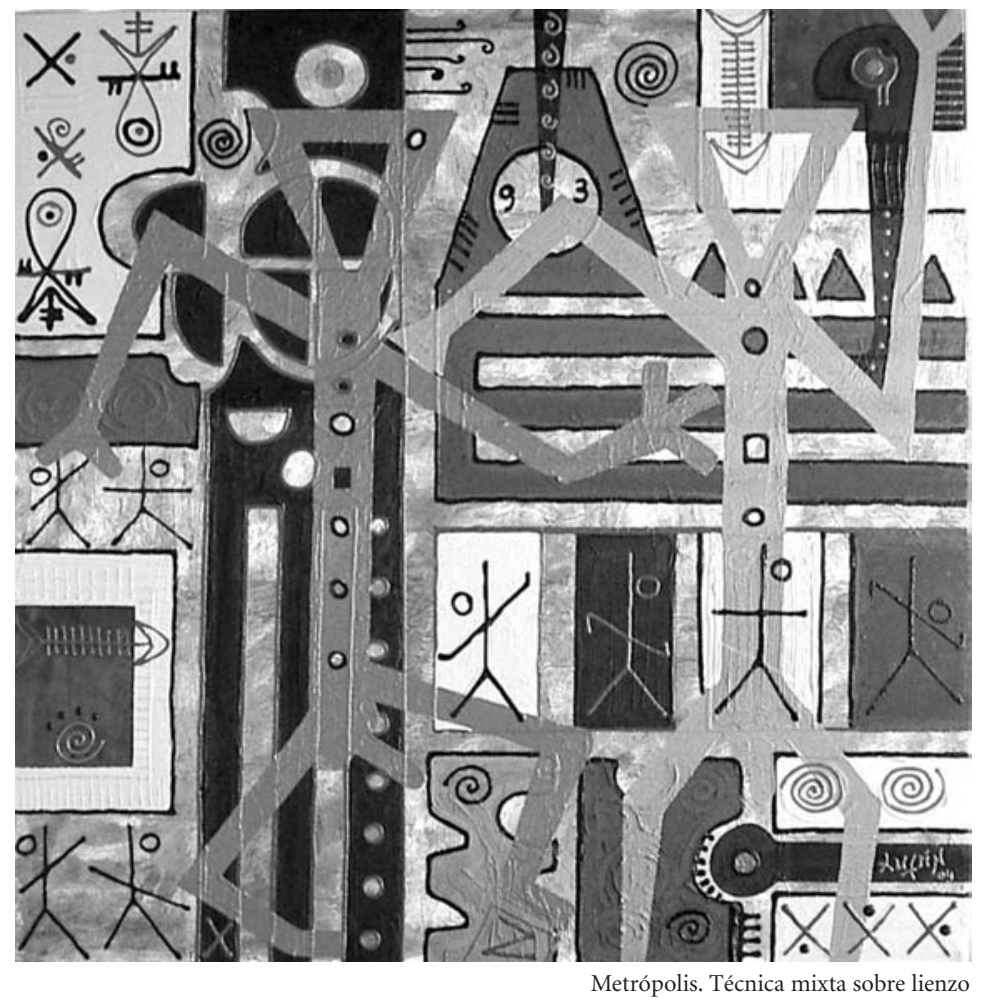

En los últimos años todos los países de América Latina han adoptado políticas para promover de manera acelerada cultivos energéticos para la producción de agrocombustibles (Bravo, 2006). Estas nuevas fuentes de energía son promovidas con el argumento de que a través de ellas, los países importadores de derivados de pe- tróleo pueden alcanzar su soberanía energética, que son una solución para el cambio climático y una respuesta a la crisis del agro que viven muchos países del Tercer Mundo.

Sin embargo, la crisis alimentaria mundial que se inició en el 2007 y se prolongó hasta mediados de 2008, ha obligado a revisar algunos de

* Docente de la Carrera de Gestión local para el Desarrollo Sostenible. Integrante de Acción Ecológica. 
los argumentos. El Relator Especial de las Naciones Unidas sobre el Derecho a la Alimentación, Olivier De Schutter asoció las variaciones en el precio de los alimentos con el uso de granos en la producción de etanol, y pidió a los gobiernos del mundo que revisen sus políticas sobre agrocombustibles (BBC News / World, 2008).

Por otro lado, un estudio del Banco Mundial reveló que los agrocombustibles incrementaron en un $75 \%$ los precios de los alimentos, contradiciendo lo que ha mantenido el gobierno de Estados Unidos, quien sostiene que sólo el 3\% de esta crisis es atribuible a los agrocombustibles (Ribeiro, 2008).

La crisis financiera frenó el incremento en el precio de los cereales y en algunos casos los precios cayeron. Así, el precio de la tonelada de maíz en septiembre de 2008 estaba en US $\$ 23,44$, lo que significa que bajó en un $35 \%$ en relación al mes de junio, cuando alcanzó un precio de US $\$ 294,18$ la tonelada. En octubre el precio siguió bajando llegando a cotizarse a $\$ 180,70$ la tonelada. Sin embargo, a pesar de la caída, el precio del maíz se mantuvo por encima del registrado en septiembre de 2007, cuando estuvo en US\$ 157,77 la tonelada, y aún más alto que el precio de septiembre del 2006, cuando alcanzó los US\$120,76 (FAO, 2008).

Como respuesta a estas evidencias, en varios círculos se propone (y se impulsa) establecer cultivos energéticos en las llamadas "tierras marginales", es decir, en las tierras que al momento no son utilizadas para la agricultura, por no poseer las condiciones óptimas para ello. De esta manera se estaría reactivando la economía de las poblaciones asentadas en esas zonas, sin afectar la producción de alimentos, porque esas zonas son improductivas.

\section{Tierras marginales}

El concepto de tierras marginales está cobrando cada vez más importancia en los debates políticos y científicos sobre agrocombustibles, y se promueve a los cultivos que pueden ser plantados en estas zonas, como una alternativa a otros cultivos energéticos como es el maíz, que compite abiertamente con los alimentos, o como la palma y la caña, que destruyen ecosistemas naturales de alto valor.

Un informe reciente de la Agencia de Combustibles Renovables del Reino Unido, conocido como Gallagher Review, dice que se pueden evitar los impactos indirectos generados por los agrocombustibles si éstos se siembran en tierras marginales. Del mismo modo la Sociedad Real Británica (2008) en su informe sobre "agrocombustibles sustentables", recomienda que los cultivos energéticos deben establecerse en zonas con niveles pobres en biodiversidad, tierras marginales o abandonadas. De esa manera, se reactiva la economía rural, se contribuye a desacelerar el calentamiento global, y se pone en producción tierras degradadas o improductivas.

¿Qué es una tierra marginal? Artemi Cerdà las define en los siguientes términos:

\begin{abstract}
El concepto de tierra marginal se refiere a aquellas tierras de escasa fertilidad, lo que llevó, en sistemas socioeconómicos de autoabastecimiento, a su explotación como pastos, bosques, matorrales o incluso eriales. (Son) ... suelos que presentan limitaciones para el cultivo con las modernas técnicas agrícolas. Suelos poco potentes, pedregosos, escasos en nutrientes y situados en laderas muy pendientes explican estas circunstancias.
\end{abstract}

Se ve a la inserción de las tierras marginales en la producción de cultivos energéticos, como una estrategia en la que "todos ganan": ganan los campesinos porque tendrán fuentes de trabajo o un mercado para sus productos, ganan los grandes empresarios de los agrocombustibles, gana el planeta porque se soluciona el problema del calentamiento global.

Ante esto nos preguntamos si esas áreas son en realidad improductivas, o simplemente son zonas que no se han insertado a la agricultura industrial. En muchos casos, son comunidades muy tradicionales que viven en un delicado equilibrio con el ambiente, precisamente por su fragilidad. La biodiversidad de estas zonas puede ser de alto 
valor, por su endemismo. Por lo tanto, cualquier cambio en este equilibrio puede ser fatal.

Otro aspecto que es ignorado en el debate sobre las tierras marginales, es que en éstas se reproduce una biodiversidad agrícola de gran importancia, pues son pequeños reductos de variedades adaptadas a condiciones ecológicas especiales, que están en proceso de erosión genética en otros lugares del país.

Dado que los grupos de poder económico (nacional o internacional) son los que ocupan estos nuevos espacios, desplazando de manera explícita o implícita a las poblaciones locales de sus territorios, o al menos destruyen sus formas de producción tradicionales, se crea por un sistema de colonialismo interno, a través de una serie de mecanismos modernos de dominación, por ejemplo por la destrucción de las formas autónomas de trabajo; la modificación de las formas de confiscación del territorio, que deja de ser comunitaria para ser privada. Una de las formas de apropiación del territorio es a través de la tecnología, incluyendo la introducción de nuevos cultivos y de nuevas formas de producción.

En este debate no se realiza una evaluación acerca del impacto que la agricultura intensiva puede tener en estos suelos, que por definición son pobres. Para que sean productivos, por lo menos, a la escala requerida para la producción a gran escala de cultivos energéticos, se requerirá de fertilizantes inorgánicos, y luego de plaguicidas y otros insumos agrícolas, por ejemplo, semillas. Sin ninguna duda se establecerán relaciones de dependencia entre estos campesinos pobres que han vivido bajo economías de subsistencia, con los empresarios impulsadores de estos cultivos. Los primeros entregarán sus cosechas; los segundos, los insumos. El endeudamiento será frecuente, lo que aumentarán las redes de dependencia.

Otra posibilidad es que simplemente los campesinos se conviertan en trabajadores de grandes empresarios agrícolas, pues, éstos pueden ser presionados a que vendan sus tierras. En cualquier caso lo que se conseguirá es introducir en el mercado, áreas que antes estaban dedicadas a la soberanía alimentaria local y regional.

Finalmente, aun cuando estas plantaciones se establezcan en zonas consideradas como marginales, los empresarios siempre buscarán las mejores tierras dentro de estas áreas con el propósito de asegurar su inversión, por ejemplo, en remanentes de bosques naturales, agravando los problemas de aridez, pues se estarían destruyendo una de las fuentes de agua que los alimenta.

Para abordar esta problemática, a continuación se analiza el debate en torno a la introducción del piñón en el Sur de Manabí.

\section{El piñón en zonas semi-áridas}

Entre las especies propuestas para la producción de biodiesel, se destaca el piñón (Jatropha curcas L.), oleaginosa arbustiva, perteneciente a la familia de Euforbiacea. Muchos mitos rodean ha esta planta: que no requiere de suelos fértiles para crecer, ni de grandes cantidades de agua; que no existen plagas conocidas que lo ataquen. Se ha llegado incluso a decir que el piñón es un árbol con vocación tercermundista, porque:

\begin{abstract}
Sobrevive y crece en las tierras marginales y erosionadas, en las tierras que ya no sirven para la actividad agricola, porque se agotaron. Existe una variedad traída desde Cabo Verde, que necesita poca agua para crecer: con 200-250 mm de precipitaciones lluviosas por año tiene suficiente, aunque tampoco le molestan las lluvias copiosas de hasta 2 mil mm por año. En pocas palabras, la Jatropha curcas L. crece donde no se desarrolla casi nada y se puede adaptar a la inundación y a la sequía. En cuanto a la productividad, su vocación es de servicio: empieza a producir de manera rentable al cabo de un año de sembrado, su producción se incrementa año con año durante los primeros 5 años y a partir de ahí se estabiliza en los 30-50 años que le quedan de vida (Fernández, 2008).
\end{abstract}

Estos argumentos hacen que el piñón esté siendo promovido en varias zonas áridas del mundo como el cultivo energético por excelencia.

En Etiopía se ha propuesto dedicar un millón de hectáreas a este cultivo. En China la empresa petrolera estatal china (CNOOC) está pla- 
nificando sembrar 30.000 ha en la provincia de Sichuan hasta el año 2010.

La empresa petrolera nacional de Las Filipinas destinó 14 millones de dólares para invertir en plantaciones y producción de Piñón. En Indonesia, a más de los millones de hectáreas ya existentes de palma aceitera, se sumarán otras tantas de piñón, y para su procesamiento se planifica establecer 52 plantas de biodiesel (Sappenfiel, 2007).

En Guatemala se plantea introducir 600.000 ha de piñón en tierras comunitarias. Entre las empresas que están invirtiendo en este sector, está el grupo industrial CIE Automotive, compañía de origen vasco, que está trabajando en el desarrollo de las materias primas para la producción de agrodiesel. El objetivo es conseguir gestionar una capacidad instalada de más de $700 \mathrm{mil} \mathrm{m}^{3}$ de agrodiesel.

En Perú se inauguró una planta de producción de Biodiesel, basados en semillas de piñón. La planta pertenece a Heaven Petroleum Operators. Se plantará unas 100 mil ha de piñón en la zona de San Martín (Medina, 2008).

La empresa británica D1 Oils es la principal productora de piñón. Este grupo industrial planificó en un primer momento trabajar con colza, pero los precios eran muy altos. Es importante notar a este respecto, que la colza es un cultivo de zonas templadas, que los principales productores son la Unión Europea y Canadá, por lo que se entiende que los precios sean más altos.

Entonces, la compañía apostó al cultivo del piñón en regiones del mundo donde la tierra y el trabajo humano son más baratos. D1 entró en asociación con la gigante petrolera británica BP para formar la empresa D1-BP Fuel Crops, la misma que tiene operaciones también en la India y en el Sud Este Asiático (Sappenfiel, 2007).

En África ha establecido centros de desarrollo regional en la isla de Cape Verde, en Zambia y en Swazilandia. Está plantando piñón también en Madagascar. Como resultado de un acuerdo con Rolls-Royce, se ha instalado una refinería en la ciudad de Durban - Sudáfrica para

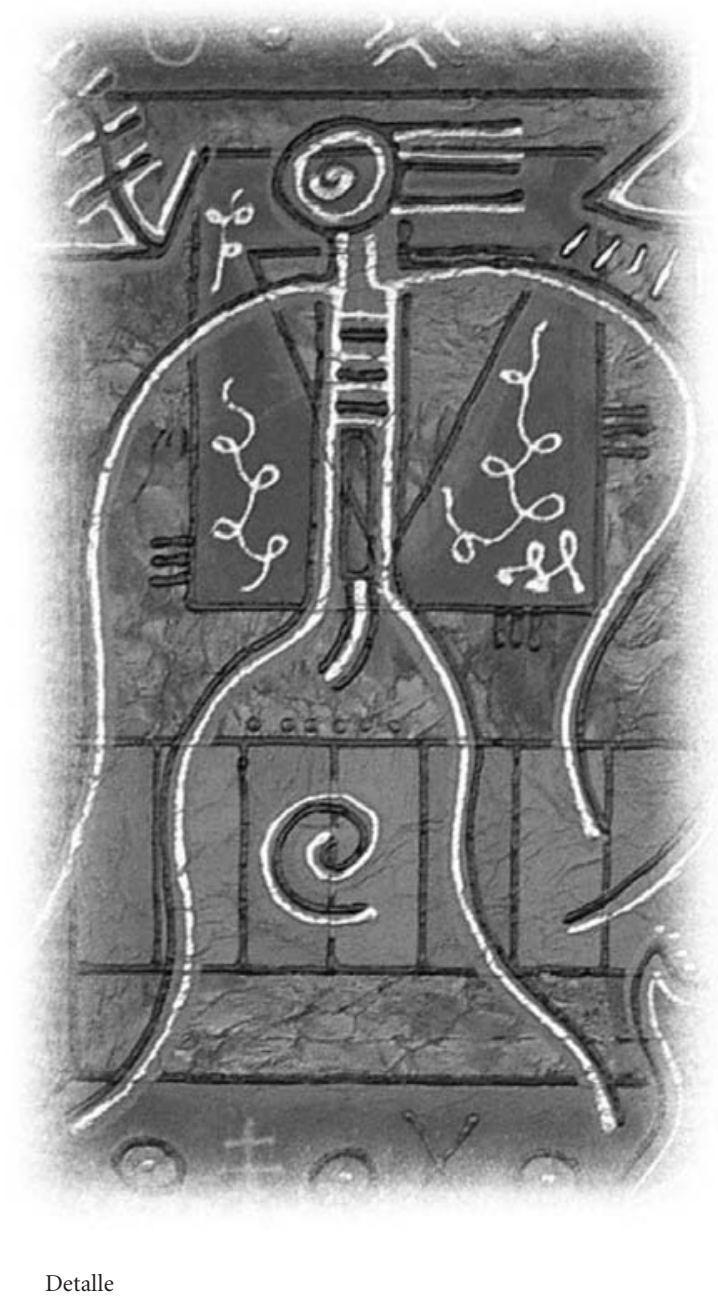

procesar ocho millones de litros de agrodiesel al año. Para abastecerse con aceite de piñón, D1 ha firmado además acuerdos con Stancom Tobacco Ltd de Malawi, por un periodo de diez años, a partir de las plantaciones de los campesinos con los que Stancom tiene contratos. La empresa aspira firmar contratos con unos 27 mil campesinos en Malawi y Zambia.

En la India exporta todas las semillas que se produce a Inglaterra para su procesamiento, como en los viejos tiempos de la colonia (Bravo, 2007). En ese país, se asoció con Mohan Brewe- 


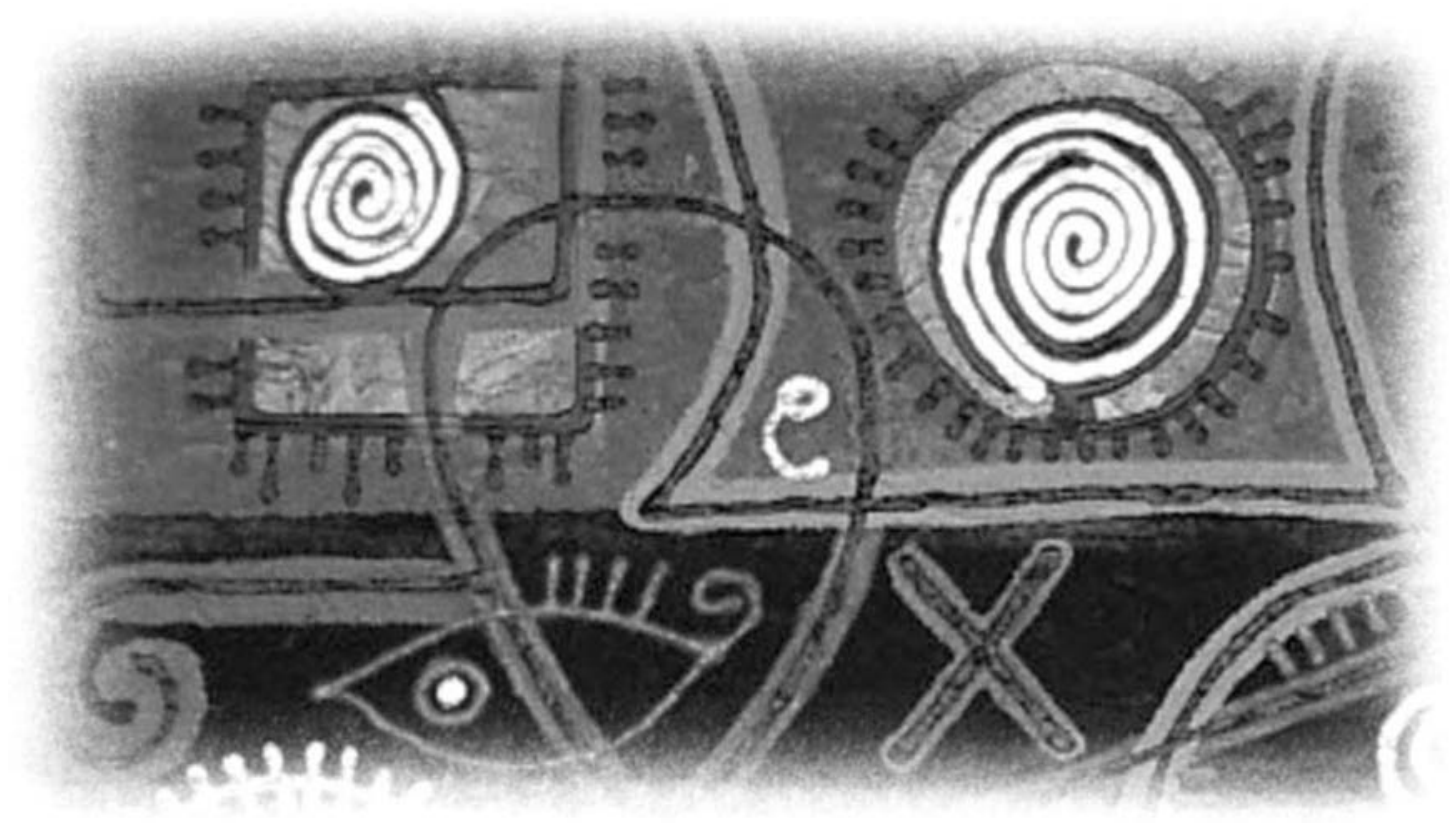

Omnipresencia. Detalle

ries \& Distilleries Ltd. para sembrar piñón bajo la agricultura de contrato en el Estado de Tamil Nadu al Sur del país, con el apoyo de organizaciones no gubernamentrales. En este Estado ha establecido su centro de investigación científica regional.

En el 2006, D1-BP entró en asociación con Williamson Magor \& Co. Limited dueña de la más grande productora de té en la India, con quien va a sembrar piñón en la conflictiva zona del Noreste de la India.

En Brasil, después de una fuerte presión de la Associação Brasileira de Produtores de Pinhão-Manso (ABPPM), el gobierno de Brasil aceptó inscribir al piñón como una especie a ser usada en la producción de agrodiesel. Esto significa que ahora puede contar con el crédito y el seguro agrario destinados a las variedades ya registradas.

De las más de ciento cincuenta refinerías de agrodiesel que hay en Brasil, veintinueve (en funcionamiento, construcción o planificadas) examinan la posibilidad de usar piñón como materia prima. Aquí tiene también intereses D1BP Fuel Crops Limited que opera en el interior del Estado de San Paulo. Invierten en este país en piñón, además, la suiza Global Agricultural Resources - GAR en Minas. En el Estado de Tocatins funciona la empresa Companhia Produtora de Biodiesel do Tocantins (Biotins Energia). La española CIE Automotive ${ }^{1}$ trabaja en el Norte de Minas, se ha asociado con la empresa NNE Minas Agro Florestal, para Biojan, que trabajará en el mejoramiento genético del piñón, al tiempo que vende semillas y plántulas (Centro de Monitoramento da Agrocombustíveis, 2008).

La mayoría de empresas en Brasil trabajan con el modelo de agricultura de contrato a través de asociaciones con agricultores familiares y otros productores. La presencia de los pequeños productores facilita que las empresas mencionadas, obtengan el sello social que entrega el gobierno de Brasil dentro de Plan Nacional de Biocombustibles. 


\section{El piñón de Manabí}

El piñón es uno de los cultivos que se está promoviendo en el Ecuador para la producción de agrodiesel. En un país tan pequeño como el Ecuador, se han identificado 200.000 ha de suelos secos para este cultivo, aunque al momento se ha planificado plantar únicamente 40.000 hectáreas (Bravo E, 2007).

Como en otras partes del mundo, se dice que las plantaciones de piñón se establecerán en zonas marginales, donde no hay agricultura debido a las malas condiciones de los suelos. Y es así que se ha identificado a los cantones Jipijapa y Montecristi en la provincia de Manabí, y en ciertas regiones de la provincia de Loja, como ideales para implementar este programa. Inclusive se cuenta con el apoyo de la cooperación internacional (SNV) y del Instituto Internacional de Cooperación para la Agrícola IICA (SNV Ecuador, 2008).

El modelo de siembra propuesto es, como en otros países, la agricultura por contrato en tierras de comuneros. La empresa firma contratos con comuneros donde esta se encarga de sembrar piñón. Cuando las plantas empiezan a producir semillas, ellos entregan la producción. En la misma comuna se instala una planta de procesamiento de agrodiesel para la exportación. Las tierras comunales son usadas para producir un cultivo de exportación, y quienes defienden este modelo dicen que en ellas no se producen alimentos, que son tierras marginales y que sólo ahora se les está dando un buen uso.

A este hay que añadir que las empresas desean cobrar bonos de Carbono dentro del Mecanismo de Desarrollo Limpio ${ }^{2}$ a cuenta de estas plantaciones.

Frente a estas aseveraciones cabe preguntarse por un lado, si éstas son en realidad zonas marginales; si en ellas no se producen alimentos; o si, por otro lado, son zonas que no han sido incorporadas a la agricultura industrial, y que el propósito de este tipo de proyectos es justamente incorporarlas al agronegocio.

\section{Manabí, su biodiversidad, su gente}

La provincia de Manabí está influenciada por la corriente fría y seca de Humboldt y el Fenómeno del Niño, lo que divide a la provincia en dos zonas ecológicamente bien determinadas; un Sur seco y un Norte húmedo, y dos regiones marcadas: una lluviosa, de enero a mayo, y la otra seca, de junio a diciembre.

Tanto la agricultura como las sociedades que viven en el Sur de Manabí -lugar donde se están implementando los proyectos del piñón- están adaptadas al ambiente seco. El abastecimiento de agua depende totalmente de la lluvia que en algunas zonas no alcanzan a los $250 \mathrm{~mm}$ al año.

Muchas de las poblaciones están organizadas en comunas ${ }^{3}$. En verano, los bosques secos en los que se asientan estas comunas, parecen yermos, desérticos, los que van tornándose verdes a medida que avanza el invierno (o estación lluviosa). Son en estas zonas, donde se desarrolló la cultura Manta. Al tiempo de la llegada de los primeros conquistadores españoles se desarrollaba ahí el Señorío de Çalangome quienes visualizaron terrazas y centros urbanos en los cerros de Chongón y Colonche, y al interior de los valles. El cronista Cieza de León describe a la región comprendida entre Bahía de Caráquez y la Península de Santa Elena, como tierras muy fértiles, donde crecía el maíz y la yuca, el camote y otros tubérculos comestibles; tres clases de guayabas, guabas, aguacate, dos clases de tunas, cerecillas, melones, caimitos, toda clase de legumbres y fabas; además de la variedad de animales que habitaban la zona, como perdices, venados, puercos americanos, abejas de tierra que hace panal... (Marcos, 2005: 37).

Ya en esa época se describían las albarradas, que se usan hasta hoy, y que es uno de los mecanismos más sofisticados de adaptación a la escasez de lluvia. Según Pino, et al. (2006: 9394), la albarrada es un sistema tradicional hidráulico, resultado de un desarrollo tecnológico indispensable para la ocupación humana en 
las áreas dominadas por bosques secos tropicales, y han sido usadas desde hace tres mil ochocientos años. Los autores mantienen que este sistema de manejo del agua caracteriza al pueblo Manta-Huancavilca ${ }^{4}$, y se caracteriza por su perdurabilidad en el tiempo. Las albarradas son una adaptación a los excesos de lluvia de los años de El Niño y a la desigual distribución durante el año, previenen la erosión ocasionada por la escorrentía y aseguran el abasteci-

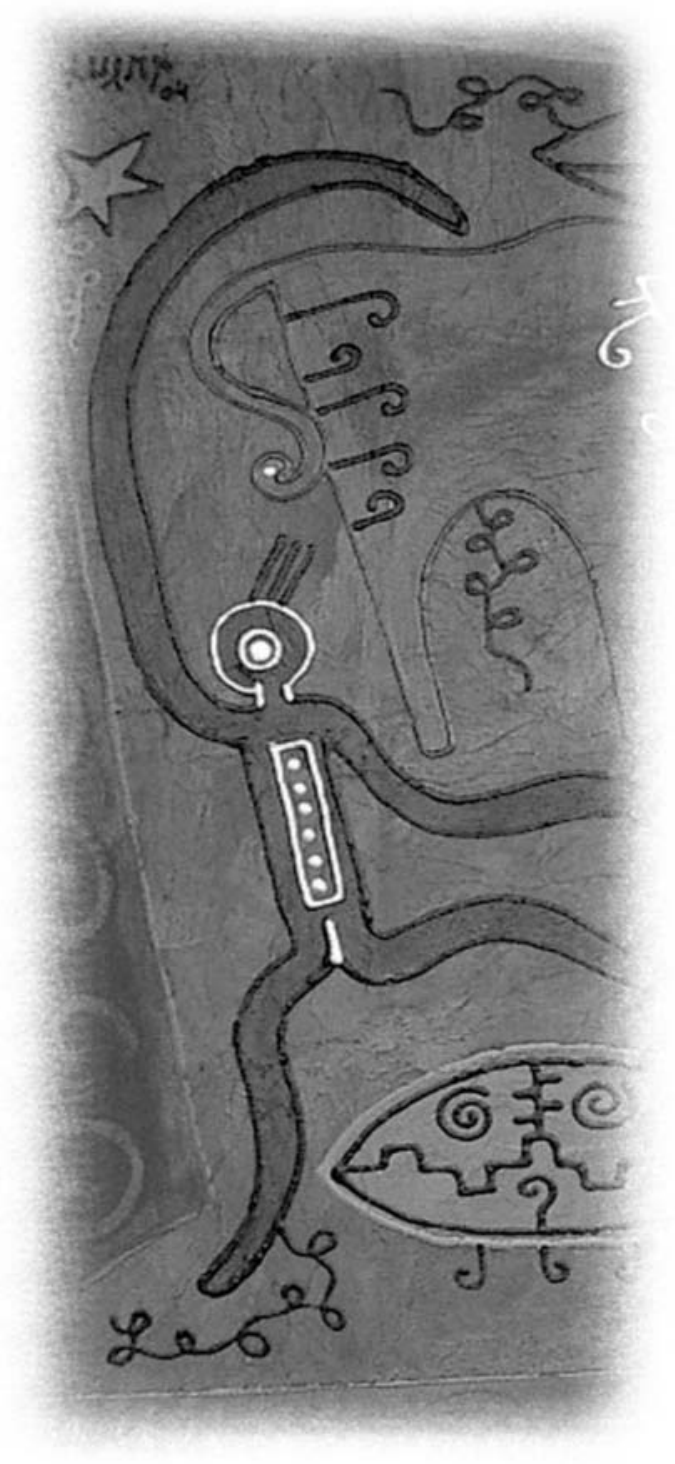

Intimismo. Detalle miento de agua para sus cultivos, para dar de beber a los animales (pollos, puercos y pocos bovinos) y a los humanos.

Álvarez (2004: 406) reporta la existencia de 36 albarradas en la provincia de Manabí. Algunas de ellas son públicas, otras son privadas y otras comunales y están destinadas a la agricultura, como bebedero de animales, para el consumo humano y para fines didácticos y granjas experimentales. Algunas albarradas no están en uso, posiblemente porque fueron construidas por el gobierno sin la participación de la población.

Esta lógica de gestión del agua ha permitido el desarrollo de un tipo de agricultura y de crianza de animales característica de los bosques secos, con cultivos de secano ${ }^{5}$ como el maíz, leguminosas y pocas hortalizas, así como pastos invernales, que se desarrollan gracias a la humedad almacenada en el suelo en los meses de invierno (Maignan y Nicolalde, 2007).

\section{¿Se producen alimentos en estas zonas?}

Según el historiador ecológico Norberto Ferreras (2008), una de las primeras actividades del ser humano es transformar la naturaleza y luego, hacer que la naturaleza supla sus necesidades, siendo la alimentación, la principal necesidad que el ser humano satisface, desde la naturaleza. Por ello, un análisis de cómo una comunidad se relaciona con la naturaleza y cómo la transforma -por ejemplo, a través de la agricultura- se hace analizando su alimentación, pues, los hábitos alimenticios se conservan aun cuando se pierdan ciertas prácticas agrícolas.

Manabí está considerada como la provincia con una culinaria óptima, lo que podría indicarnos que esta práctica culinaria se corresponde a un tipo de agricultura también óptima, existente al momento, o en el pasado.

En el Cuadro 1 se presenta un resumen de la alimentación y la biodiversidad en Manabí. 
Cuadro 1. Biodiversidad y alimentación en Manabí

\begin{tabular}{|c|c|}
\hline Producto & Usos en la alimentación y otros procesos de transformación \\
\hline Maíz & $\begin{array}{l}\text { El uso más común es la mazorca cocida o asada. Con maíz maduro y seco se elabora harina } \\
\text { para una amplia variedad de platos para el consumo de la población (humitas, ayacas, tortillas, } \\
\text { natilla, mazamorra). } \\
\text { Se usa en sopas, menestra (el maíz tierno). } \\
\text { El maíz se usa además como alimento para los pollos y chanchos, muy importante en la } \\
\text { economía familiar. }\end{array}$ \\
\hline Haba & Ingredientes de sopas, menestras y estofados. \\
\hline Habichuela & Sopa, menestra y estofados. \\
\hline Fréjol & Ingrediente básico de sopas, menestras y estofados, etc. \\
\hline Maní & $\begin{array}{l}\text { Es un ingrediente básico de la alimentación manabita. Varias sopas, tamales, bolas de verde, } \\
\text { bollos llevan maní. Además está la popular salprieta, que es hecha también con maíz. Con } \\
\text { frecuencia se combina el verde, el maní con otros ingredientes como es el caso del corvi- } \\
\text { che que tiene además pescado. }\end{array}$ \\
\hline Plátano & $\begin{array}{l}\text { Se usa en sopas, menestras (sango), frito, asado y hervido. Hay por lo menos } 70 \text { platos en } \\
\text { base al plátano. }\end{array}$ \\
\hline Yuca & $\begin{array}{l}\text { Se extrae harina y almidón para hacer pan. Se utiliza en sopas, acompañando el pescado, la } \\
\text { gallina y la carne estofada. Se hacen tortillas, pasteles dulces y salados, yuca frita, sancocho, } \\
\text { sopa de yuca, locro de yuca, menestra de yuca, entre otros. }\end{array}$ \\
\hline Ajonjolí & Se usa en confitería, en los panes, turrones con panela. \\
\hline Coco & Cocada, manjar de leche con coco, jugos de coco, se toma el agua como refresco, helados. \\
\hline Caña & Panela, aguardiente. \\
\hline Arroz & Comida esencial en todas las comidas. Se usa también en el aguado de pollo (sopa). \\
\hline Frutas & Elaboran dulces, mermeladas, jugos, refrescos, helados, postres, mistelas o se consumen crudas \\
\hline Cacao & Chocolate con leche, confites, mistelas. \\
\hline Café & Bebida caliente, cremas y mistelas. \\
\hline Achogcha & Rellena, ensaladas, se pone en las sopas (especialmente en el viche y sancocho). \\
\hline Sidrayota & Ensaladas, sopas. \\
\hline Camote & Cocinada, en pastel de dulce y de sal. \\
\hline Zapallo & Sopas, pasteles. \\
\hline Pepinillos & Ensaladas, encurtidos. \\
\hline
\end{tabular}

Fuentes: Bravo A.L., 2009, y Ela Velásquez, comunicación personal

La culinaria manabita responde a una agricultura tradicional basada en una rica biodiversidad agrícola, o biodiversidad silvestre que es aprovechada por la población.
En el caso de la biodiversidad silvestre, en un estudio hecho por Hernández y Josse (1997) encontraron 45 especies silvestres comestibles, la mayoría de ellas frutas, usadas en el Parque Na- 
cional Machalilla, área ubicada al sur de Manabí, que protege bosques secos y de neblinas.

Aunque la biodiversidad agrícola de Manabí ha sido menos estudiada que en otras regiones del Ecuador, en el banco de datos de los recursos filogenéticos del INIAP ${ }^{6}$ se registran una gran cantidad de variedades agrícolas tradicionales, y otras en estado silvestre, que posiblemente son las antecesoras de las especies domesticadas, lo que ubica a esta zona como un importante centro de biodiversidad agrícola, como se ve en el Cuadro 2.

Cuadro 2. Recursos genéticos registrados ${ }^{7}$ en Manabí

\begin{tabular}{|c|c|c|}
\hline Nombre científico & Nombre común & Tipo de recurso genético \\
\hline $\begin{array}{l}\text { Amaranthus sp. } \\
\text { Annona muricata } \\
\text { Arachis hypogaea } \\
\text { Bromelia pinguin } \\
\text { Cajanus cajan } \\
\text { Carica sp. } \\
\text { Capsicum annuum } \\
\text { Capsicum chinense } \\
\text { Capsicum frutescens } \\
\text { Capsicum sp. } \\
\text { Cereus sp. } \\
\text { Clavija sp. } \\
\text { Cucurbita ecuadorensis } \\
\text { Cucurbita moschata } \\
\text { Cucurbita moschata } \\
\text { Cucurbita sp. } \\
\text { Cyclanthera pedata } \\
\text { Derris elliptica } \\
\text { Erythrina sp. } \\
\text { Guazuma sp. } \\
\text { Inga } \\
\text { Ipomoea asarifolia } \\
\text { Ipomoea batatas } \\
\text { Ipomoea batatas } \\
\text { Ipomoea nil } \\
\text { Ipomoea ophioides } \\
\text { Ipomoea sp. } \\
\text { Lagenaria siceraria } \\
\text { Lycopersicon pimpinellifolium } \\
\text { Lycopersicon pimpinellifolium } \\
\text { Lycopersicon sp. } \\
\text { Mangifera indica } \\
\text { Manihot esculente } \\
\text { Opuntia sp. } \\
\text { Pachyrhizus tuberosus } \\
\text { Passiflora edulis } \\
\text { Passiflora quadrangularis }\end{array}$ & $\begin{array}{l}\text { Guanábana } \\
\text { Maní } \\
\text { Puñuela } \\
\text { Tipo de papaya } \\
\text { Ají } \\
\text { Ají } \\
\text { Ají } \\
\text { Ají } \\
\text { Tipo pitahaya } \\
\text { Huevo de tigre } \\
\text { Tipo zambo } \\
\text { Calabaza } \\
\text { Calabaza } \\
\text { Achogcha } \\
\text { Sabadilla } \\
\text { Fréjol de palo } \\
\text { Guasmo } \\
\text { Guaba } \\
\text { Camote } \\
\text { Camote } \\
\text { Camote } \\
\text { Camote } \\
\text { Camote } \\
\text { Camote } \\
\text { Jícaro } \\
\text { Tomatillo } \\
\text { Tomatillo } \\
\text { Tomate } \\
\text { Mango } \\
\text { Yuca } \\
\text { Tuna } \\
\text { Jícama } \\
\text { Maracuyá } \\
\text { Granadilla }\end{array}$ & $\begin{array}{l}\text { silvestre } \\
\text { Silvestre } \\
\text { Cultivar tradicional } \\
\text { Silvestre } \\
\text { Cultivar tradicional } \\
\text { Cultivar tradicional } \\
\text { Cultivar tradicional } \\
\text { Cultivar tradicional } \\
\text { Silvestre } \\
\text { Silvestre } \\
\text { Silvestre } \\
\text { Cultivar tradicional } \\
\text { Silvestre } \\
\text { Cultivar tradicional } \\
\text { Silvestre } \\
\text { Silvestre } \\
\text { Silvestre } \\
\text { Silvestre } \\
\text { Cultivar tradicional } \\
\text { Silvestre } \\
\text { Silvestre }\end{array}$ \\
\hline
\end{tabular}




\begin{tabular}{|l|l|l|}
\hline Nombre científico & Nombre común & Tipo de recurso genético \\
\hline Passiflora sp. & Tipo granadilla & Silvestre \\
Pentagonia sp. & Tabaco caspi & Silvestre \\
Phaseolus sp. & Fréjol & Silvestre \\
Physalis peruviana & Tipo uvilla & Silvestre \\
Pithecellobium $s p$. & Es un tipo de fréjo & Silvestre \\
Pourouma sp. & Uva de monte & Silvestre \\
Psidium guajava & Guayaba & Silvestre \\
Sicana odorifera & Casa banana o curuba & \\
Solanum sp. & Hierba mora & Silvestre \\
Vitex gigantea & Pechiche & Silvestre \\
Vitis viridis & & \\
Zea mays & Maíz & Variedad tradicional \\
Ziziphus sp. & Jujube o azufaifo & Silvestre \\
\hline
\end{tabular}

Fuente: Conservación y uso sostenible de la biodiversidad agrícola: el banco de germoplasma de INIAP http://www.pgrfa.org/gpa/ecu/report.jspx?quesno=protab\&linkvalue=288_N-58-1

Por otro lado, se han identificado al menos 11 especies de peces de agua dulce, uno de camarón de río y decenas de frutas. Como especies vegetales artesanales se destaca la paja toquilla y la tagua.

En las comunas del sur de Manabí la agricultura gira en torno al maíz, que lo empiezan a sembrar con las primeras lluvias del invierno. El maíz es destinado para autoconsumo, para alimentación animal y a veces se producen excedentes.

Producen para el mercado, además zapallo, algodón, higuerilla, melón, entre otros... Para el consumo familiar siembran fréjol, maíz amarillo y yuca. En invierno se siembra además pimiento, tomate, sandía, melón, mango y fréjol. El cultivo más importante es el maní ${ }^{8}$.

En la comuna Sacán, en el cantón Jipijapa, se venden todos los días tortillas de maíz en la carretera; y en Julcuy, la actividad más importante es la cría de chivos, animales muy adaptados a los bosques secos.

En varias comunas se complementa la economía con la elaboración de ladrillos (en cuya elaboración utilizan varios elementos del bosque seco). En otras comunas las mujeres se dedi- can al tejido de sombreros de paja toquilla, cuya calidad es reconocida mundialmente, con el nombre de "sobreros de Panamá".

En algunas zonas secas de la provincia de Loja también se está plantando piñón para ser usado como agrocombustible, bajo el mismo argumento, que son zonas marginales donde no se producen alimentos.

Sobre esta zona Le Gall (2007) reporta que hay una rica práctica agrícola donde se cultiva maíz mediante un sistema de tala y quema: cada año se tala y quema el bosque y luego se cultiva maíz, mientras que las parcelas usadas se dejaban en barbecho por unos 15 años. Durante la época seca los animales aprovechan los residuos del maíz.

En Loja, al igual que en Manabí se cría cabras, que están adaptadas a las condiciones del bosques seco, pues se mantienen todo el año con la alimentación proveniente del bosque, en el campo abierto. Aprovechan los frutos y la hojarasca (verde en invierno o seca en verano) de los árboles. Se alimentan también de las hierbas que crecen a los pies de los árboles en invierno. Pastorean grandes superficies del campo abierto, sin cuidado del dueño, y regresan diaria- 
mente a los corrales que están cerca de las casas. En invierno pastorean cerca de las casa y en verano en las zonas del bosque donde hay más follaje Le Gall (2007).

\section{Conclusión}

Si analizamos lo que está sucediendo con estas comunidades que viven en estas zonas que han sido llamadas zonas marginales, tanto en el Ecuador como en otros países tropicales, podemos mirar que se está imponiendo el siguiente modelo:

- Se determinan ciertas zonas como marginales; zonas donde no se produce alimentos.

- Hay una empresa que expresa su interés de plantar piñón (o algún otro cultivo como la higuerilla) para la producción de agrocombustible.

- Se introducen a estas comunidades de manera violenta al gran mercado, a través de la

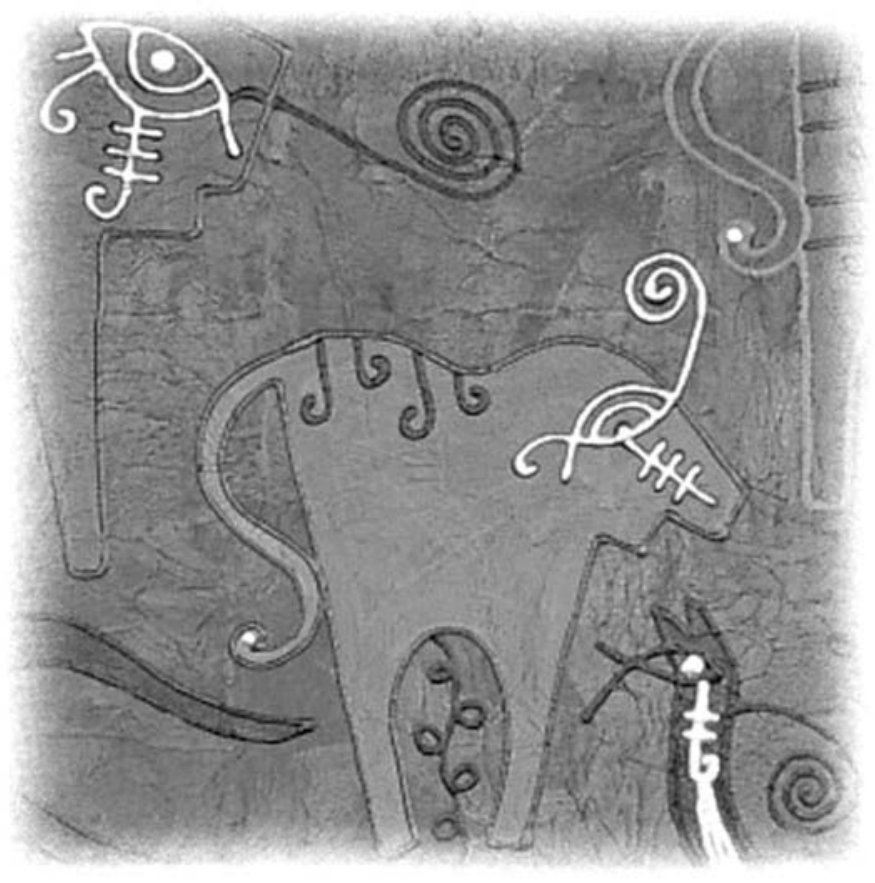

Intimismo. Detalle agricultura de contrato para la producción de cultivos energéticos

- Las comunidades dejan de producir alimentos, y con ello pierden soberanía alimentaria.

- A cambio, reciben un monto de dinero.

- La empresa recibe, además bonos de carbono por la captación de $\mathrm{CO}_{2}$ para frenar el cambio climático, a partir de las tierras y el trabajo de unas comunidades que no tienen ninguna responsabilidad en el calentamiento global.

Es decir, se apunta a un cambio radical del modelo de desarrollo imperante en la zona. En principio, este nuevo modelo genera más ingresos monetarios. La pregunta es si este cambio va a ser positivo o negativo para las poblaciones locales; si va a significar una ruptura en la forma de vida de las poblaciones locales; cómo va a afectar en el uso del territorio, en el uso del tiempo de los comuneros, y por lo mismo, en las relaciones inter-comunales. Es decir, cómo afectará en su Buen Vivir9.

En todo caso, el "Buen Vivir" es un concepto que viene de la cosmovisión andina (en kichwa Sumak kawsay) que piensa en "un modelo de desarrollo equitativo, armónico, en el que el ser humano y la naturaleza se constituyen en la base del desarrollo de la vida y el fin último de la existencia”. Se basa en la reciprocidad entre humanos y con la madre tierra o Pachamama (Noboa, 2005).

Es un concepto que nos permite entender el relacionamiento de las personas con la naturaleza, con la historia y la sociedad. Dávalos (2006) señala que el "Buen Vivir", es otro de los aportes de los pueblos indígenas del Abya-Yala, a los pueblos del mundo, y es parte de su largo camino en la lucha por la descolonización de la vida, de la historia y del futuro; estableciendo un nuevo relacionamiento del ser humano y su entorno social y natural, alejado del concepto judeo-cristiano de sojuzgar y someter la naturaleza para beneficio individual.

No debe confundirse con el "estilo o nivel de vida" promovido por la sociedades occidentales. Tampoco con el "bien común" o con la idea 
de producir para generar crecimiento económico como base del desarrollo, que promueve...

el individualismo, la búsqueda del lucro, la relación costo-beneficio como axiomática social, la utilización de la naturaleza, la relación estratégica entre seres humanos, la mercantilización total de todas las esferas de la vida humana, la violencia inherente al egoísmo del consumidor, etc. (Dávalos, 2008).

Sin duda el modelo piñón con el Sumak Kausay no es compatible con el "buen vivir" de las poblaciones del Sur de Manabí.

\section{Bibliografía}

- ÁlVAREZ, Silvia. 2004. Comunas y Comunidades son sistemas de albarrada. Descripciones etnográficas. Ediciones Abya Yala. Quito. pp. 527.

- BRAVO, Ana Lucía. 2009. Agrobiodiversidad y Conocimientos Tradicionales en Ecuador: Estudios de Caso en Cayambe, Manabi y Pastaza. CRIC-Terranueva. Quito.

- BRAVO, Elizabeth. 2007. Agrocombustibles y el Fortalecimiento de los Agronegocios en América Latina. Ponencia presentada en el 5to. Congresso Brasileiro de Agroecología. Espíritu Santo, Brasil.

- CERDÀ, Artemi. 2002-2003. Tierras marginales, abandono del campo y erosión. Mètode. Anuari Universitat de València.

- Centro de Monitoramento da Agrocombustíveis. 2008. O Brasil do Agrocombustíveis. Palmáceas, Algodão, Milho y Pinhão-Manso 2008. Impactos das Lavouras sobre a Terra, o Meio e a Sociedade. pp. 50.

- DÁVAlOS, Pablo. 2006. El "Sumak Kawsay" ("Buen vivir") y las cesuras del desarrollo. América Latina en Movimiento. Mayo, 2006.

- DÁVALOS, Pablo: "Reflexiones sobre el Sumak kawsay (el buen vivir) y las teorías del desarrollo". Página de izquierda Antiautoritaria. Septiembre, 2008.

- HERNÁNDEZ, Consuelo y Josse, Carmen.
1007. Plantas Silvestres Comestibles. Parque Nacional Machalilla. En Hombre y ambiente. No. 40. Ediciones Abya-Yala.

- LE GALL, Angelè. 2007. Conservación del bosque seco e intensificación agropecuaria en Cazaderes: ¿Se inclina la balanza? En Mosaico Agrario. Diversidades y antagonismos socioeconómicos en el campo ecuatoriano. Vaillant, Michael; Cepeda, Darío; Gondard, Pierre; Zapata, Alex; Meunier, Alexis. Editores. Quito: SIPAE, IRD, IFEA. 320 pp.

- MAIGNAN, Samuel. y Vinicio Nicolalde. 2007. "Límites de la intensificación agropecuaria en un contexto de mercado inestable: El caso de la cuenca baja del río Portoviejo". En: Mosaico Agrario. Diversidades y antagonismos socio-económicos en el campo ecuatoriano. Vaillant, Michael; Cepeda, Darío; Gondard, Pierre; Zapata, Alex; Meunier, Alexis. Editores. Quito: SIPAE, IRD, IFEA. 320 pp.

- MARCOS, Jorge. 2005. Los pueblos navegantes del Ecuador Prehispánico. Ediciones Abya-Yala - ESPOL. Quito, pp. 206.

- PINO. 2006. "Albarradas y camellones en la región costera del antiguo Ecuador". En: Agricultura ancestral camellos y albarradas. Contexto social, usos y retos del pasado y del presente. Francisco Valdez Editor. Actas y Memorias del IFEA 3: $93-108$.

\section{Periódicos y Sitios WEB}

- BBC News / World. The UN's new top adviser on food has urged a freeze on biofuel investment, saying the blind pursuit of the policy is "irresponsible". 2 de mayo, 2008. http://news.bbc.co.uk/2/low/7381392.stm

- D1 Oil News. Rolls-Royce funds new D1 refinery.. 22 de Febrero 2005 www.d1plc.com/news.php?article $=31$

- FAO. 2009. Internacional commodities prices. http://www.fao.org/es/esc/prices/CIWPQueryServlet 
- FAO, 2008. Prospección de cultivos y la situación de los alimentos.

- Newsroomamerica.com. Agrofuels Adding To Global Food Crisis: UN. 12 de septiembre 2008.

- Conservación y uso sostenible de la biodiversidad agrícola: el banco de germoplasma de INIAP

http://www.pgrfa.org/gpa/ecu/report.jspx$?$ quesno $=$ protab\&linkvalue $=288 \_\mathrm{N}-58-1$

- Ribeiro, Silvia. 2008. Agrocombustibles. Se- cretos y trampas del Banco Mundial. La Jornada, México.

- The Finantial Express. TN to fuel jatropha cultivation. 15 de abril 2007. Mumbai

- SNV - Ecuador. Biocombustibles Inclusivos: Promoviendo la producción sostenible y la inversión entre pequeños productores y grandes empresas. Noticias América Latina. 1 de noviembre 2008.

http://www.snv-la.org/noticia/?idnoti$\mathrm{cia}=529$

1 Presente también en Guatemala

2 El Mecanismo de Desarrollo Limpio es uno de los instrumentos creados a través del Protocolo de Kyoto del Convenio sobre Cambio Climático a través del cual los países que tienen menor responsabilidad en el cambio climático, implementan proyectos de absorción de CO2 con el financiamiento de los países que sí son responsables, de tal manera que hay una transferencia de responsabilidades del Norte al Sur.

3 Son unidades socio-políticas de carácter estable, identificadas por su asociación a un territorio políticoproductivo de origen étnico sobre el que tienen derechos exclusivos, y a un tipo de asentamiento nucleado de naturaleza urbana (Álvarez et al., 2002).

4 Ahora el pueblo Manta se ha reivindicado como un pueblo distinto al Huancavilca.

5 Cultivos en terrenos no irrigados y sin disponibilidad de agua.

6 Instituto Ecuatoriano de Investigaciones Agropecuarias.

7 En el banco de datos de recursos filogenéticos del INIAP.

8 Información personal Atahualpa Pincay. Parroquia Julcuy.

9 La nueva Constitución del Ecuador incorpora como un eje transversal del modelo de desarrollo al "Buen Vivir”. 


\section{¿Puede haber algo que se llame una política ambiental?}

Freddy Álvarez*

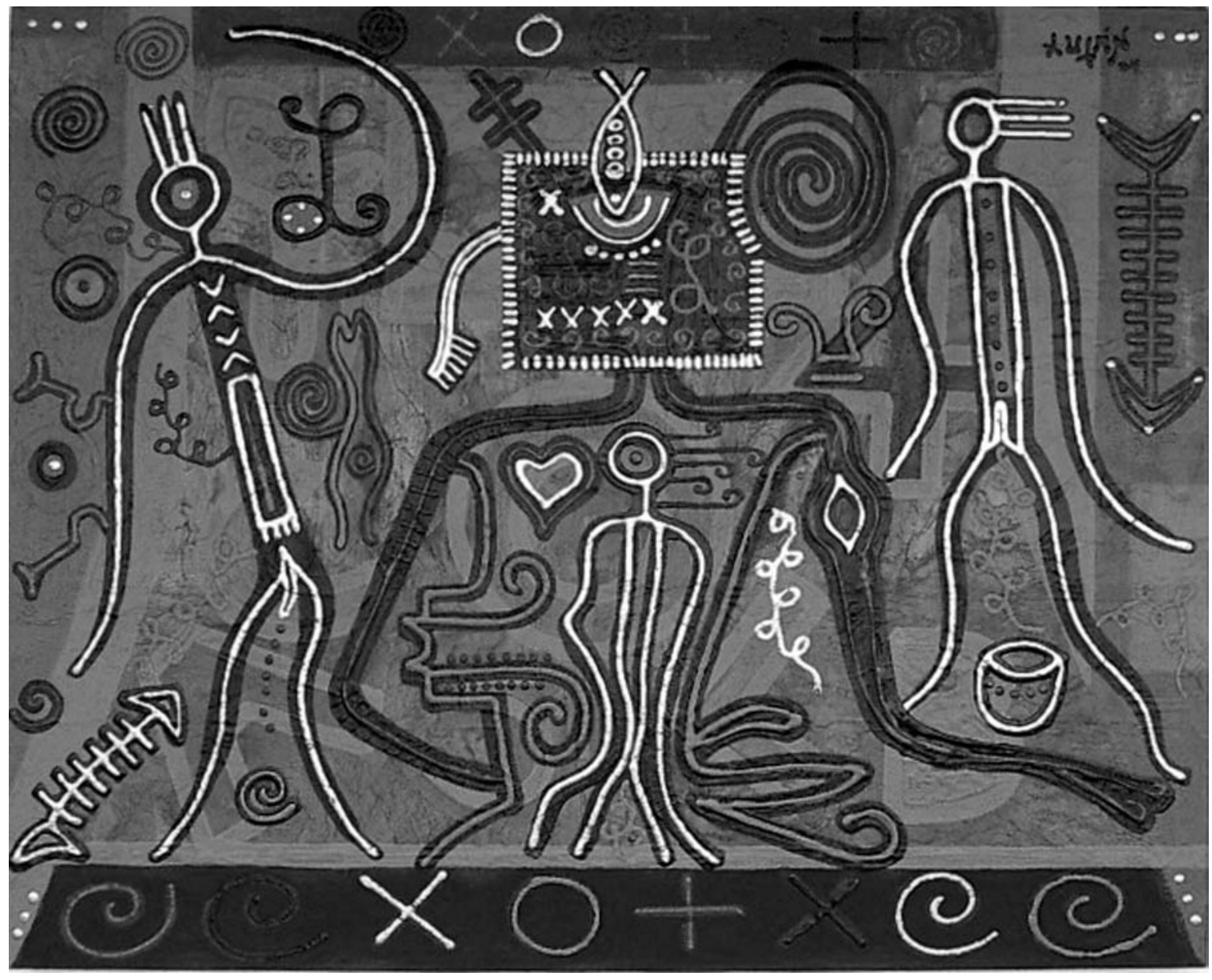

Cosas mías. Técnica mixta sobre lienzo

* Doctor en filosofía por la Sorbona (París VIII). Profesor investigador de la Carrera de Comunicación Social de la UPS y autor de artículos y publicaciones varias sobre filosofía, conocimiento y desarrollo. 


\section{La normalidad psicoanalítica del contexto ambientalista: la paranoia de los líderes, la neu- rosis de los desarrollados, la esquizofrenia de las ONG, la hipocresía de la cooperación y la demencia de la maquinaria burócrata}

La pregunta enunciada de esta manera "puede haber", cuestiona no sólo sobre la existencia de algo, pues existen políticas ambientales; no indaga sobre el "hay" ya que la existencia no está en duda; la pregunta versa sobre el poder de la existencia: es saber si puede existir una política ambiental o no. La existencia nace del poder, porque ser es una cuestión de poder ser, el poder no es la causa del ser, pero no hay ser sin poder. Además no es tener poder, es ser a través del poder. En consecuencia, no existe una política ambiental sólo por querer que haya una política ambiental, hay una política ambiental porque el poder quiere una política ambiental, sin embargo, el poder es limitado y limita el "haber" de la política ambiental. El poder es indispensable para la vulnerabilidad de la políti$\mathrm{ca}$, y el poder vulnera el topos de la política. Luego, el "puede haber" una política ambiental se refiere a la probabilidad, no a una certeza, por tal motivo contiene una tonalidad irreverente porque de hecho casi todos los países del mundo, democráticos y no democráticos, tienen políticas ambientalistas, las cuales no se cumplen en la mayoría de los casos. Pero, ¿por qué iniciar con una pregunta de este modo?

Resulta extraño encontrar que los países ricos con el desarrollo más brutal y contaminante para el mundo, y sin ninguna intención en cambiar dicho modelo, están preocupados por el Medio Ambiente mundial, pero desde horizontes locales proteccionistas, pues, sus desechos peligrosos los envían a países pobres. Ellos han mantenido y mantienen prácticas de saqueo inmisericorde de los recursos renovables y no re- novables del tercer mundo con políticas colonialistas y humillantes, y ahora tales países pretenden dictarle al Sur las políticas ambientalistas sin renunciar a imponer un modelo de desarrollo que sigue manteniendo la dicotomía entre superior e inferior beneficiando sus intereses hegemónicos. En efecto, en torno a la gravedad de los fenómenos ambientales circulan una serie de personajes neuróticos que colocan preguntas lógicas y responden con una multiplicidad de respuestas contradictorias y sin sentido.

Es apenas obvio que las políticas ambientalistas venidas del Norte obedecen a criterios de un Estado de Bienestar, es decir, la demanda ambientalista se inscribe dentro de una neurosis planetaria que después de llegar a un nivel de vida cómodo a costa de políticas extractivistas y coloniales fuera de su país, la mejor manera de disfrutar y gozar de sus beneficios es exigiendo demandas ambientales de los otros.

Mientras tanto algunos líderes políticos del Sur, desde procesos de emancipación, radicales, moderados o incipientes, -muchas veces contradictorios- buscan emanciparse por medio de una disyuntiva cotidiana: o explotar recursos para responder a las promesas políticas hechas a sus electores, o dejar intactos los recursos protegiendo la naturaleza; o arrancar las riquezas de la tierra para solucionar los problemas del hambre y dar inicio a procesos de desarrollo autónomo, o buscar solucionar la pobreza sin recurrir al modelo extractivista del Estado que ha sido endosado por gobiernos invasores y últimamente por transnacionales. La necesidad de recursos apremia por las demandas sociales y las condiciones precarias en las que viven las poblaciones. En consecuencia la oposición de movimientos ambientalistas puristas, que ven a la naturaleza separada de las necesidades sociales y económicas intenta ser contrarrestada por una serie de posturas políticas paranoicas que ven el mal en todo tipo de oposición. Así unos y otros dejan intacto el modelo de desarrollo lineal, mecánico, universal y, pretendidamente, neutral. 
De igual manera, muchos de los Ministerios de Ambiente del Sur siguen atados a las agendas de los Organismos Internacionales por lo que sus políticas reales se quedan en pura retórica. El Norte puede darse el lujo de una política ambiental para sí pero no para los otros, pues allí se suelen encontrar sus fábricas y los recursos que requieren para vivir bien. De hecho, los Ministerios de Ambiente son cooptados a sus demandas ya que el mayor financiador proviene de la Cooperación Internacional quien de cualquier modo coloca los temas a ser tratados subyaciendo en su política la incapacidad del Sur para definir su propio destino. Así, la experiencia de la impotencia de la política ambiental es evidenciada no sólo fuera, sino dentro de la burocracia ministerial. De esta manera, se ocupa un lugar de trabajo desde el cual se sabe, después de un corto tiempo, que allí son muy pocas las situaciones que pueden ser transformadas. Dicha conciencia del fracaso acompaña el día a día de un burócrata provocando que el ángel de la redención sea reemplazado por el diablo de la cotidianidad.

La experiencia de la impotencia y la conciencia del fracaso provocan la inacción burocrática, dentro del vértigo, a veces, de acciones sin sentido que se repiten, replican, traslapan, en un medio institucional parcelado, compartimentado y fragmentado. Se hace nada haciendo muchas cosas o respondiendo automáticamente con atención a no salirse de los marcos legales. El no hacer nada sucede en la carrera por demostrar que se hace algo. Así se cubre la impotencia y el fracaso de no poder redimir a través del cambio.

Las políticas del desarrollo y de la econo-

\section{Bajo la lucha por lo ambiental, nos encontramos con una serie de prácticas} no ambientales. La locura de la lucha ambiental no es pura. Nadie es lo que dice ser, ni siquiera las acciones son la revelación del ser. mía no están articuladas con las vulnerables y vulneradas políticas ambientales. La pregunta ambiental es silenciada ante la urgencia decisiva del factor económico y la incuestionable respuesta decimonónica del desarrollo. La política ambiental navega y naufraga constantemente en un medio esquizofrénico en el que las políticas se hacen para cumplir con determinados convenios, pero no para ser tomados seriamente en cuenta a partir de las necesidades ambientales de las poblaciones y de la naturaleza.

La esquizofrenia de la acción ambiental es experimentada con mayor fuerza en algunas de las ONG ambientalistas financiadas con dineros provenientes de las empresas contaminantes. Luego, la lucha por un medio ambiente no es separable de sus problemas no en una línea causal sino en la relación interdependiente, irónica y circular, por lo tanto, la causa del medio ambiente genera defensores y es porque hay defensores que se requiere de un planeta en llamas. Dicha circularidad a veces toma giros sorprendentes y cínicos cuando a veces entendemos que el énfasis está puesto no en el planeta sino en los intereses de las promesas ecológicas.

Por último, nos encontramos con la Cooperación Internacional quien supuestamente apoya las buenas causas de los gobiernos pobres y que al mismo tiempo opera como centros de inteligencia de los países representados. Grandes títulos ambientalistas se colocan en los edificios de representaciones internacionales para justificar de modo indirecto la larga presencia de una política invasora defensora de los intereses de empresas extractivistas extranjeras y naciones "amigas".

Bajo la lucha por lo ambiental, entonces, nos encontramos con una serie de prácticas no ambientales. La locura de la lucha ambiental no es pura. Nadie es lo que dice ser, ni siquiera las acciones son la revelación del ser. Así, la demencia en la causa ecológica tiene sus propias manifestaciones. La neurosis ante la experiencia de los límites del planeta, la paranoia frente a los grupos ecológicos, la conciencia del fracaso desde 
dentro y la esquizofrenia en la que se sostienen sus políticas constituyen la maldita normalidad.

Las razones no son únicamente marxistas, aunque exista la preponderancia del factor económico. Decir que el planeta se destruye porque lo económico está por encima de lo ambiental es decir mucho y no decir nada. El énfasis marxista tiene también connotaciones anti-ambientales porque en la medida que condenamos lo económico colocamos a las causas ambientales en el punto imposible, tanto para los países dependientes como para los países desarrollados. Un punto imposible es aquel donde la nada es la que comienza a hacer. Así los efectos provocados son aquellos que se quisieron evitar.

¿Cuáles son esas otras razones desde una normalidad psicoanalítica que atraviesan las políticas ambientalistas? ¿Por qué una política ambiental es un posible-imposible? ¿Es la realpolítica un marco justo para la política ambiental? Son éstas las preguntas que nos lanzan en nuestra reflexión sobre el poder hacer de las políticas ambientales. Para la reflexión vamos a comenzar por la necesidad de la contextualidad y el problema universal, luego abordaremos el asunto de la realidad, lo imposible y lo ideal, para terminar en el problema de la topia de las políticas ambientales.

\section{El universalismo contextual de la política ambiental y la necesi- dad de pensar las interrelacio- nes del contexto con el mundo}

De todos lados nos llegan mensajes sobre los problemas ambientales locales, nacionales y mundiales. Ahora algo está ocurriendo que antes no pasaba. El carácter inaudito busca reconocimiento en la política internacional, sin mucho éxito en la política nacional. No es más la repetición, algo emerge con un rostro monstruoso y apocalíptico. Sus características son tan letales que no parecen reales. El presagio pierde su condición futurista pues no señala el adveni-

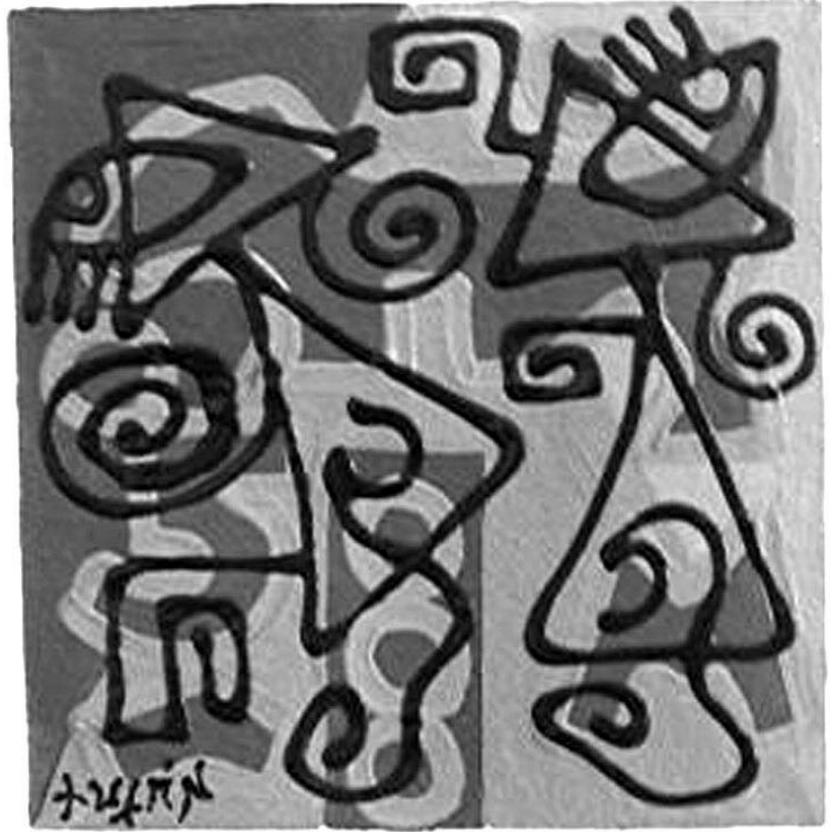

Acrílico sobre papel hecho a mano

miento, por el contrario, ya no ad-viene, está viniendo y no hay manera de detenerlo por su carácter de irreversibilidad. Sin embargo, una figura tan imponente tiene la desventaja de situarnos en una escena mítica e irreal, en cierto sentido, la realidad es tan desbordante y cercana que nos parece imposible que algo así este ocurriendo, es tan real que pasa inmediatamente al ámbito de lo irreal.

El mundo ya no es el mismo ante la catástrofe ecológica. Los desarreglos ambientales nos colocan frente a la comprensión de un mundo diferente: el mundo está interrelacionado y es interdependiente. La casa es de todos y lo que pase en uno de sus cuartos nos afecta a todos por igual. La extrañeza de lo otro, los otros y las otras nos convierte en potenciales asesinos. Dependemos de lo que los otros hagan, así como los otros dependen de lo que nosotros hagamos en esta parte de la casa. Tenemos necesidad de repensar la relación entre nosotros y los otros. Los otros 


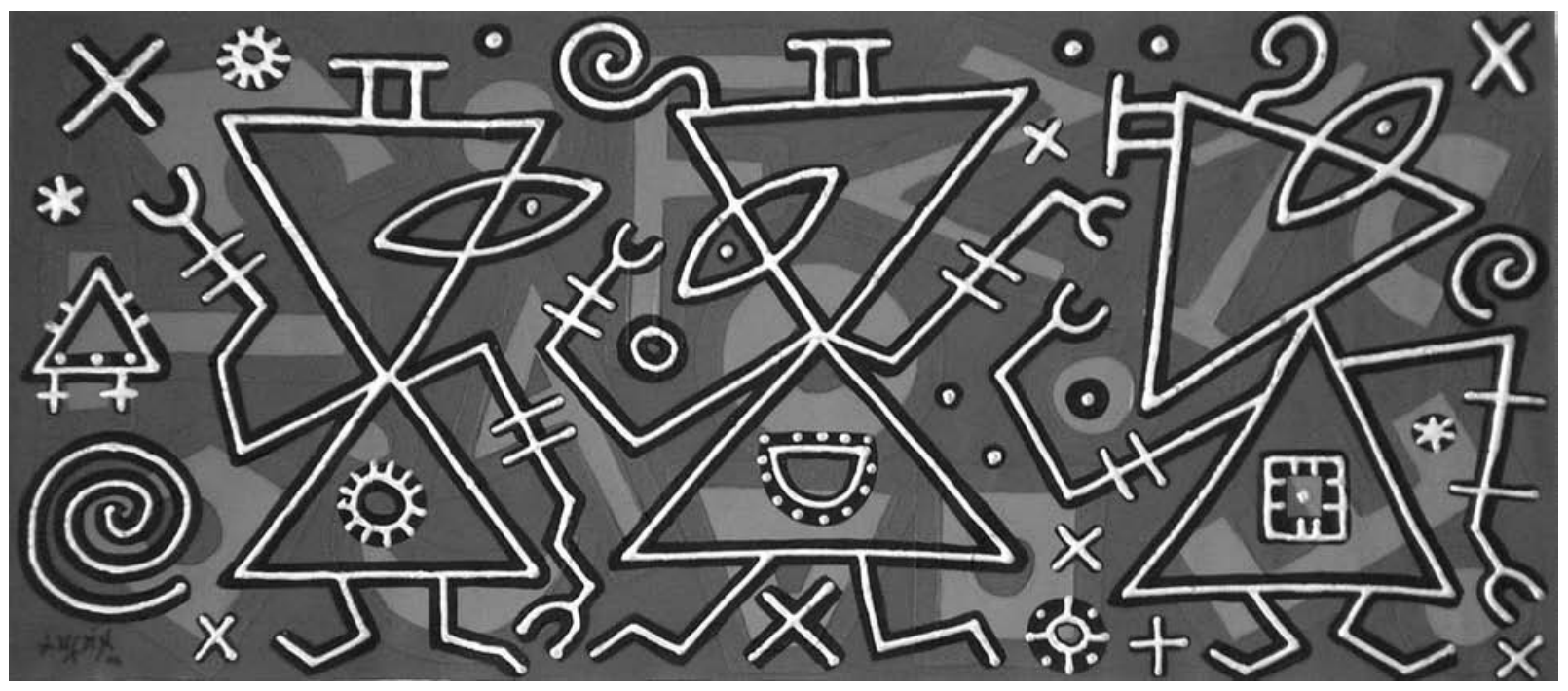

Informalismo panorámico III. Técnica mixta sobre lienzo

habían estado fuera del nosotros. Nosotros éramos en la medida que no éramos los otros. Los otros eran lo que no queríamos ser, sin embargo no había los otros sin nosotros. Nosotros éramos esos otros inconfesos. Ahora sin los otros no hay nosotros y sin nosotros los otros están condenados. La lógica de la acumulación y el racismo está retada en su núcleo. La exclusión y la eliminación eran necesarias para la riqueza como lo han sido para el desarrollo del Norte. El desarreglo del planeta invierte la lógica de la exclusión y la eliminación. Si algo pasa al nosotros, el otro es afectado, porque el duelo ya no es sólo una acción de la voluntad.

La responsabilidad tiene connotaciones mundiales. La responsabilidad nacional en el tema del ambiente nos descubre idiotas. Tenemos tanto derecho a opinar sobre la capa de ozono o la Antártida, como responsabilidad a escuchar las voces sobre la protección de la biodiversidad de la Amazonía. Una responsabilidad parcelada no es más responsabilidad, es inmoral e irresponsable, no es ni siquiera respetable. La responsabilidad es una respuesta a voces con otros, otras y nosotros.
Levinas decía que toda muerte me convierte en culpable. Heidegger pensaba que sólo experimentamos la muerte de otros. Hay un "demasiado tarde" en la experimentación de la propia muerte que contrasta con la muerte antes de tiempo, del inocente. Hablamos de la muerte real de los otros y hablamos de la muerte propia como un hecho irreal. Una distancia tal nos hace caer en trampas. Una de ellas es la experiencia de lo extraño y extranjero. Hay una relación entre lo extraño, lo desconocido, lo lejano y la conciencia en el mundo ambiental. Quizás ya nadie puede decir que no sabía. No podemos evadir la degradación del planeta, y quizás la tragedia sea esa: no la destrucción del planeta, sino la imposible huida. Tenemos mala conciencia desde que nos colocamos frente al espejo para afeitarnos. El mundo se ha convertido en estrecho. El planeta era más solidario que lo imaginado por las grandes utopías, la condición de la biosfera era común y el destino nos unía desde antes.

Pero tras una universalidad ambiental con tintes trágicos se esconden una serie de retos y límites que nos vienen desde la contextualidad. La universalidad es extensiva. Las preocu- 
paciones ambientales se extienden en la conciencia de un alemán, un palestino y un ecuatoriano; sin embargo, el contexto limita y da significado a los sentidos de la interpretación y las respuestas reales. La preocupación es universal pero no la interpretación y mucho menos las respuestas desde lugares específicos. Luego, todos somos o tenemos que ser ecológicos, pero no de la misma manera y con las mismas respuestas e interpretaciones.

Para un alemán la preocupación por el ambiente no está relacionada con los mismos problemas económicos de un palestino o un ecuatoriano. Una respuesta ambiental de un país desarrollado se complejiza en contextos pobres. Las políticas ambientales de Alemania pueden ser ejemplarizantes, mientras ellos inviertan en transnacionales dedicadas a la deforestación de los países pobres. Vivir en situaciones de guerra forcluye las preocupaciones ecológicas para un palestino. La relación con los animales en los países desarrollados es un escándalo con respecto a las políticas internacionales que justifican o se callan frente a la eliminación de los palestinos de parte del Estado de Israel. La pregunta de la vida y la muerte no pasa necesariamente por la pregunta ecológica sino en la medida que la pérdida de la tierra, la negación del agua atenta directamente contra su capacidad de supervivencia. En cierto modo, es más difícil ser ecólogo en Ecuador que en Alemania o Palestina porque los modelos de desarrollo no dejan de ser extractivistas y represivos, no hay interés en investigar en otros modelos y los gobiernos están obligados y son suficientemente corruptos e inmediatistas para no abandonar dicho modelo.

Cuando un modelo ambiental del Norte es colocado en un contexto del Sur se lo hace sin conexiones con lo económico, cultural y social. Fácilmente se pregona una visión de mundo ambiental sin relación con lo social. Se puede apreciar una visión indígena pero de manera exótica. Dichas visiones ecológicas puras no abandonan su carácter colonialista porque son ellos los que enseñan a cuidar el planeta pues los otros son in- capaces mientras siguen sosteniendo relaciones económicas dentro de una ideología neoliberal a ultranza. Los lugares ecológicos valorados sirven para su turismo y un tipo de investigación del expolio al servicio de sus farmacéuticas y de sus patentes.

Pero el panorama de la relación con un universal, aparentemente, siempre impuro enunciado en el campo internacional no implica una renuncia a dar una respuesta desde la cuestión del universal. Tanto la uni-diversidad o la unimultiplicidad van señalando otros caminos en la discusión. Lo cierto es que en un lado y en otro nos encontramos con entrabes. Así, como el marco de un universalismo ha sido impuesto y hace parte de la noción de hegemonía en sentido gramsciano, la contextualidad nos deja frente a algunas trampas. Una de ellas es el aislacionismo o atomismo en el que puede derivar la política, propio de países que actúan desde un nacionalismo a ultranza.

Se ha creído que lo universal es válido y lo contextual es de consumo local. Sin embargo, tenemos elementos contextuales con una enorme capacidad de convertirse en universales y, universales que pierden su carácter dentro de contextos mucho más significativos y diversos. La noción de "Buen Vivir" y "los Derechos de la Naturaleza" de la Nueva Constitución Ecuatoriana se constituyen en patrimonios planetarios. La noción de vida de la Biosfera tiene una carga científica válida pero inaccesible, sin mayores connotaciones culturales, sociales, pero sí económicas. La noción de "vivir bien" del Estado de Bienestar del siglo XIX no corresponde con el "Buen Vivir" del mundo indígena de los Andes. El "vivir bien" del mundo occidental sigue prevaleciendo y tiene una carga importante en la aspiración del desarrollo. El "vivir bien" desconoce las consecuencias éticas, sociales, culturales y económicas. Situar el "Buen Vivir" en la discusión mundial es un asunto de una importancia indiscutible. Pero no todo lo contextual tiene necesidad de ser reconocido universalmente más allá del derecho de la vida a ser construida den- 
No podemos pensar lo ambiental de manera aislada y fragmentada. El contextualismo no es ruptura, es advertir los lazos intercontextuales y mundiales en su espacio y tiempo.

tro de un contexto. Así, la discusión sobre la degradación de la biosfera no es sólo un asunto de reducción de la emisión de gases, es un imperativo a transformar los modos de vida, de producción, de ser, de pensar, de estética y de soñarnos a nosotros mismos. De igual manera, los derechos de la naturaleza son una extensión de la vida a otros sistemas que han dependido del paradigma antropocéntrico. No reconocer los derechos de la naturaleza no es sólo pasar por encima de ella, es pasar por encima de las poblaciones que dependen de ella. Los derechos pertenecen a los individuos y las poblaciones, pero éstos no son posibles sin que la naturaleza no tenga sus propios derechos. Por consiguiente la contextualidad no es aquello que se arrincona en lo local y lo universal no es lo condenado por su condición tensionante con lo local.

La contextualidad es ilusa si no intenta ver más allá de sí misma. En cierto modo, una política ambiental atrapada en los nacionalismos tiene una fuerte dosis de cinismo. No cuidamos la naturaleza por ser ambientalistas, por el contrario el nacionalismo sigue defendiendo un modelo de desarrollo extractivista y contiene en sí los elementos antinacionalistas de la colonialidad. Es decir, el nacionalismo lleva en sí aquello de lo que se intenta separar. Romper con el provincialismo de la política es uno de los desafíos de la política ambiental, porque los hechos de afuera tienen la capacidad de afectarnos adentro, y depende de lo que hagamos aquí con el Medio Ambiente, que afectamos a otros y a otras fuera de nuestro territorio. Cerrarnos a entornos más amplios es propio de un embrutecimiento ilustrado. En consecuencia, aunque la política am- biental tiene que ser redactada en contextos muy específicos, ella no puede ser ajena a la occidentalización del mundo, la internacionalización de la guerra y la crisis económica mundial. Una política ambiental de lo contrario confiesa su presencia correcta en un mundo político interesado en que no vaya más allá, por eso no puede ser ajena a la lucha contra la occidentalización del mundo.

Luchar contra la occidentalización es colocar en las mesas de reflexión de la política ambiental los procesos de mundialización de tipo demográfico, económico, técnico e ideológico que interfieren de manera tumultuosa y conflictiva. Debido a tales flujos, la política ambientalista tiene que ser dinámica. La fidelidad del contextualismo implica estar abiertos a reflexionar sobre el mundo y sus procesos. Los procesos económicos están siendo afectados permanentemente y en la medida que respondamos de manera justa y adecuada a ellos podemos innovar políticas ambientalistas reales, y a la inversa, porque respetamos a la naturaleza y sus derechos podemos pensar en una economía sustentable. Porque nos importa la naturaleza tenemos que buscar respuestas reales desde el desarrollo sustentable, porque hay desarrollo no podemos dejar de lado la pregunta por la naturaleza y el medio ambiente. No podemos ofrecer una solución ambiental sin pensar en nuevas soluciones en los ámbitos sociales, económicos e incluso culturales.

Tenemos que apuntar en política ambiental a una universalidad sin imposiciones pero firme, construida en el diálogo y el desacuerdo que reconozca al mismo tiempo la complementariedad y el antagonismo de la unidad y la multiplicidad. Es un craso error separar el análisis y las respuestas a la crisis de los alimentos, de las fuentes de energía, de la economía de lo ambiental. No podemos pensar lo ambiental de manera aislada y fragmentada. El contextualismo no es ruptura, es advertir los lazos intercontextuales y mundiales en su espacio y tiempo.

La universalidad del contextualismo nos conduce hacia una política ambiental de las interrelaciones de hecho, interrelaciones a partir de 
lo que sucede y que escapa a todo control porque acontece por azar, hacia lo que se quiere, pues las interrelaciones suceden por todas partes, por egoísmo, violaciones, por deseo y algunas mínimas porque son planificadas.

Por último, una política ambiental que junte el contexto con lo universal sabe que las interrelaciones son múltiples, que sus causas son múltiples y que los efectos son más imprevisibles que previsibles. La interdependencia del mundo nos obliga a hacer otro tipo de política ambiental sin caer en una unidad romántica, pues las mismas leyes que nos unen, nos separan, nos juntan y nos dividen; nos igualan y desigualan. Por tal motivo, la reflexión sobre lo real en la política ambiental se impone.

\section{La disyuntiva de lo real y lo ideal en la construcción de la política ambiental}

¿Qué tan real tiene que ser la política ambiental? ¿Qué consecuencias tiene una política ideal en el mundo ambiental? Existe una fuerte tradición en el mundo de la política que se refiere a la real-polítik. Pareciera que nos equivocamos menos cuando partimos de la realidad, así, en política prevalecen las interpretaciones sobre lo dado, por encima de lo que debería suceder porque tiene que ocurrir. Gramsci, Maquiavelo, Weber y Marx coinciden en el rectángulo de lo real. La crueldad y el cinismo son valores indispensables para ingresar en dicho espacio.

Una de las consecuencias de privilegiar la real-polítik es caer en el inmediatismo. La interpretación se hace sobre lo sucedido. El futuro depende de la manera como las piezas vayan siendo movidas en el tablero de ajedrez. La política siempre es nueva, cada día tiene su preocupación, pero dentro de un marco en el que las contradicciones no son sincrónicas sino diacrónicas. Una cosa se dice en un día y puede ser negado en otro porque la situación cambia. Los valores son fruto de la situación y no lo contrario. Así, en un tiempo somos desarrollistas y en otro, ecologistas, todo depende del canto de las sirenas.

La política que menos tiene sentido dentro del ejercicio de la política actual es la política de los ideales. La política ideal traza los caminos por los cuales la realidad debería caminar. Forzamos la realidad para que sea de acuerdo a la manera como nosotros creemos que el mundo debería ser. Así, la real-polítik fácilmente se adapta al mundo de la política renunciado a los ideales del inicio y generando en nosotros un sentimiento de traidores. La ideal-polítik sostiene y agudiza la neurosis al constatar permanentemente que el mundo no es como lo pensamos, que los discursos de izquierda tienen líneas de fuga hacia la derecha, que los amigos pueden ser enemigos y los enemigos pueden ser aliados. Así, aunque la derecha económica no comparta nuestro ideario revolucionario, no por ello deja de ser nuestro aliado cuando se tiene que aprobar un plan de desarrollo de tipo extractivista.

La real-politik es mucho más exigente y se presta a mayores equivocaciones porque el mundo de hoy, no es el mismo de ayer y mañana no será igual al de hoy. Hay una necesidad de estar mirando constantemente el presente, o lo que se denomina comúnmente, "haciendo análisis de coyuntura". En la ideal política, el problema no está en la ideas sino en la realidad. Si el mundo no va bien, es culpa del mundo y no de las ideas. Las ideas las podemos discutir para reemplazar las ideas anteriores. Sin embargo, ¿qué tal real es el mundo de la real-polítik? ¿Y qué tan ideal sea el mundo de la ideal-politik?

La realidad nunca es tan real. No vemos a la realidad de frente, hay una pantalla entre la realidad y nosotros, y lo que vemos depende del lugar en el que nos encontremos, la cultura desde la que lo hagamos, la educación que hayamos recibido, los valores en los que hayamos sido formados. Lo real es un tejido de simbolismos, imaginario y real. Intentar separarlo tiene como consecuencia la pérdida de lo real. Toda mirada a la realidad es una traducción, luego la real-política 
cuando nos quiere decir que ella parte de la realidad mientras que los otros lo hacen desde el ideal. De igual manera, lo ideal no está separado de lo real, como tampoco de lo ideológico. La realidad en ambos casos está puesta en cuestión. La ideal-política sería más honesta porque sólo se atrapa la realidad desde el concepto, situación inaceptable para los obreros de la real-política. Por tal motivo, en muchos casos lo real suele ser más el sueño, la utopía.

Pero la cuestión no es sólo de orden hermenéutico. La realidad nunca es tan real. Dentro de la realidad está lo invisible de la realidad. En todo juicio hay algo que se oculta, toda verdad miente y toda afirmación niega. La realidad tiende a ocultarse en el momento que la señalamos. La problemática ambiental afirma situaciones reales y esconde otras. La objetividad está mediada entre lo que no puede ser dicho sino por otros y atrapada entre lo que se dice y se ve y lo que se oculta, no puede ser visto y es indecible. Cuando Foucault descubre la relación entre saber y poder, devela el ocultamiento de lo no dicho en lo dicho pues el poder está detrás del enunciado, hace parte del ejercicio de la enunciación. La lucha por la objetividad es la lucha por imponer el poder a través de los enunciados. No es raro que en el espacio de los ecologistas sea condenado porque se crítica sus pretendidas posturas objetivas. Es común que los defensores del desarrollo consideran a la ecología como una fábula.

Pero la discusión no es solamente entre lo oculto o no, es también entre lo predecible o no. Morin advierte sobre otro fenómeno llamado los acontecimientos- sphinx los cuales nos muestran la complejidad de la realidad. Un acontencimien-

\section{Los análisis y las acciones simples} rompen el realismo de la realidad. No podemos ser realistas cuando tenemos necesidad de dividir para comprender, de clasificar para ordenar, de explicar para comprender. to-sphinx es aquel que sólo puede ser descifrado en el momento de ser realizado. Si preguntamos a un vulcanólogo sobre la predicción calculada de una determinada erupción volcánica, lo más honesto sería advertir que ese acontecimiento sucederá en el momento que ocurra. La tautología causa risa para un lógico y un científico positivista, sin embargo, en la realidad eso es lo que sucede. ¿Qué significa? Una realidad contiene irrealismos los cuales eran posibles en determinadas circunstancias. Luego, hay realidades que no son comprendidas y, sin embargo, fueron claves en ciertos tiempos. Hay realidades tomadas de manera inadecuada, las cuales se dejaron pasar de largo y retardaron procesos o se convirtieron después en un lastre.

La política en general está acostumbrada a hacer análisis simples. No es raro que la política ambiental quiera ser solamente tratada desde lo ambiental y dentro de lo ambiental los reduccionismos de la política debido a la artesanía de un politólogo, o un abogado, o un biólogo marino, o un ingeniero forestal, llevan a graves consecuencias. Los análisis y las acciones simples rompen el realismo de la realidad. No podemos ser realistas cuando tenemos necesidad de dividir para comprender, de clasificar para ordenar, de explicar para comprender.

Es cierto que debemos ser realistas para hacer una política ambiental, pero sin caer en el inmediatismo que secciona el tiempo o en el idealismo que no está libre de errores. Ninguna teoría va a reflejar la realidad si no es por una creencia metafísica. Debemos saber que la realidad es la idea de realidad y que, por tanto, una política ambiental tiene que ser realista en la medida que hace la apuesta por la realidad posible. Si el realismo es lo inmediato, entonces es ciego, si el realismo es solamente una idea todo lo que este fuera de esa idea es una amenaza para nuestra ideología. El ideal tiene la fuerza para que lo real se calle.

No hay ninguna idea de realidad que no tenga la probabilidad de ser tomada por mitos y por culturas las cuales también están expuestas a 
errores, ilusiones y cegueras. Un mito puede ser más fuerte que los datos de la realidad. El mito tiene la capacidad de desplazar las fuentes históricas y sus causalidades. En consecuencia, ¿hasta dónde parte del discurso ambiental ha sido tomado por mitos indígenas? Las certezas son vulnerables para el mito y la duda suele ser más fuerte que cualquier certeza tal como lo dice el film La Duda de Brian Burns.

Una política ambiental auténtica dialectiza la ideal-politik con la real-politik porque quienes parten de la realidad desconocen incertidumbres, quienes parten de ideas caen en una serie de promesas abstractas. Ni las ideas ni las realidades pueden dejar de lado la discusión sobre lo posible. No todo es posible en un momento determinado. Lo posible tiende a convertirse en imposible. Tener políticas ambientales en el contexto actual es posible, sin embargo, dicha labor se ha convertido en imposible por quienes se enriquecen a costa de un desarrollo lineal, mecánico y brutal para la naturaleza y la salud de las poblaciones y el equilibrio del planeta. Pero así como lo posible se ha convertido en imposible tenemos que hacer la apuesta para que lo imposible se convierta en posible. En consecuencia, la política ambiental tiene la obligación de una mayor audacia. Lo único que nos está prohibido es la superación del segundo principio de la Termodinámica el cual nos recuerda que no hay historia segura, que nada ni nadie es inmortal, que no hay paraíso terrestre y no existe el movimiento perpetuo, todo lo que queda fuera de este principio es posible.

La política es un principio de acción, sin embargo, es probable que la política ambiental nos lleve a la inacción. Si es el caso hay tres consideraciones puestas por Morin para ser tenidas en cuenta: la primera es el efecto perverso, el cual suele ser más importante que el efecto noble. Muchas cosas buenas se pueden hacer, pero si hay algún error, o equivocación, todo es colocado en cuestión por la oposición, e intentará ser enviado al traste, por lo tanto, aunque nos equivoquemos debemos tener la ética para corregir y seguir teniendo persistencia. El segundo principio es la inanidad de la innovación, entre más cambia más tiende a ser la misma cosa, por lo tanto, no debemos celebrar antes de tiempo, ni confundirnos con una política de los resultados. Los resultados pueden aparecer sin que sean indicadores claros del cambio. La política ambiental nos señala la importancia de cambiar modelos de desarrollo y modos de vida que han persistido durante siglos; no es fácil dar un salto pero es un momento para ser audaces. La tercera es la puesta en peligro de las adquisiciones obtenidas. Los grandes saltos en política ambiental colocan en riesgo libertades y seguridades. En muchos momentos este riesgo lo tenemos que afrontar, en otros ser conscientes para que las libertades y seguridades correspondan a una humanidad inter-solidaridades y justa y tener la capacidad de advertir nuevos peligros y nuevas esclavitudes. 


\section{La política utópica entre las topías planetarias}

La crisis planetaria del ambiente impone un formato a la política ambiental el cual nos obliga a responder a la pregunta sobre la barbarie de la civilización en el origen de ella, como lo insinuó Walter Benjamin o en la constante producción de nuevas barbaries en el enfoque freudiano por medio de la ciencia, la técnica y la burocracia. La ciencia con la doble capacidad de solucionar y generar nuevos problemas. La técnica provocando nuevos desafíos de civilización. La burocracia con su funcionamiento obsceno.

¿Qué significa una política ambiental en el horizonte de los límites? La topía de la política se frena frente al futuro teniendo que ir en la búsqueda de una unidad pérdida. Las maletas han quedado en el andén de las promesas. Más allá del olvido del ser está la pregunta por las interrelaciones entre la naturaleza/la especie, la tierra/los individuos y las sociedades/Estado. No podemos seguir edificando una humanidad en oposición a la naturaleza. La tierra no es simplemente el territorio. La especie hace parte del Individuo. El ataque a las sociedades es un ataque a la tierra. La naturaleza tiene que estar al principio y al final.

Si la política del desarrollo fue la promesa del crecimiento infinito e indetenible, los límites emergen por todos los lados, desde la economía, las fuentes de energía, la alimenta- ción, la sostenibilidad del planeta y la capacidad auto-destructora de la civilización. Frente al genio todopoderoso del progreso nos encontramos con el niño a la intemperie del ambientalismo. No todo se puede, tenemos necesidad de girar de lo contrario nos espera un suicidio planetario. La vida precaria de Butler frente a la prepotencia del desarrollo, es aquí donde nos autoreconocemos en la necesidad de una nueva invención que pasa necesariamente por el acto de reinventarnos. De esta manera, la política ambiental se abre contra el modelo de desarrollo impuesto con sus formas destructivas, la esclavitud y la explotación. Quien siga apostándole a este tipo de desarrollo es un genocida. Así, la política ambiental nace en la promesa fallida del paraíso y se construye frente a las puertas del infierno producidas por su discurso.

Las formas de muerte se multiplicaron. La capacidad asesina de la llamada humanidad no se detiene. Una nueva causa de muerte emerge del fondo del Hades provocada por el desarrollo tecno-industrial. Se trata de una muerte en la esfera de la propia vida: la destrucción de la biosfera. Por consiguiente, no podemos seguir afirmando el mundo ordenado de Newton mientras el mundo conocido y domesticado siga generando indefinibles realidades invisibles y peligrosas por su reduccionismo.

El topos de la nueva política nos exige no sólo una relación con un mundo diferente sino también la afirmación del planeta dentro de un universo que con- 
tiene lo desconocido, lo insondable y lo inconcebible. Dentro de este universo surgió la vida, aquí se sitúa nuestro destino, en él encontramos nuestros fantasmas, miedos y voluntades. La vida afirmada en el topos ambiental es interdependiente de la especie y contiene los mismos componentes físico-químicos del planeta.

El límite en el que nace la política ambiental coloca al progreso ya no como una certeza. La evolución no puede ser concebida como un ascenso dada la capacidad destructiva y autodestructiva de la humanidad. Aun los desarrollados no pueden evitar el subdesarrollo mental, psíquico y ético, pues, el desarrollo económico les genera a los desarrollados una miseria humana a manera de un virus sin redención.

La política ambiental implica un reordenamiento de las finalidades terminus. La finalidad no es desarrollarnos, la finalidad es el "Buen Vivir”, y si en esto colabora el desarrollo, bienvenido sea. Pero el desarrollo presente hasta ahora es para "vivir bien" debido al papel que ocupa la economía. El futuro ha sido hipertrofiado por el desarrollo y la economía. Sin embargo, la frustración contagiada por dicho futuro no puede hacernos caer en refugiarnos en un pasado inexistente. Tampoco podemos sacrificar el presente a un pasado autoritario y a un futuro ilusorio. La apuesta por el futuro tiene que estar llena de posibilidades. Ergo, la política ambiental nos lleva a ser vigilantes con las herencias culturales, y comprensivos con las necesidades de recursos.

En el siglo XIX la política tomó a su cargo la economía, a finales del siglo XX la economía ocupa el puesto de la política, pues la política se quedó enredada en el acceso al poder por medio de los partidos. El crecimiento, la estimu- lación y la planificación ha sido parte de la economía. El Estado ha ido haciendo una biopolíti$\mathrm{ca}$, pues su preocupación es la protección, la seguridad, el trabajo, la enfermedad, la vejez, la maternidad, la educación, el tiempo libre. Sin embargo, la política de las grandes ideas se ha ido vaciando para depender de los objetivos económicos: la estabilidad de la moneda, las tasas de crecimiento, el balance del comercio exterior, la productividad, la competitividad, la deuda, etc. La política atrapada en el discurso económico ha caído en un tipo de esclerosis perdiendo la capacidad de comprender los nuevos problemas, de englobar los problemas en enfoques multidimensionales. La política determinada por la economía se disuelve en los problemas administrativos y técnicos. Los burócratas ahora dependen de los econocratas.

En consecuencia, el mayor límite de la política ambiental es la prioridad de la economía sobre cualquier otra dimensión de la política. Después viene la incapacidad de escapar de lo inmediato para construir las políticas a medio término y a largo plazo. La política casi siempre es coyuntural. En lo político se trabaja sobre lo urgente y se deja de lado lo importante.

Además de los tres tiempos existen tres sujetos: las personas, las culturas y las naciones. La política ambiental tiene alcances planetarios los cuales deben ser coherentes con las políticas educativas y sociales. Apuntamos al cambio de las personas sin dejar de lado el diálogo con las cultural y la concreción de políticas internacionales.

Por último, la política ambiental después del fracaso del sueño del desarrollo se enfrenta a un desafío transcendental y es desacelerar la máquina sin control de la tecno-industria. 


\section{Sumak kawsay en la Constitución ecuatoriana de 2008:

\author{
apuntes en torno a sus alcences \\ y desafíos
}

Pablo Ortiz*

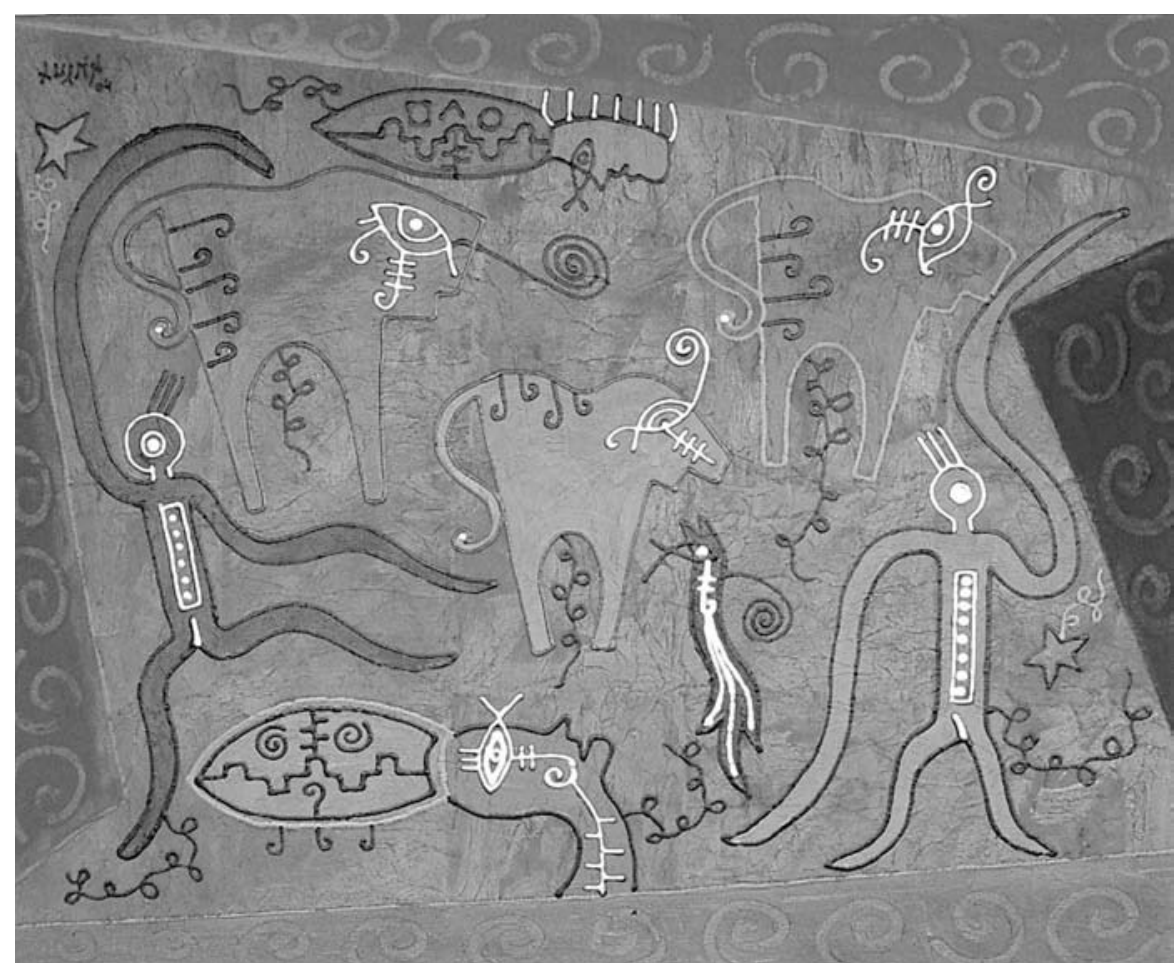

Intimismo. Técnica mixta sobre lienzo

Cuando se aprobó la Constitución de 1998, la sensación incierta de haber logrado algo invadió los círculos intelectuales y políticos cercanos a algunos movimientos sociales, en particular, al movimiento indígena. Los derechos colectivos junto a ciertos principios, insertos en la parte dogmática, constituyeron sin duda un avance, pero quedó la duda cuando otras disposiciones, inclu-

* Docente de la Escuela de Gestión para el Desarrollo Local e investigador. Sociólogo y Msc. en Ciencias Políticas, candidato a doctor en Estudios Culturales. Ha laborado durante varios años en organizaciones indígenas de la Cuenca Amazónica, en áreas de gestión territorial y de bosques tropicales. Colabora como asesor en la cooperación alemana. 
yendo transitorias, posibilitaron varias reformas legales e institucionales acordes a las prioridades de las políticas de ajuste neoliberal.

Sólo un ejemplo breve de muestra: poco se pudo hacer en materia de derechos de pueblos indígenas a ser consultados previamente, si una decisión en torno a un proyecto extractivo afectara sus territorios, espacios de vida, economía y cultura. A pesar de que la Constitución de 1998 establecía esa obligación por parte del Estado, entre el año 2000 y el 2002, los sucesivos gobiernos de Jamil Mahuad y Gustavo Noboa Bejarano, buscaron sortear dicha disposición mediante la expedición de un reglamento focalizado en un sector altamente sensible: la explotación de hidrocarburos en territorios indígenas. Y lo más curioso de ese caso, no fue la sensibilidad y preocupación de las autoridades por garantizar la vigencia o aplicabilidad de los derechos de los pueblos indígenas, o cumplir lo que mandaba el Art. 16 de esa Constitución, "que se garantiza los derechos a todas las personas sin discriminación", o lo dispuesto por el Art. 17 que "los derechos humanos son directa e inmediatamente aplicables (...), que no se podrá exigir requisitos o condiciones no establecidos en la Constitución y la ley". Simplemente respondieron a las preocupaciones de varias empresas petroleras y gremios privados, que veían en la ausencia de reglamentación en esa materia, riesgos para la validez de futuros contratos y licitaciones en el sector.

$\mathrm{Al}$ inicio de 2000, las corporaciones multinacionales, aglutinadas en la Asociación de la Industria Hidrocarburífera del Ecuador (AIHE), dejaron todo en manos de las autoridades estatales. Luego, ante el fracaso de éstas, impulsaron con el apoyo de la oficina del Banco Mundial en Quito, su propio proyecto de "reglamento de consulta previa", que se constituyó en la base del que finalmente fue aprobado en las vísperas navideñas de 2002, que en lo fundamental, restringía y distorsionaba de manera casi total, los principios y definiciones establecidas en el Convenio 169 de la OIT, relacionados al derecho de los pueblos indígenas a ser consultados de buena fe sobre temas, programas o proyectos que los involucrase y afectase de manera directa.

$\mathrm{Ni}$ los procedimientos, ni los plazos, ni quiénes son sujetos de la consulta, ni el sujeto consultante estaban claros o coherentemente definidos. Fuera de la ausencia de una ley marco, la ambigüedad con la que fue redactado ese reglamento abría las puertas a la discrecionalidad y al arbitrio de los funcionarios o autoridades de turno, como sucedió con los dos primeros casos prácticos de aplicación de dicho reglamento en el 2003 en comunidades Kichwa de Orellana, Napo y una parte del norte de Pastaza.

La turbulencia y gran inestabilidad política vivida por el país entre esos años y el abril "forajido" de 2005, impidieron concretar lo que en el gobierno de Mahuad se denominó "Plan de apertura a las inversiones 2000", que entre otros graves aspectos atentatorios a los intereses de la mayoría del pueblo ecuatoriano, implicaba la concesión de 13 nuevos bloques petroleros en la Amazonía; es decir, más de 2 millones y medio de hectáreas para actividades exploratorias y de explotación, en su totalidad ubicadas en territorios de 7 de las 10 nacionalidades ancestrales existentes en esa región, de las cuales al menos 3 se encuentran en situación de extrema vulnerabilidad etno-cultural, junto con los últimos remanentes de bosques nativos, de una biodiversidad única. En condiciones políticas estables se hubiera vivido un genocidio y un ecocidio, de magnitudes enormes, junto con un escenario altamente conflictivo en la región, y con ello se habría visibilizado buena parte de la trama que configuró el ordenamiento jurídico del país en estos años.

¿Qué significaba ese entorno de amenazas para la "vida en armonía" o el sumak kawsay? ¿Cuál es la diferencia con el entorno actual, tanto del texto constitucional como del contexto político nacional? ¿Qué perspectivas y desafíos plantea en el orden ético, cultural, político, ético e institucional la incorporación del principio del sumak kawsay en la Constitución del Ecuador aprobada en septiembre de 2008? Son las inte- 
rrogantes que orientan los presentes apuntes, de cara a motivar un diálogo y una reflexión en torno a este tema.

\section{Sumak kawsay, vida límpida $\mathrm{y}$ armónica}

Junto con la conquista y la colonización de lo que hoy se conoce como "las Américas", la historia da cuenta durante más de cinco siglos de la imposición y establecimiento de leyes, instituciones, lengua, conocimiento y códigos, acorde a la cosmovisión de los vencedores.

La conciencia del origen europeo de tales nociones religiosas, morales, filosóficas, jurídicas, poco a poco, se fue desvaneciendo junto con el hecho mismo de la conquista. La geopolítica del conocimiento finalmente logró que el conocimiento válido y legítimo se mida con parámetros occidentales. La colonización supuso la imposición de la perspectiva eurocéntrica. Como lo señala Aníbal Quijano "en América Latina y el Caribe, desde siempre en su historia, está planteado un conflicto entre tendencias que se dirigen hacia una reoriginalización cultural y otras de represión contra ellas o de reabsorción de sus productos dentro del poder dominante en la sociedad. Este conflicto impregna nuestra más profunda experiencia histórica, porque no solamente subyace en la raíz de nuestros problemas de identidad, sino que atraviesa toda nuestra historia, desde el comienzo mismo de la constitución de América, como una tensión continua de la subjetividad, donde el carácter del imaginario y de los modos de conocer y de producir conocimiento es una cuestión siempre abierta" (Aníbal Quijano, citado por Mignolo, 2002: 117).

En síntesis, la destrucción de nuestras sociedades originarias y sus descendencias, implicó -siguiendo la tesis de Quijano- la condena de las poblaciones dominadas a ser integradas a un patrón de poder configurado básicamente por los siguientes rasgos:
El patrón de dominación fue establecido en base a la idea de raza, con todas sus implicaciones, en especial como factor de clasificación e identificación social.

Los colonizadores definieron la nueva identidad de los conquistados como "indios", despojándolos de sus identidades originales, mientras que los conquistadores que originalmente provenían de distintos puntos de Europa, y específicamente de la península ibérica asumieron el genérico de "blancos".

Esa distribución de identidades sería el fundamento de toda la clasificación social de la población en América, articulando a su alrededor las relaciones de poder.

Se impuso un patrón de poder, mediante la relación jerarquizada y de desigualdad entre tales identidades "europeas" y "no europeas". Las instituciones y las normas estarían diseñadas y destinadas a preservar ese nuevo fundamento histórico de clasificación social.

Las poblaciones colonizadas fueron reducidas a ser campesinas e iletradas. Los conquistadores se apropiarían y monopolizarían el carácter de miembros de sociedades urbanas y letradas. En la sociedad colonial, sólo algunos entre los colonizados podrían llegar a tener acceso a la letra, a la escritura y de manera exclusiva en el idioma de los dominadores y para los fines de éstos.

Serían impedidos de objetivar sus propias imágenes, símbolos y experiencias subjetivas, de modo autónomo, es decir con sus propios patrones de expresión visual y plástica.

Fueron compelidos a abandonar bajo represión todas las prácticas de relación con lo sagrado propio o realizarlas sólo de modo clandestino con todas las distorsiones implicadas.

Fueron llevadas a admitir, o simular admitir frente a los dominadores, la condición deshonrosa de su propio imaginario.

Sólo en lo que pudo ser preservado, en su propio mundo, aunque sus formas institucionales fueran modificadas, según los patronos de sus dominadores, especialmente en las "comunidades" y en el seno de las familias, los valores pro- 
pios, la reciprocidad, el control de la autoridad, la igualdad social, pudieron ser practicados, aunque readaptados continuamente a las exigencias cambiantes del patrón global de la colonialidad.

En ese marco hay que entender que el Sumak kawsay es apenas un principio y parte de una filosofía de vida, derivada y asociada a su vez a formas específicas e históricas de organización social, económica, territorial, política y cultural de los pueblos ancestrales. Algo semejante sucede con el principio aymara del Qhip nayra, que es un camino del conocimiento que permite entender el presente a través de la interrogación al pasado. En ese proceso de interrogación surge un principio que es de "lo propio" o jiwaspacha, lo que es primordial por cuanto constituye el fundamento de la autodeterminación, materia de una reflexión aparte que rebasa los alcances del presente artículo.

El Sumak kawsay (vida límpida y armónica) en el caso de los kichwa de la Alta Amazonía ecuatoriana, orienta el modo de vivir. Norma las relaciones entre las personas en base a principios igualitarios, comunitarios y de reciprocidad; se alimenta del diálogo con la naturaleza y su dimensión espiritual. El Sacha runa riksina, es el arte de entender-comprender-conocer-convencerse, estar seguro y ver. Según Leonardo Viteri Gualinga "todo en la vida diaria ocurre con directa mediación de los espíritus. La vida está en la base de todo lo creado. El agua tiene vida, la selva, las plantas, los animales, los seres superiores. Por eso la naturale- za es el espacio vital en que las personas podemos vivir en libertad" (Cf. Silva Charvet, 2003: 85). De esa base conceptual nace el $\mathrm{Su}$ mak allpa (Tierra sin Mal) que es el principio que regula la relación entre los seres humanos y la naturaleza mediante un uso y manejo equilibrado-dinámico del territorio y los recursos naturales, $\mathrm{y}$ constituye el fundamento de la descentralización de los asentamientos poblaciones en muchos pueblos ancestrales amazónicos.

Para entender y vivir esto existe un conjunto de conocimientos y prácticas que están sintetizadas en el Sacha runa yachai, que aglutina métodos, conceptos y técnicas para lograr una vida en armonía consigo mismo, con las demás personas, con la familia, con la organización y con la naturaleza. Es la ciencia del Sumak kawsay, pero como lo remarca un viejo dirigente de OPIP, "no hay Sumak kawsay sin Sumak allpa", o en otras palabras no hay sociedad armónica ni vida límpida sin una naturaleza equilibrada, cuidada, renovada (el principio del Mushuk allpa-tierra en permanente renovación y equilibrio-).

Estos principios filosóficos básicos a su vez se apoyan en un conjunto de conceptos y herramientas que son expresiones de la sabiduría ancestral, tan menospreciada y trivializada desde la época de la colonia hasta nuestros días, cuando muchas expresiones culturales son descontextualizadas, manipuladas y reducidas a una expresión burda, meramente exótica o folklórica. Entre esos 


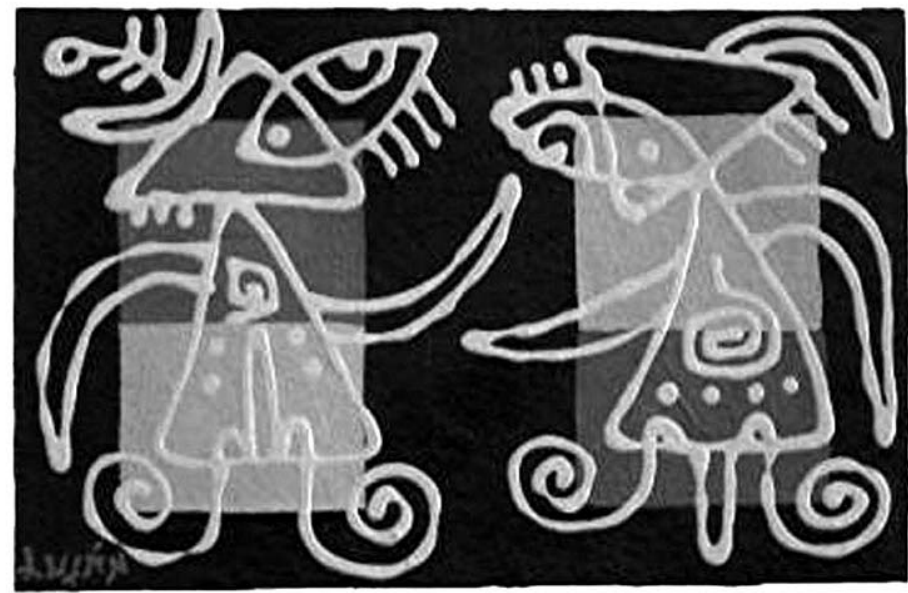

Acrílico sobre papel hecho a mano

conceptos cabe mencionar el Taki (contacto con el mundo espiritual y el tiempo originario); el Mus$k u y$ (la manera de interpretar y sentir el futuro); el Riksina rikuna (ver-tener visión); el Ushay (tener una visión y poder); el Sasi (métodos de aprendizaje); el Runa rimay (palabras ciertas que luego son acciones), entre otros.

Si uno revisa las historias de estos pueblos amazónicos milenarios a mediados del siglo XX o las crónicas misioneras del siglo XVI al XIX, es posible advertir cambios derivados de las sucesivas oleadas colonizadoras y los intentos de control de esos territorios. Cambios que son dramáticos en los últimos 40 años de ofensiva y violencia por parte del capital extractivo en la región y que se traduce en tres fenómenos centrales: pérdida total o parcial del control de los territorios ancestrales; alteración profunda de los patrones de asentamiento y gestión de los recursos de la selva; sedenterización, desplazamiento poblacional hacia otras regiones y alteración de patrones culturales centrales.

En la misma nacionalidad Kichwa amazónica es cada vez más incierto que esos tres ejes materiales puedan asegurarse en el mediano y en el largo plazo, y con ellos la vigencia de un modo de organización social y una filosofía de vida integral basados en el binario Sumak kawsay-Sumak allpa.
¿Qué espacio cabe en el proyecto criollo de Estado-nación de estos principios? ¿Qué reconocimiento real es posible de principios como el $\mathrm{Su}$ mak kawsay-Sumak allpa en un marco definido por el proyecto occidental de modernidad?

No olvidemos que la modernidad aparece cuando Europa se autoafirma como el "centro" de una Historia Mundo que ella inaugura; la "periferia" que rodea este centro es, consecuentemente, parte de esa auto-definición. La oclusión de esta periferia llevó a la intelectualidad europea a construir lo que Dussel denomina "el mito de la modernidad” (Mignolo, 2007: 55 ss.). Es decir, sostener que el proyecto de modernidad es únicamente emancipatorio, afirmado y asumido que visibiliza únicamente su lado positivo, en la ciencia, la técnica y las ideas de libertad e igualdad, pero por otro lado que oculta la irracionalidad y justificación de la violencia genocida.

El debate pasa por redescubrir el rol de las periferias en la historia y en la construcción del proyecto de modernidad y el lugar que ocupan en la historia. Específicamente las fronteras y las regiones, históricamente escenarios excluidos de los proyectos nacionales, junto con los pueblos y comunidades subalternas que las habitan. A nivel nacional esto plantea re-leer los procesos de constitución, interacción y conflicto tanto de regiones como de pueblos con quienes han controlado y direccionado desde el centro y desde arriba, los proyectos políticos, económicos y territoriales del país.

El Sumak kawsay pone en entredicho la capacidad del actual proyecto de reformas políticas que vive el Ecuador, para superar el marco conceptual colonial con el que se ha definido el denominado "proyecto de Estado-nación". O dicho en otras palabras, para descolonizar el pensamiento y las tesis que orientan su proyecto político. Surgen al respecto algunas interrogantes como: ¿Cuáles son las premisas con las que orientan sus acciones los actuales líderes de la autodenominada "revolución ciudadana"? ¿Cuáles son sus nociones de desarrollo, naturaleza, identidad, soberanía, nación, Estado, economía? 
¿Cuán distintas son de aquellas que orientaron las acciones de los responsables de las políticas "desarrollistas" de los años 60 y 70 y de los "neoliberales" de los 80 y 90 ? O colocado de manera inversa, ¿acaso no somos testigos de la construcción de una versión re-encauchada del viejo proyecto de modernidad, desarrollismo y de construcción de "Estado-nación"?

\section{Entre el pos-desarrollismo y el desarrollo sustentable ¿más de lo mismo?}

Hay que recordar que el "desarrollo" surgió como concepto, a principios en el periodo de 1945 a 1960, posterior a la Segunda Posguerra Mundial, aunque sus raíces se pueden hallar en procesos más profundos de la modernidad y el capitalismo. Su discurso posibilitó la creación de aparatos burocrático-institucionales a través de los cuales se desplegó y difundió sus principios, es decir aquellos que políticamente contrarrestaron el otro concepto central de la época: revolución, como posibilidad cierta de superar estructural y conceptualmente el capitalismo. El aparataje que acompañó y posibilitó que la idea de "desarrollo" se expandiera e introdujera en la conciencia colectiva iba desde el Banco Mundial, el Fondo Monetario Internacional (FMI), el Banco Interamericano de Desarrollo (BID), hasta las agencias nacionales como la Junta Nacional de Planificación (JUNAPLA) o el Consejo Nacional de Desarrollo (CONADE).

Como lo recuerda Arturo Escobar, el discurso del desarrollo ha operado a través de dos mecanismos principales: a) la profesionalización de problemas de desarrollo, lo cual ha incluido el surgimiento de conocimientos especializados, así como campos para lidiar con todos los aspectos del "subdesarrollo" (incluyendo el campo en sí de los estudios del desarrollo); y b) la institucionalización del desarrollo, la vasta red de organizaciones ya mencionadas (Escobar, 1996: 13).
Son procesos que posibilitaron ligar teoría y práctica, así como las estrategias aplicadas al sector rural, a través de las conocidas políticas de "desarrollo rural" y "desarrollo rural integral" que constituyeron un ejemplo "aplicado" de conceptos referidos a agricultura, alimentos, manejo de suelos, crédito, infraestructura, etc., que se constituyeron en los verdaderos instrumentos para imponer un modelo de organización y transformar el campo y las sociedades campesinas (Breton, 2001).Todo conforme a los lineamientos capitalistas de tierra, agricultura, crianza de animales, crédito, mercado, producción, etc.

El concepto de desarrollo sustentable es bastante reciente. Surgió en la década de los 70 y aparece en las memorias de la Unión Internacional para la Conservación de la Naturaleza (IUCN en sus siglas en inglés), siendo luego popularizado en el llamado Informe Brundtland "Nuestro Futuro Común", en 1987. De manera muy rápida, especialmente a partir de la Conferencia de las Naciones Unidas sobre Medio Ambiente y Desarrollo (CNUMAD), en 1992, en Río de Janeiro, la noción de desarrollo sustentable fue acogida y asimilada, y hoy en día está en el centro de todo el discurso ecológico oficial y dominante a nivel global, sin que exista, al mismo tiempo un consenso en torno a su significado y sin que siquiera se haya colocado la cuestión a debate, siendo tan determinante en la formulación de políticas y la toma de decisiones.

Al buscarse un desarrollo sustentable hoy se está, al menos implícitamente, pensando en un desarrollo capitalista sustentable. Es decir, una sustentabilidad dentro del cuadro institucional de un capitalismo de mercado. Mientras

El Sumak kawsay pone en entredicho la capacidad del actual proyecto de reformas políticas del Ecuador, para superar el marco colonial con el que se ha definido el denominado "proyecto de Estado-nación". 
tanto, no se ha colocado la interrogante básica en cuanto a la propia posibilidad (real) de tal sustentabilidad. ¿Es posible un capitalismo sustentable? Si no aborda ni profundiza tal cuestión, se corre el riesgo de convertirse en un concepto vacío, que apenas sirve para dar legitimidad a la expansión insustentable del propio capitalismo.

La crisis ambiental global, reconocida desde hace unas cuatro décadas, unida y asociada a la crisis económica del propio sistema capitalista, ha colocado en un nivel prioritario y urgente la inclusión de la problemática de la entropía en el pensamiento económico, una vez que lo que amenaza la insustentabilidad del proceso económico es justamente la base material que le sirve de soporte, bien como capacidad del medio de absorver la alta entropía resultante del proceso económico (Cf. Martínez Allier y Roca Jusmet, 2001) ${ }^{1}$.

En su formulación más simple, que la explica Martínez Allier, nosotros podemos ver la tendencia a una entropía creciente de un sistema cerrado, dada por la segunda ley de la termodinámica, como una tendencia a la transformación de la energía libre o disponible en una energía disipada o presa y no disponible más. Se trata de una transformación cualitativa, pues desde el punto de vista cuantitativo, en el sistema, como un todo, continúa prevaleciendo la ley de conservación de la materia y de la energía, dada por la primera ley de la termodinámica. Mientras que la primera ley de la termodinámica afirma que en un sistema cerrado la cantidad total de energía y materia es invariable (siendo compatible con el paradigma newtoniano); la segunda ley de la termodinámica, o ley de la entropía, al apuntar para un movimiento irreversible, unidireccional y para una alteración cualitativa, pone en jaque a la física mecánica y su visión circular, reversible y puramente cuantitativa de movimiento. La quema del carbón, con la consiguiente disipación del calor por el sistema y la consiguiente transformación del carbón en cenizas, es un ejemplo de un fenómeno entrópico, como son el desgaste de los neumáticos en el asfalto, la oxidación de los metales o el fluir de las aguas al mar. El nivel entrópico sería en ese sentido, un índice de disponibilidad de energía y materia en su forma ordenada, lo que en términos generales da orden o sentido a un sistema (Cf. Roca Jusmet, citado por Medina y Kwiatkowsnka, 2000).

Lo que en términos más simples significa que la vida se sustenta en cuanto capacidad de mantener la estructura frente a la presión y al desgaste de la entropía, de la muerte. Desde el punto de vista de la biósfera, el planeta Tierra no sólo es un sistema abierto en términos energéticos (ya que la vida se sustenta por la absorción de la baja entropía solar), sino que también es un sistema estable desde el punto de vista material, puesto que la sustentabilidad de la biósfera se basa justamente en su capacidad de reciclaje material. La universalidad o no de la ley de la entropía no es relevante para nuestra discusión en torno al Sumak kawsay. Lo importante es anotar como se presenta el proceso económico desde el punto de vista entrópico y más aún cómo opera el capitalismo industrial desde esta perspectiva. $\mathrm{La}$ contribución del físico rumano Georgescu-Roegen (citado por Martínez Allier et.al.) en torno a este tema radica en entender que el proceso económico, desde el punto de vista de la física, es una transformación de energía y recursos naturales disponibles (baja entropía) en basura y polución (alta entropía).

No se trata de discutir la sustentabilidad en términos abstractos, sino de entenderla en el marco del funcionamiento del capitalismo en sus múltiples formaciones. Sin pretender extender mucho sobre ese punto, es importante recordar

El Sumak kawsay norma las relaciones entre las personas en base a principios igualitarios, comunitarios y de reciprocidad; se alimenta del diálogo con la naturaleza y su dimensión espiritual. 
aquello que Marx (1978) ya demostró a mediados del siglo XIX. En la base del desarrollo capitalista está el capital, entidad que sólo tiene existencia como proceso o movimiento, lo que denominó el circuito del capital (D-M-D'). La base del funcionamiento del capitalismo como un todo está dada por la búsqueda de expansión y acumulación del capital, obtenida en la producción de mercancías cuyo valor de cambio supere o exceda lo invertido en la producción. En otras palabras, la lógica del capital no es sino aquella de la expansión y acumulación sin límite. La circulación del dinero como capital tiene su finalidad en sí misma, pues la expansión del valor sólo existe en ese movimiento continuamente renovado. Por eso el movimiento del capital no tiene límites. De ahí, como lo señalaba Marx, la primacía del valor de cambio por sobre el valor de uso, nos lleva al carácter unidimensional del mercado. Éste direcciona y sanciona los desarrollos compatibles con la lógica de la acumulación y de la expansión capitalista. La eficiencia productiva, al igual que los costos de una ineficiencia social o de una ineficiencia ambiental (las externalidades negativas para los economistas) es una necesidad de sobrevivencia en el cuadro del capitalismo de mercado.

Mientras eso es así, en la racionalidad capitalista de mercado y occidental, en otras culturas, los criterios de sanción social responsable, por ejemplo, por la adopción o no de una nueva tecnología, han sido definidos a partir de variables cualitativas (éticas, religiosas, normativas e institucionales, como son las tradiciones, las creencias míticas, los valores comunitarios, etc.). En el capitalismo los criterios de incentivo o castigo van a depender de las lógicas del mercado, por su capacidad de generar lucro o no. En otras palabras, en tanto en otras sociedades no capitalistas y no occidentales, el crecimiento económico o tecnológico está sujeto a un control político de la sociedad, en el capitalismo tal desarrollo puede buscar su libre expansión en el mercado, dirigido y sancionado por la concurrencia económica. De un control cualitativo (presente en las culturas ancestrales) se pasó a la primacía de lo cuantitativo.

Sin embargo, cuando se habla de desarrollo sustentable debemos considerar no sólo los aspectos materiales, económicos y cuantitativos, sino un conjunto multidimensional y multifacético que integra el denominado desarrollo en sus aspectos políticos, sociales, culturales y materiales. La sustentabilidad del todo, sólo podría reposar en la sustentabilidad de las partes. Esos factores y sus respectivos equilibrios descansan sobre factores cualitativos, como son los grados de cohesión y armonía social, cuestiones como ciudadanía, alienación, valores éticos y morales, o el grado de polarización social y política, los valores de la sociedad y el nivel entrópico del sistema. Es una característica de las ciencias occidentales contemporáneas los énfasis en los aspectos cuantitativos y su desprecio por los aspectos cualitativos, cuando son justamente éstos los más esenciales. La propia vida se caracteriza por su esencialidad cualitativa, como son la búsqueda del bienestar colectivo o de la felicidad individual (o cualquier otro criterio que se quiera tomar como motivador, en última instancia, de las acciones individuales o colectivas).

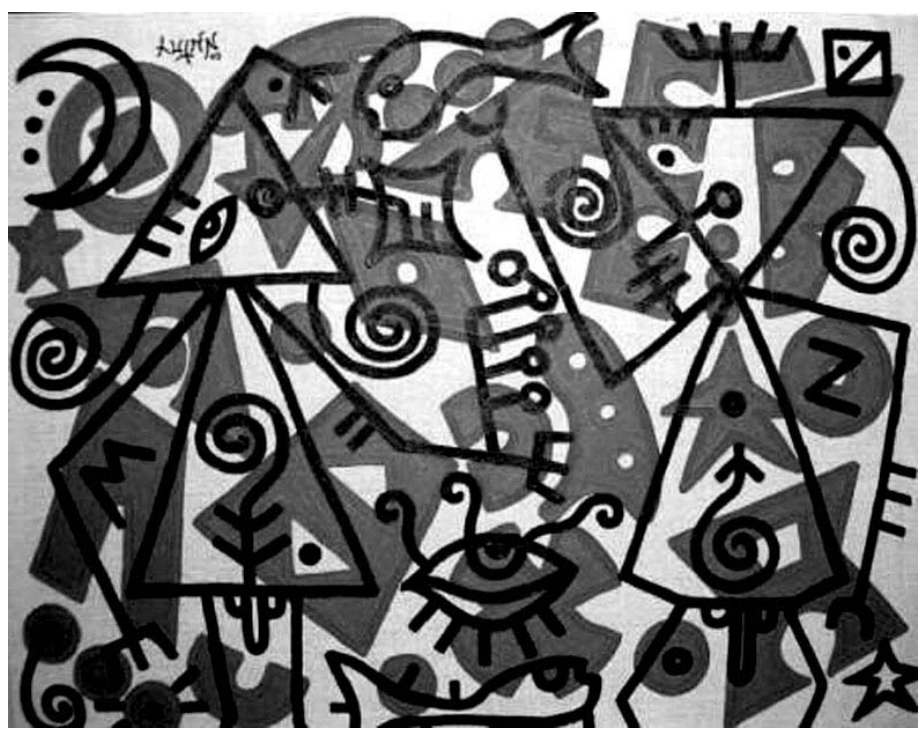

Informalismo II. Acrílico sobre yute 
¿Podrá la unidimensionalidad del mercado ser capaz de asegurar esos equilibrios cualitativos? Para responder a esta interrogante, muchas corrientes ecologistas suelen proponer la internalización de las externalidades, y al hacerlo parten de un doble reduccionismo: en primer lugar, señalan que los efectos cualitativos que acompañan y se derivan del proceso económico pueden poner en riesgo cualquier equilibrio vital para la sustentabilidad del mismo proceso (de ahí que sean vistos como externalidades negativas) y ser reducidos a un valor monetario (internalizados mediante impuestos, regulaciones, multas, compensaciones por daños ambientales, etc.). De modo que esta alteración cuantitativa en sus precios/costos lleve a un direccionamiento de las actividades, eliminando estas externalidades cualitativas. Así, por ejemplo, si la polarización social (la concentración y más aún la desigual distribución de poder económico y político) y la consecuente ausencia de conciencia política, de ciudadanía, la lucha por la sobrevivencia y el inmediatismo, etc., son vistos como ejemplos de un desequilibrio político-social, con graves consecuencias para los demás equilibrios vitales y centrales para la sustentabilidad, entonces la introducción de nuevas técnicas de producción que tiendan a aumentar la concentración de la renta o el poder político, o que atentasen a la ciudadanía, tendrían que ser evaluadas de tal manera que ese factor externo fuese perfectamente traducido y reducido a un valor monetario.

En segundo lugar, se supone que las decisiones basadas en esos indicadores cuantitativos sean de tal modo influenciadas y dirigidas, que ellas eviten o minimicen hacia un nivel sustentable o tolerable, sus efectos o impactos externos. Es decir, que la cantidad se traduzca en los efectos cualitativos deseados. La clara imposibilidad de tal proceso muestra los límites de ese enfoque. Si no, ¿cómo valorar monetariamente la pérdida de poder político o los costos en términos de sustentabilidad de una concentración de la renta? Más allá de eso, los costos de las externalidades cualitativas de cualquier innovación dependen sobre todo del contexto socio-histórico en el cual éstas ocurren. Dependen de una multiplicidad y complejidad de factores que ciertamente ningún econometrista puede evaluar, dado que no son estables ni constantes en el largo plazo, dado que fenónemos que generan externalidades negativas en determinados contextos pueden generar externalidades positivas en otros. La revolución de las telecomunicaciones (la red global, la internet, la telefonía celular, etc.) y de la informática, por ejemplo, ¿es un factor positivo o negativo en la "construcción" de sustentabilidad? ¿Aumenta la democratización del saber? ¿Refuerza la producción de ciudadanía? ¿Fortalece la conciencia de los derechos individuales y colectivos? ¿Las personas de un país conocen mejor su lugar, su historia, están más claros y sólidos en sus identidades? ¿O desata procesos de mayor concentración de renta? ¿Acaso no hay desiguales accesos a la comunicación y al conocimiento? ¿Acaso no se concentra aún más el saber en manos de los especialistas y de la tecno-estructura global? Si las respuestas fuesen afirmativas a las primeras interrogantes, tendríamos externalidades positivas, que tendrían que ser estimuladas mediante subsidios, inversiones públicas, etc., pues estaría en la dirección correcta de la sustentabilidad del sistema. Si las respuestas fuesen lo contrario, un conjunto de externalidades negativas, tal proceso tendría que ser neutralizado mediante tarifas, impuestos, etc. Probablemente ambas tendencias ocurren, dependiendo del resultado de una multiplicidad de factores y de la propia forma como la sociedad, la economía y la cultura se apropian de esas innovaciones.

\section{Los desafíos del Sumak kawsay}

Adoptando una perspectiva de sociología del conocimiento se podría decir que las críticas al desarrollo convencional, desarrollismo o teorías del crecimiento económico o similares, fueron posibles gracias a otras críticas provenientes del mismo marxismo, de la teoría de la depen- 
dencia en sus distintas expresiones y en las críticas culturales de Paulo Freire, Iván Illich, Fals Borda o Galtung, entre otros, así como en la incorporación de nuevos marcos conceptuales, provenientes sobre todo del pos-estructuralismo. Sin embargo, se podrían plantear interrogantes que nos ayudasen a definir una posible agenda de investigación y debate, pues es importante recordar que la escogencia de una epistemología y de un marco teórico (y el Sumak kawsay implica eso) siempre es un proceso político con consecuencias para el mundo real.

Sin embargo, la alternativa del "desarrollo sustentable" como concepto no ha sido la única que ha estado en la mira de las elites intelectuales y tecno-burocráticas asociadas al actual gobierno que lidera el proyecto político de la llamada "revolución ciudadana" en Ecuador. Mucho menos visible y conocida serían las tendencias asociadas a lo que Arturo Escobar denomina "posdesarrollismo" (Cf. Mato, 2005: 17-31) referido a la posibilidad real de crear diferentes discursos y representaciones que no se encuentren tan mediados por la construcción del desarrollo (ideologías, metáforas, lenguaje, premisas, etc.), por lo tanto, plantean la necesidad de cambiar las prácticas de saber y hacer y la "economía política de la verdad" que define al régimen de desarrollo. La incorporación de la noción del Sumak kawsay en la Constitución de 2008 en Ecuador, de alguna manera respondería a esa búsqueda de otros discursos y representaciones alejadas de lo convencional, aunque al mismo tiempo queda la interrogante, sí existió en sus promotores pleno conocimiento y conciencia de las implicaciones decolonizadoras del pensamiento social, político y cultural que ello plantea, o si simplemente parten de una alta dosis de romantización de algunas tradiciones locales y de movimientos sociales (en particular de una parte del movimiento indígena) obviando el hecho de que lo local también se encuentra configurado por relaciones de poder. Pasando por alto además que cuando se habla de "necesidades de la gente", "derechos de los pueblos" o de los "derechos de la naturaleza" és-
La incorporación de la noción del Sumak kawsay en la Constitución de 2008, en Ecuador, respondería a esa búsqueda de otros discursos y representaciones alejadas de lo convencional.

tos no fuesen términos no problemáticos ni discutibles, como si los teóricos o intelectuales supieran a priori lo que la gente necesita y desea. Desde la antropología en sus orígenes, siempre se supo que aun las "necesidades materiales" son culturalmente construidas, son asuntos de sentido. Como lo señala Escobar, "hay una vasta diferencia entre satisfacer las necesidades materiales a través de una economía de mercado, capitalista y hacerlo a través de prácticas e instituciones no capitalistas (...). Muchos de los movimientos (sociales) se plantean objetivos que desde una perspectiva materialista son más inasibles, tales como derechos culturales, identidades, economías alternas (no abocadas a la acumulación) y otros por el estilo" (Ibíd., 24).

En ese contexto es fundamental resaltar que la Constitución de 2008 recoge dos principios fundamentales en teoría de los derechos humanos: la progresividad y la prohibición de no regresividad.

"Tradicionalmente se ha considerado que los derechos económicos, sociales y culturales eran exclusivamente progresivos y que los derechos civiles eran de cumplimiento inmediato. Lo cierto es que todos los derechos humanos tienen dimensiones de cumplimiento inmediato y dimensiones de progresividad" (Cf. Trujillo y Ávila, citado por Varios, s.f.: 73).

Los llamados derechos del "Buen Vivir", desde esa perspectiva equivalen a los derechos económicos, sociales y culturales. En esa categoría se encuentran el derecho al agua, alimentación, ambiente sano, comunicación, información, cultura, ciencia, educación, hábitat, vivienda, salud, trabajo y seguridad social. Lo impor- 
tante es entender que el concepto del Sumak kawsay ("Buen Vivir" como lo dice su traducción literal) plantea la relación directa entre derechos y modelo de desarrollo.

Vivir en armonía, de forma transparente y límpida implica severos y profundos desafíos a las políticas culturales, a la cultura política y al sistema educativo en su conjunto. Ir hacia un sistema económico social y solidario demanda una nueva ética, y una visión amplia del país, de sus identidades, de sus territorios, de la naturaleza. Demanda una decolonización de nuestro pensamiento. Superar el paradigma etnocéntrico de la conquista, que no es patrimonio exclusivo de Europa. La conquista de territorios, de otros pueblos, el control de ríos, montañas, valles, áreas fértiles y fuentes agua marca la historia humana. Conquistar pueblos para "expandir la fe y el imperio" fue el sueño y la misión de los colonizadores españoles, ingleses y portugueses por todo el orbe. Conquistar el secreto de la vida y manipular los genes, conquistar mercados y las altas tasas de crecimiento, conquistar más y más clientes y consumidores. Conquistar el poder del Estado y otros poderes como el religioso o profético o político. Todo ha sido convertido en objeto de conquista de una voluntad insaciable.

El Sumak kawsay nos desafía a superar el paradigma de la conquista y sus arquetipos mayores: Alejandro Magno, Hernán Cortés, Francisco Pizarro, Napoleón Bonaparte, Adolf Hitler, Franklin D.Roosevelt, etc. Nos invita a transitar hacia el paradigma del cuidado esencial de un Francisco de Asís, Mahatma Gandhi o la Madre Teresa de Calcuta. No nos queda más que del entorno que tenemos, naturaleza y culturas, cuidemos lo que queda y regeneremos -hasta donde sea posible- lo que ha sido depredado. El momento histórico que vivimos, a nivel global es de tal gravedad, por los daños que ya ha sufrido la biósfera, que el dilema central es: o cuidamos o morimos.

El Sumak kawsay presente ya en la Constitución, más que normar y sancionar, intenta incentivar y promover un giro cultural de fondo, aparte de plantear que tienen que transformarse no sólo aspectos formales de las instituciones públicas a todo nivel, nacional y local, sino componentes culturales básicos, de fondo, desde los hábitos y relaciones que se establecen en la dotación de servicios públicos básicos hasta la noción de ejercicio del poder. Ya no cabe en un ámbito del Sumak kawsay la arrogancia y la indolencia de un burócrata ante el requerimiento de un/a ciudadano/a que demanda atención o un servicio, ni tampoco, en la práctica política cabe la privatización permanente de los instrumentos y espacios que son de dominio público. Los elegidos deben mandar obedeciendo. Su única obligación es cumplir los mandatos dados por el colectivo. "El Buen Vivir, en genera comprende los derechos e instituciones que tienden a dotar a los habitantes del Ecuador, las condiciones para gozar efectivamente de los derechos humanos, vivir en armonía con sus semejantes y con la naturaleza, para que esta sea el hábitat de las presentes y futuras generaciones. El conjunto está enunciado en la parte dogmática y, en la parte orgánica, para garantizar la posibilidad de su ejercicio y el goce efectivo, se establecen sistemas, políticas y servicios públicos y la planificación para otro tipo de desarrollo" (Cf. Trujillo y Ávila, citado por Varios, s.f.: 77).

El desafío está planteado y corresponde al conjunto de todos y todas los/las ciudadanos/as asumirlo como propio. La palabra y la acción están en cada uno de nosotros.

\section{Bibliografía}

- BRETÓN, Víctor: Cooperación al desarrollo y demandas étnicas en los Andes ecuatorianos. FLACSO, Quito, 2001.

- DUSSEL, Enrique: "Eurocentrismo y Modernidad (introducción a las lecturas de Frankfurt)". En: MIGNOLO, Walter: Capitalismo y geopolítica del conocimiento. El eurocentrismo y la filosofía de la liberación en el debate intelectual contemporáneo. Ediciones del Signo- 
Duke University, Buenos Aires, 2007.

- ESCOBAR, Arturo: La invención del Tercer Mundo. Construcción y deconstrucción del desarrollo, Editorial Norma, Bogotá, 1996.

- MARTÍNEZ ALLIER, Joan y Jusmet Roca: Economía, ecológica y política ambiental. 2 da. Edición, Fondo de Cultura Económica, México, 2001.

- MARX, Karl: Líneas fundamentales de la crítica de la economía política (Grundrisse). Ediciones Crítica, Barcelona, 1978.

- MARX, Karl, "Progreso técnico y desarrollo capitalista". Cuadernos de Pasado y Presente No.93, México, 1982.

- QUIJANO, Aníbal: "Colonialidad del poder, cultura y conocimento en América Latina". En: MIGNOLO, Walter: Capitalismo y geopolítica del conocimiento. El eurocentrismo y la filosofía de la liberación en el debate intelectual contemporáneo. Ediciones del Signo-Duke University, Buenos Aires, 2007.

- ROCA JUSMET, Jordi: "La economía, la ecología y la crisis de la economía convencional". En: MEDINA M. y T. Kwiatkowsnka, (eds.): Ciencia, Tecnología/Naturaleza, Cultura en el siglo XXI. Editorial Anthropos, Barcelona, 2000.

- SILVA CHARVET, Erika: Mushuk Allpa. La experiencia de los indígenas de Pastaza en la conservación de la selva amazónica. Comunidad Europea-Comunidec-OPIP, Quito, 2003.

- TRUJILLO, Julio César y Ramiro Ávila: "Los derechos en el proyecto de constitución”. En: Varios: Análisis de la Nueva Constitución. ILDIS-Friedrich Ebert-Revista La Tendencia, Quito.

1 La termodinámica nace en 1824 con los estudios de Sadi Carnot, quien cuantifica la economía de los procesos físicos de una máquina de vapor. Afianzado por el hecho de que calor se mueve de forma espontánea e irreversible de un cuerpo caliente a uno frío, Carnot creó las bases para la formulación posterior hecha en 1865 por R. Clausius de las leyes de la termodinámica. 


\title{
Economía solidaria: ¿en función de un desarrollo alternativo o de un neocapitalismo?
}

\author{
Diego Obando*
}

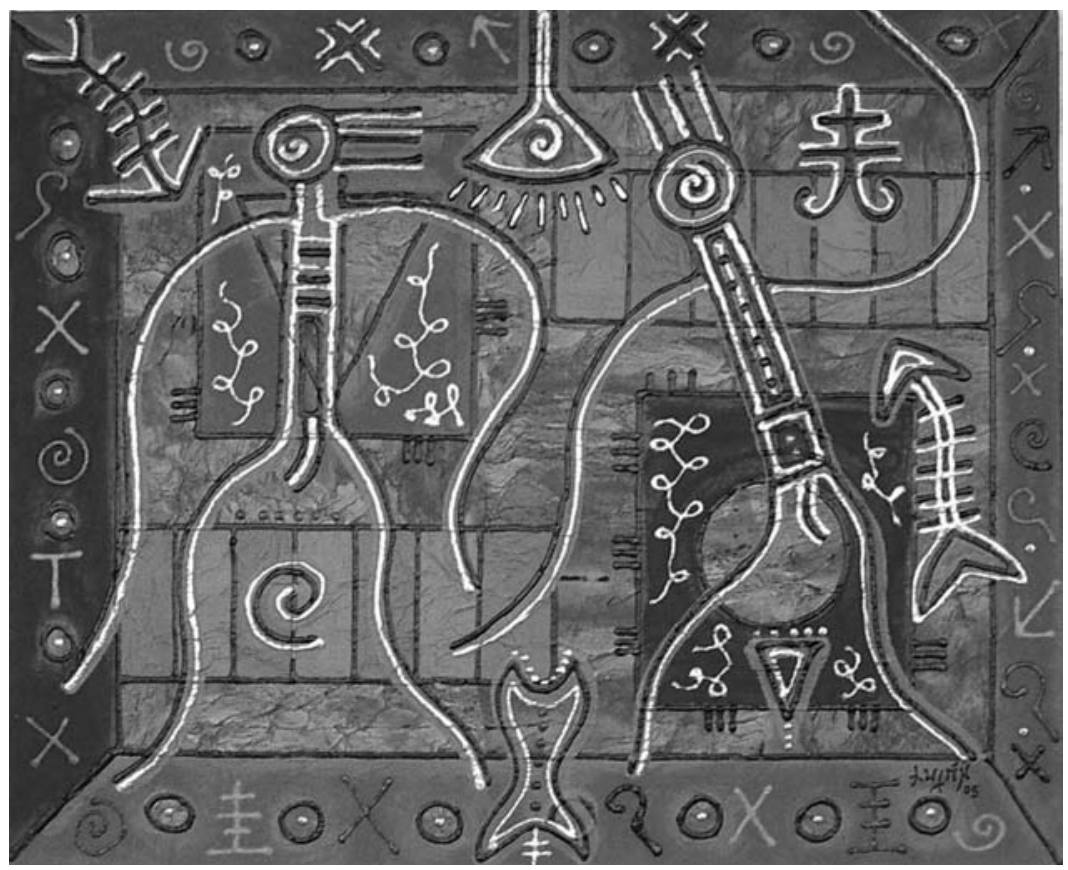

Técnica mixta sobre lienzo

La Economía Solidaria es una locución cuyo cuerpo teórico está en construcción y el celo de llenarla de contenido parte de la necesidad de encontrar alternativas a las prácticas de acumulación e individualismo que propone el modelo capitalista actual.

La pertinencia de este tipo de análisis está en el nuevo escenario político y marco legal constitucional que el Ecuador vive, en donde se reconoce a la economía solidaria: "El sistema económico se integrará por las formas de organización económica pública, privada, mixta, popular y solidaria, y las demás que la Constitución determine. La economía popular y solidaria se regulará de acuerdo con la ley e incluirá a los sectores cooperativistas, asociativos y comunitarios" 1 .

\footnotetext{
* Licenciado en Gestión para el Desarrollo Local Sostenible (2009).
} 


\section{El capitalismo y su dinámica de expansión y crisis}

\author{
El capitalismo es una “...planta vieja y \\ mutante..." (González Urbaneja).
}

El desarrollo de este modelo se ha dado entre etapas de expansión y crisis a lo largo de la historia. A continuación se expone en resumen los momentos más importantes de esta relación dinámica entre expansión y crisis.

El capitalismo naciente, en su fase industrial, tuvo una larga expansión en Europa, entre 1760 y 1800 . Época en que los comerciantes comienzan a invertir en talleres donde el trabajo ya se ha dividido por tareas. La división del trabajo y la especialización de los trabajadores tienen como efecto el aumentó de su productividad, lo que incrementó de manera importante la generación de excedentes.

La primera crisis abarca desde 1800 a 1848 , en un largo periodo caracterizado por la intranquilidad social derivada de la situación de miseria a la que fueron llevadas las masas proletarias.

El nuevo periodo de expansión que va desde 1848 hasta 1873, se caracterizó por el aumento del tamaño de las unidades empresariales, lo que permitió economías de escala y especialización. Se expandieron los mercados domésticos y se propulsó la exportación, muchas veces facilitada mediante el uso de la fuerza y la creación de imperios coloniales receptores de los productos terminados y proveedores de materia prima.

La siguiente crisis se presenta entre los años 1890 y 1893, al final de ésta los precios habían caído un 70\% y la tasa de quiebra de las empresas se había duplicado; crisis grave y global al punto que se la denominó "la gran depresión", perdiendo su denominación sólo ante una aún mayor: la iniciada en $1929^{2}$.

Ahora el periodo de crecimiento se extiende desde 1893 a 1929, en él se desarrolla la lucha entre las potencias industrializadas por asegurar (u obtener nuevas) colonias y mercados (los primeros para asegurarse el suministro de materias primas para sus industrias; los segundos con el fin de colocar la producción siempre creciente resultado de la acumulación de capital ampliada), lucha que culmina con la Primera Guerra Mundial.

La gran crisis de 1929, iniciada en Estados Unidos, pero de alcance global, se extiende hasta 1941. La quiebra de empresas y la desocupación alcanza valores récord; la pobreza se extiende por todos los países, a la vez, que disminuyen dramáticamente los salarios reales. La crisis se vio potenciada por una especulación financiera sin precedentes que propulsó el precio de las acciones en la década del veinte hizo eclosión en el día negro del 29 de octubre.

La expansión iniciada en 1941 (aunque sus reales efectos se visualicen en la posguerra debida a la enorme magnitud del conflicto bélico) continuará hasta 1973. Se le ha denominado la "edad de oro del capitalismo" debido a su duración y a las tasas de crecimiento logradas...

En 1973, se vivirá una nueva crisis que, para algunos autores se extiende hasta 1990. A la depresión se le suma la inflación, en un fenómeno inédito en el capitalismo y que destroza el sistema keynesiano ${ }^{3}$.

Los sectores dominantes de los países desarrollados, luego de las crisis del petróleo de 1973 y 1980 comienzan a cambiar las condiciones del sistema económico mundial con el objetivo de lograr la recuperación de la rentabilidad de sus empresas, principalmente multinacionales. Y esta recuperación de las ganancias se busca aumentando los excedentes producidos en los procesos productivos de los países avanzados, a través de una elevación de la productividad por una profunda reconversión tecnológica, pero también con una mayor apropiación de parte de los excedentes generados en los países subdesarrollados.

El crecimiento se retomará con fuerza, por casi una década, a partir de 1992, mediante la combinación de una profunda reconversión tecnológica y de gestión que elevó la productividad de la mano de obra y mejoró la utilización 
de los activos (donde, obligado es decirlo, el mercado cedió lugar a la creciente planificación de las empresas, siguiendo el modelo japonés), un abaratamiento del costo de las materias (y en especial el petróleo, el precio de las materias primas no petroleras se recuperaron en la segunda mitad de la década del ochenta, luego de una prolongada reducción, para volver a disminuir en los noventa) y la contención de los costos laborales de la mano de la tercerización y subcontratación, así como de la fragmentación geográfica de los procesos productivos para explotar ventajas de localización.

En este periodo se produce la reincorporación de países desconectados del sistema capitalista, en forma brusca como en el caso de la ex Unión Soviética o gradualmente como en la modernización de China.

La década de los noventa es coincidentemente, pero no por casualidad, la del avance de la globalización que define un nuevo perfil en el sistema económico mundial: se refuerza la apertura comercial, se liberaliza el flujo de capitales a niveles nunca antes alcanzados, las empresas multinacionales pasan a constituir la unidad básica de la economía mundial con los países compitiendo en el otorgamiento de incentivos y beneficios fiscales para atraer sus inversiones y el Estado se aboca a destruir (o al menos a disminuir donde no le es posible eliminar) los elementos del Estado de Bienestar construido a lo largo de sucesivas conquistas sociales 4 .
El crecimiento se detiene al comenzar el nuevo milenio: la última crisis del sistema se da en el 2008 con el quiebre masivo de empresas mobiliarias debido a la especulación de capital, lo que provoca una gran recesión económica en el mundo entero, de la que los países del tercer mundo se ven afectados especialmente en la remesas de migrantes y el desempleo masificado. Una vez más el Estado con fondos públicos interviene el mercado para salvar a las empresas multinacionales.

\section{El neocapitalismo}

El diccionario de la Lengua Española (2000) define al neocapitalismo como: "La ideología social y económica que surgió en la segunda mitad del siglo XX y en la que la doctrina capitalista se hace más profunda, basándose en la revolución tecnológica y en la internacionalización de los mercados."

Aunque el neocapitalismo es heredero del capitalismo, constituye una realidad distinta. Se trata de otro or-

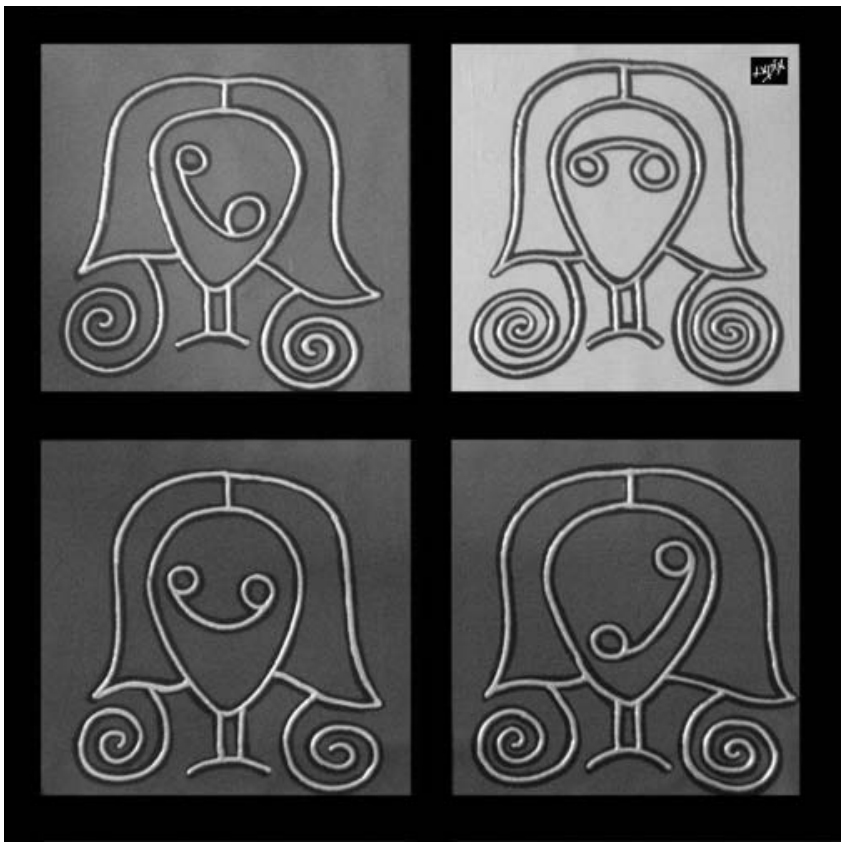

Monalily. Técnica mixta sobre lienzo den económico y de otra estructura social.

Francisco Díez del Corral en su obra-Liberación $o$ barbarie-, dice que el capitalismo ha ido transformándose de sistema de explotación en sistema de dominación.

L. Capilla, caracteriza esta nueva forma de capitalismo de la siguiente manera:

1. Democratización del consumo. 
A la clase trabajadora, considerada hasta mediados del siglo XX como productora, ahora lo central es convertirla y hacerla consumidora.

2. La ciencia y la tecnología constituyen un elemento fundamental y se necesitan personas cualificadas que formen una nueva casta de importancia central en la nueva sociedad: la tecnoestructura o tecnoburocracia. La fuerza de trabajo simple se va sustituyendo por fuerzas de trabajo especializado.

3. Difusión de los medios de comunicación como forma de poder legitimar el sistema y de manipulación de las masas.

4. Democracias controladas (Suiza, EE.UU., etc.) por la policía y los servicios de inteligencia computarizados.

5. Las Multinacionales, que aparecen en la fase superior del Imperialismo y que, en la práctica, están hasta por encima de los Estados políticos. Ellas constituyen la columna vertebral del sistema neocapitalista.

El neocapitalismo es entonces la expresión sutilizada de una nueva forma de capitalismo. Los ideales de bienestar presentes en el paradigma del nuevo capitalismo se basan en el consumo. Es una forma perfeccionada de dominación y anulación de la resistencia en tanto integra, alrededor del consumo, a las iniciativas de oposición o contradicción, desmovilizándolas y haciéndolas caer en la esperanza limitada de integrarse al sistema con el menor impacto posible.

Este modelo, como cualquier otro, construye un tipo de "persona" y de relaciones, producto de la socialización de imaginarios acerca

El neocapitalismo es la expresión sutilizada de una nueva forma de capitalismo. Los ideales de bienestar presentes en el paradigma del nuevo capitalismo se basan en el consumo. de los ideales de bienestar. Es importante hacer esta caracterización, pues, como se verá más adelante, es en esta dimensión (individual y colectiva) en la que la ES afianza el cambio de paradigma que propone.

La conciencia individual y social del sujeto neocapitalista se basa en:

El individualismo. La idea de desarrollo humano se restringe a la acumulación de conocimientos y bienes.

Competencia. La idea de luchar contra otros para ganar más beneficios que ellos.

Privilegio de la razón sobre la intuición. Se sostiene, supersticiosamente -como decía E. Husserl-, que la razón puede resolver todos los problemas. Este positivismo ha engendrado el cientificismo y la tecnocracia, que se cuestionan sobre el cómo, pero jamás sobre el por qué.

Indiferencia por el "otro". La idea de que la realidad de otros me afecta solamente cuando afecta mis intereses materiales.

Sociedades atomizadas. La fragmentación de las sociedades como manifestación de una conciencia individual.

Privilegio por la especialización. Se divide la realidad perdiendo la noción de integralidad.

Cultura de la inmediatez. Se valora la rapidez en la que se desarrollan las relaciones con el entorno.

Instrumentalización del medio ambiente. La naturaleza es una fuente de recursos a controlar y someter en función del hombre.

\section{La economía solidaria y sus con- ceptos afines}

El tema de la denominación es de fondo, o como diría Marx es una discusión material. Es material en tanto es una discusión sobre los contenidos y no sobre la forma o la apariencia, la cuestión del nombre no es menor porque hace a la identidad, es decir a una determinada manera de hacerse presente y ser reconocido en el mundo (Martí, 2008). 
Con el concepto de Economía Solidaria se ha relacionado algunos como los de Economía Social, Tercer Sector, Sector non profit (no lucrativo), Socioeconomía de Solidaridad, Economía Popular o de Trabajo, entre los más importantes. Lo que es común entre ellos es que todos se refieren a la economía no capitalista y no estatal. En su ensayo sobre La Economía Solidaria y su aporte al desarrollo, Martí establece la necesidad de definir estos conceptos por lo que son, y no por lo que no son. Esto, respondiendo a algunos autores que sostienen que se trata de una identidad residual.

El concepto de sector non profit o no lucrativo, nace en los Estados Unidos y se utilizó para designar aquellas organizaciones que no participaban del mercado con fines de lucro. Su eje fundamental son las fundaciones. Los rasgos característicos de estas organizaciones eran el contar con una estructura formal a diferencia de las redes informales o las economías domésticas; eran de carácter privado y sujetas al principio de no distribución de utilidades. La lógica de estas fundaciones como la Rockefeller o la Carnegie era la de la beneficencia, que responden a tradiciones filantrópicas y caritativas. La crítica que soportaron estas organizaciones es que hacen políticamente soportables los conflictos y demandas sociales que ni el Estado ni el mercado son capaces de resolver (Martí, Ibíd.).

En lo que se refiere al concepto de Tercer Sector, aparece en Francia en los años setenta y está asociado con la clase trabajadora que compartía la pirámide social conjuntamente con la nobleza y el clero, una especie de Tercer Estado. Se utilizó para designar a las organizaciones y empresas que no pertenecen al estado ni tampoco a la economía capitalista, su eje principal son las asociaciones.

El concepto de Economía Social nace en Europa al final de los años setenta y se utilizaba para designar a las empresas y asociaciones de la sociedad civil separadas del Estado y del capital. La necesidad de rescatar el sentido social que la economía debe tener, llevó a replantearse las pre- misas de la economía clásica. "En los [economías modernas] órdenes extensos tanto la solidaridad como el altruismo quedan restringidos a los pequeños subgrupos... todo intento de ajustar el comportamiento normal a tales principios redundaría en detrimento de la capacidad coordinadora del sistema. En la medida en que la mayor parte de las actividades productivas de los miembros trascienden los límites de la producción individual, los impulsos altruistas innatos obstaculizan las plasmación [el normal funcionamiento de las economías modernas]" (Von Hayeck, 1990:137).

\section{Concepto y principios de la economía solidaria}

El término Economía Solidaria hace referencia a un conjunto heterogéneo de concepciones y enfoques teóricos, realidades socioeconómicas e institucionales y prácticas empresariales y asociativas que desde el último cuarto del XX, vienen desarrollando un creciente sentido de pertenencia a una forma diferente de entender el papel de la economía y los procesos económicos en las sociedades contemporáneas (Pérez, 2008).

En lo que se refiere a la conceptualización teórica de Economía Solidaria, se distinguen dos enfoques: El europeo de origen francés y belga y el latinoamericano desarrollado en Chile, Argentina y Brasil.

La corriente teórica latinoamericana emerge con los estudios del economista chileno Luis Razeto, se destaca su trabajo (economía de la solidaridad y mercado democrático), completado en el 2000. Según Razeto, la Economía Solidaria se caracteriza por una orientación fuertemente crítica y decididamente transformadora respecto a las grandes estructuras y modos de organización y acción que caracterizan la economía contemporánea. Uno de los elementos esenciales que definen a la Economía Solidaria es las prevalencia del trabajo sobre el capital. La distribución, la redistribución, el valor monetario, la lógica de reciprocidad y la cooperación son la 
base de la circulación y la asignación de recursos productivos, bienes y servicios. Uno de los aportes fundamentales de Razeto es el Factor C, que se refiere a los principios sobre los cuales se basa una nueva forma de hacer economía: La colaboración, la coordinación, lo colectivo y comunitario, lo solidario, la confianza, la comunicación, el compañerismo.

Según Pablo Guerra, además del trabajo de Razeto, la corriente latinoamericana se nutre de los aportes de la Confederación Latinoamericana de Cooperativas de Trabajadores (COLACOOT) y de la experiencia de Brasil sobre todo en el área de investigación: Red de Instituciones académicas con líneas de investigación sobre el tema (Unitrabalho).

Según Guerra, lo que une a las posturas latinoamericanas es "la lectura especialmente crítica que hacen de las estructuras económicas contemporáneas, el rescate de la autogestión y del asociacionismo en las clases populares. (...) claramente, sus defensores ubican esta corriente y sus experiencias como contra-guión referentes al neoliberalismo e incluso al capitalismo).

En lo que se refiere a la corriente Europea se basa en la práctica de las cooperativas, mutua- listas y asociaciones. Se puede decir que se diferencia del Enfoque latinoamericano por las prácticas de las mutualistas y otras organizaciones mutuales que se han convertido en organizaciones "paraestatales" perdiendo en el camino su carácter de filiación voluntarias y su independencia de los poderes públicos (Ibíd, 2008).

Para fines del presente ensayo se tomará la definición de la Economía Solidaria (ES) expuesto por Pablo Guerra: Entendida como socioeconomía de la solidaridad, se da cuenta de todas la numerosas experiencias de hacer economía en sus fase de producción, distribución, consumo y acumulación, que logran mover recursos, relaciones y valores alternativos a los que hegemonizan los mercados dominantes (Guerra, 2007). Una definición que resume de manera sencilla es la que podemos encontrar en el portal de ES en la Web: $L a$ economía solidaria o economía de solidaridad es una búsqueda teórica y práctica de formas alternativas de hacer economía, basadas en la solidaridad $y$ el trabajo.

Aunque los conceptos y la praxis en ES, ha ido variando de acuerdo a cada país, se puede decir que los principios fundamentales que propone la ES son los mismos.

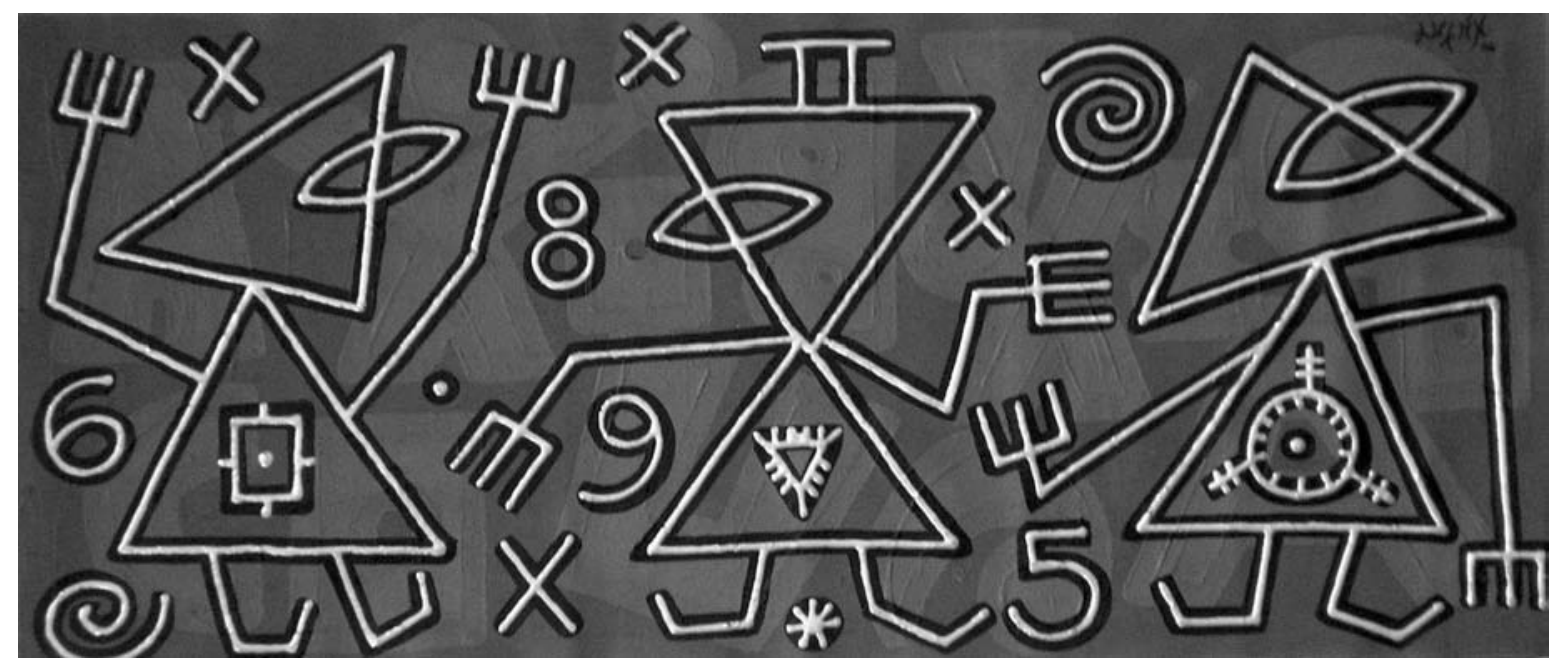

Informalismo panorámico IV. Técnica mixta sobre lienzo 
Ahora bien, ¿de qué manera la teoría de la ES se aparta de las teorías clásicas y neoclásicas? La primera identificaba tres factores productivos importantes: tierra, capital y trabajo. Los neoclásicos los redujeron a dos: capital y trabajo, explicando que la tierra finalmente es otro tipo de capital.

Como lo explica Razeto, las teorías modernas han determinado la presencia de cinco factores productivos importantes: la fuerza de trabajo (mano de obra), medios materiales (materia prima, maquinarias, etc.), tecnología (el saber hacer), financiamiento (dinero para cubrir costos) y la gestión (administración). Razeto integra a este esquema el Factor "C", como factor de cohesión e integración humana. A este Factor "C" no se le paga nada. Aporta y no tiene ninguna recompensa, ninguna remuneración, porque ni siquiera se lo reconoce 5 .

Aunque pareciera que el tema de las relaciones de cooperativismo y sinergia ya se lo ha trabajado en la teoría de la administración de empresas, la diferencia radica en que la empresa capitalista se organiza por el factor financiero, $y$ este factor le da forma a todos los demás, en cambio una empresa solidaria se articula por el Factor "C6".

Los cambios que plantea la ES como nuevo paradigma de desarrollo en la conciencia individual y colectiva serían:

La solidaridad. La idea de que el ser humano se construye en colectivo y no de manera aislada. Que la comunidad es un espacio de apoyo y de aporte.

La alteridad. La capacidad de entender al otro no como una forma de "tolerancia" sino de entendimiento de la diversidad.

\section{La implementación de un nuevo} modelo requiere una interacción continua, tanto a nivel académico como político y social, con quienes lo cuestionan.
La corresponsabilidad. La idea de que los procesos sociales son afectados desde el actuar individual, que cada uno tiene algo que decir y hacer frente a los cambios que la comunidad necesita.

La justicia. Es una valoración subjetiva de lo que es ecuánime para uno y para todos en relación con las particularidades de las personas y las situaciones (equidad).

La reciprocidad. La idea del equilibrio entre lo que uno da y recibe (don y contra don).

El respeto al medio ambiente. La naturaleza al igual que los seres humanos es un sujeto de derechos.

La cultura del consenso. Un nuevo imaginario que sobrepasa las prácticas de democracia ortodoxa (la mayoría sobre la minoría). La idea de que es posible lograr acuerdos, en donde no existe la división maniquea de perdedores y ganadores.

La motivación y la proactividad. La idea de que los aportes individuales son escuchados y acogidos genera la posibilidad de una automotivación por el trabajo y la convivencia.

Estos principios pueden ser observables en muchas experiencias de economía solidaria que han sobrevivido a la presión cultural del capitalismo. Aunque las experiencias más exitosa se han dado a nivel local, es un reto de la ES alcanzar niveles de impacto nacional. Esto necesariamente debe ser acompañado de un proyecto político nacional que trabaje esencialmente en las actitudes culturales.

\section{Interacción del paradigma de ES con el paradigma del capitalismo}

Tomás Kuhn plantea que los paradigmas no son consecutivos linealmente, sino que muchas veces coexisten en un mismo tiempo. Este planteamiento conduce a la reflexión acerca de la forma en que el paradigma de la ES cohabitará con el paradigma de la economía del mercado hasta que se imponga alguno de ellos. 
Cuando el Banco Interamericano de Desarrollo (BID) asume el discurso del Desarrollo Local como alternativa de crecimiento, se plantearon algunos conceptos que terminaron en función de la lógica del mercado, por ejemplo, el turismo ecológico, servicios ambientales, microempresa, entre las más importantes. Lo que sucedió es que estas acciones terminaron siendo una forma de localizar el capitalismo; pues desligaba aun más las responsabilidades del Estado en las zonas más alejadas y se abría la posibilidad de que el patrón de acumulación capitalista se desarrolle a nivel más local.

La ES tiene un gran reto delante de sí, contener la influencia de los valores capitalistas de tal manera que no sea un virus que la termine enfermando.

La implementación de un nuevo modelo requiere una interacción continua, tanto a nivel académico como político y social, con quienes lo cuestionan, esto es importante porque enriquece el discurso y amplia el debate. Las redes sociales e institucionales juegan un papel importante en este momento, son ellas las que mantendrán la propuesta vigente la retroalimentarán.

Esta interacción se da en un contexto en el que el paradigma Capitalista lleva a su favor toda una estructura montada material y subjetiva, de la que puede sacar provecho para reinstalarse y dominar nuevamente. Cabe entonces que la ES, como una nueva forma de comprender la realidad, empiece siga ganando espacios de reproducción social, los centros de formación, las comunidades, espacios de participación social y política, etc.

\section{ES, contradicción radical o com- plementación a la economía de mercado}

Como se ha expuesto anteriormente las crisis del modelo capitalista son antesalas de momentos de expansión. En aquellos momentos la resistencia social cuenta con menos adhesiones, pues, el espejismo del desarrollo parece más real. La crisis actual puede servir para posicionar la idea de un nuevo modelo, fortalecer las experiencias locales y exigir el reconocimiento y su potencial expansivo.

El nuevo paradigma de la ES apunta al cambio desde lo local a lo global, en este sentido tiene un gran camino por recorrer y un gran peso que contener si no quiere sucumbir ante la presión de la economía de mercado. Esto es una debilidad pero una fortaleza a la vez pues cuenta con la base social para el cambio.

Propone un cambio de valores y de significados acerca del trabajo y de la relación con el medio ambiente, es más que un conjunto de técnicas y herramientas que genera un producto determinado, es un cambio en la estructura material y subjetiva de los individuos y las relaciones entre ellos. Es decir su crítica al modelo actual la realiza desde todos los frentes, contingencia fundamental para confrontar e imponerse.

Los intentos por desarrollar ES en países latinoamericanos, han respondido a crisis coyunturales y algunos se han mantenido con dificultad en su gestión. La debilidad en sostenerse y desarrollarse en el tiempo puede amenazar con claudi-

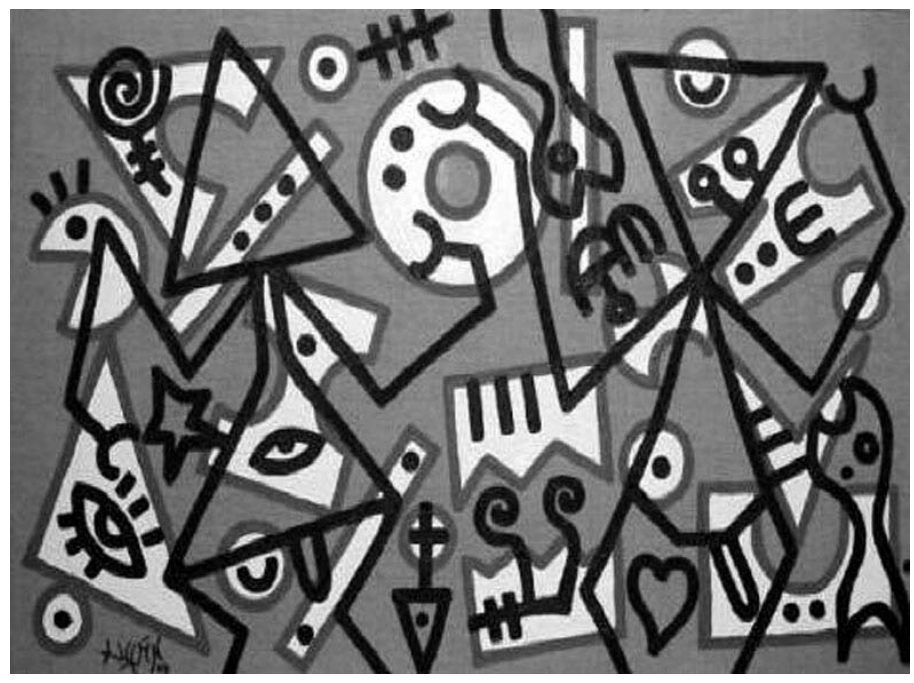

Danzeterías. Acrílico sobre yute 


\section{Es necesario contar con información} sobre el impacto real que la economía solidaria representa en la economía de los países para visualizar su avance y desarrollo.

caciones en este intento. Se deberá enfocar en las experiencias exitosas y aprender de las fallidas.

Cuando Razetto y Guerra hablan de un marco teórico para la ES, cabe preguntarse si esta necesidad es o puede terminar siendo una forma de legitimar un paradigma nuevo con los principios de aquel que se quiere cambiar. Por ello se hace necesario replantearse la estructura del conocimiento científico y los alcances prácticos de la teoría. Tal vez es momento de sobrepasar la estructura clásica que exige la ciencia para este tipo de teorías (explicativo y predictivo) y construir una nueva forma de hacer teoría.

En este último aspecto, un elemento que aporta la ES en la generación de conocimiento, es el hecho de que éste se ha construido colectivamente, invirtiendo la pirámide clásica de innovación-socialización-adopción, en donde la punta la constituyen un grupo reducido de intelectuales o agentes de poder, la franja intermedia los intérpretes y socializadores de las "innovaciones", y la base, la gran masa que acata y ejecuta.

La institucionalidad no debe desconectarse de las bases ni burocratizar la propuesta. En el caso de la participación por ejemplo, en nuestro país la institucionalidad y su dependencia financiera con el Estado han derivado en dependencia también en las decisiones.

Finalmente, la ES debe anticiparse a las nuevas mutaciones del sistema capitalista que hoy por hoy pretende adoptar la forma de Capitalismo Ético. La posición radical es una fortaleza que debe mantener para que no se negocien posturas con un hábil negociador como lo es el sistema capitalista.

\section{Conclusiones}

Las crisis cíclicas del modelo capitalista en la historia, dan razón de que muy probablemente el modelo se recicle y lo acompañe una etapa de expansión.

Si la ES cuestiona las estructuras del modelo actual, deberá también cuestionar la manera de construir conocimientos empezando por zafarse de las limitaciones que la ciencia exige para que una teoría se considerada "oficialmente" como tal.

Los nuevos valores sociales e individuales que propone la ES, son bastante ambiciosos y de largo plazo. Para ello es importante plantearse estrategias inmediatas y mediatas. Las primeras son de esencial importancia, pues serán las que sostengan el proceso.

Es necesario contar con información sobre el impacto real que la ES representa en la economía de los países para visualizar su avance y desarrollo.

Sin claudicar en sus principios la ES deberá negociar con actores políticos nacionales y regionales para que su implementación sea posible en dos direcciones señaladas.

Las experiencias exitosas deben pasar del laboratorio, a desarrollar su potencial expansivo.

\section{Bibliografía}

- ÁlVAREZ, Luis, Fragmento de Cuadernos de Lanzarote II. 1997.

- Biblioteca virtual de economía y sociedad y $E M V I$, enciclopedia multimedia virtual interactiva, editada por eumed.net.

- Campus Virtual Sobre Economía Solidaria, en http://www.economiasolidaria.net/

- CAPILlA, L, "Capitalismo y Neocapitalismo, Artículo sacado de http://www.mercaba.org/DicPC/C/capitalismo_y_neocapitalismo.htm

- Constitución Política del Ecuador, 2008.

- Encyclopedia Britannica, 1964, Vol. IV.

- GUERRA, Pablo, "Cartillas de economía Soli- 
daria” Programa Kolping, Uruguay 2007.

- MARTÍ, J. Pablo, "Economía Solidaria y su aporte al desarrollo", Medellín, 2008.

- MARTÍNEZ, Eva, artículo de prensa "Brown ve en la crisis la debilidad del liberalismo desenfrenado y ofrece un modelo basado en valores éticos", Londres, 2008.

- PÉREZ, Etxarri y Aldanondo: En ¿De qué hablamos cuando hablamos de Economía Social y Solidaria?, conceptos y nociones afines, Bilbao, 2008.

- RAY, Aynd: Capítulo primero del libro What is Capitalism?, publicado por The New Ame- rican Library. 1967

- RAZETO, Luis: En El Factor "C" "Charla de Luis Razeto", Escuela de Cooperativa "Luis Arrona". Venezuela, 1997.

\section{Documentos electrónicos}

- http://www.elpais.com/diccionarios/castellano/neocapitalismo

- http://www.eumed.net/cursecon/libreria/2004/rk/2c.htm

- Artículo "La crisis en la Historia de Capitalismo".

1 Constitución Política del Ecuador, 2008. Art. 283.

2 Biblioteca virtual de economía y sociedad y EMVI, enciclopedia multimedia virtual interactiva, editada por eumed.net

3 Biblioteca virtual de economía y sociedad y EMVI, enciclopedia multimedia virtual interactiva, editada por eumed.net

4 Biblioteca virtual de economía y sociedad y EMVI, enciclopedia multimedia virtual interactiva, editada por eumed.net

5 Charla de Luis Razeto, Escuela de Cooperativa “Luis Arrona”. Venezuela, 1997

6 Ibíd, 1997 


\section{Actividades académi cas}

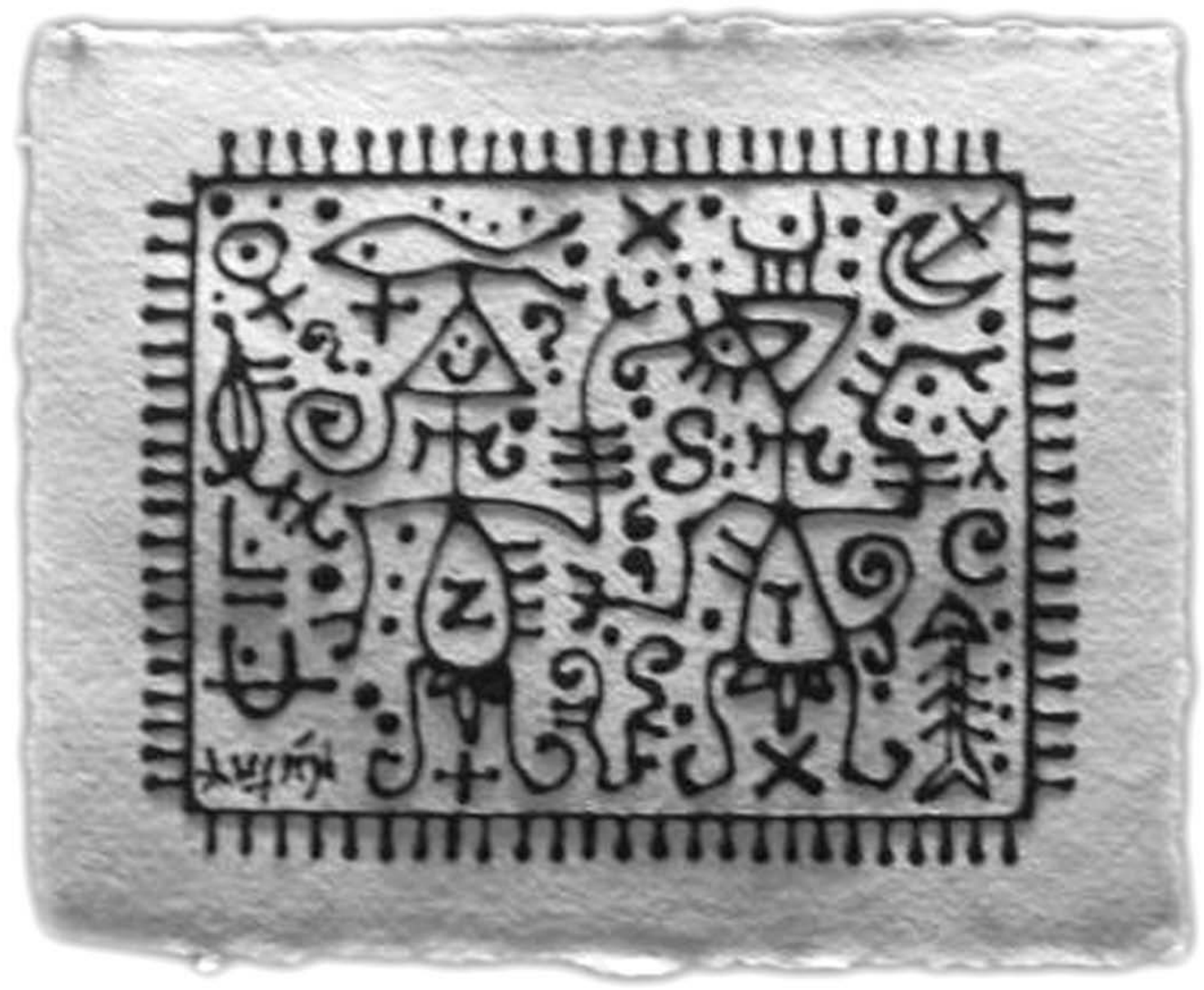




\section{Actividades académicas del Centro Psicológico y de la Carrera de Psicología}

Encuentro académico "El Ecuador y las drogas”. El Comité Consultivo del Observatorio Nacional de Drogas, con el apoyo del Consejo Nacional de Sustancias Estupefacientes y Psicotrópicas (CONSEP), y con el auspicio de las Universidades Andina Simón Bolívar y la Universidad Politécnica Salesiana, realizó un Encuentro académico denominado El Ecuador y las drogas, los días 20 y 21 de noviembre de 2008 . El objetivo principal fue contribuir a la construcción de una perspectiva renovada sobre la investigación y la incidencia en el país del denominado "problema drogas", respecto al cual se han formulado propuestas desde distintos paradigmas interpretativos para orientar las decisiones nacionales en este campo.

Los temas tratados fueron los siguientes: Diversas intervenciones para el control de la oferta de las drogas (Adriana Rossi, Argentina; Ma. del Carmen Estupiñán, OND-CONSEP; Lincoln Larrea); La realidad andina y el desarrollo de nuevas perspectivas para el problema de drogas (Oscar Feo, Secretario del Organismo Andino de Salud- Convenio Hipólito Unanue, Perú); Determinantes sociales del consumo (Jaime Breilh, U. Andina); Visión crítica de la salud mental (Arturo Campaña, CEAS; Pablo Jiménez, UPS); Nuevas visiones y lenguaje de las drogas (Xavier Andrade, FLACSO; Hernán Reyes, U. Andina; Rodrigo Tenorio, OND-CONSEP; Jaime Torres, UPS); Cultura, cotidianidad y medio ambiente (Becker Reyes, UPS; Adolfo Maldonado, Acción Ecológica; Gonzalo Barreno , CECAFEC; Cecilia Bravo, U. Central).

Capacitación y apoyo psicopedagógico. El proceso educativo, por la naturaleza de sus destinatarios, siempre será motivo de constante preocupación. En tal virtud, las autoridades del Colegio Agronómico Salesiano de Paute solicitaron a la Directora de la Carrera de Psicología, Lcda. Mariana Carrillo, el apoyo psicopedagógico para los estudiantes de este centro educativo.

Con la participación de los estudiantes de la carrera de Psicología del Trabajo, y el apoyo de la Lcda. Lorena Cañizares, la actividad de capacitación se desarrolló por un periodo de 7 semanas consecutivas, mediante una metodología que involucró también a los padres de familia de los estudiantes del centro educativo. La capacitación se clausuró el 25 de enero en un acto en el que participó en pleno la comunidad educativa del plantel.

\section{Actividades académicas del Centro de Estudios Interculturales}

Sistematización del proyecto "Derechos, Gobernabilidad y Democracia inclusiva en los pueblos indígenas amazónicos fronterizos". El Centro de Estudios Interculturales realizó un convenio con CARE Internacional para la realización de la sistematización del proyecto "Derechos, Gobernabilidad y Democracia inclusiva en los Pueblos Indígenas Amazónicos Fronterizos" 
durante los meses de noviembre y diciembre de 2008. Dicha sistematización fue pensada como una memoria escrita del trabajo de un grupo de instituciones (CARE Internacional, AMUME y las Federaciones indígenas Cofán, Shuar, Siona, Secoya y Kichwa amazónico) que durante dos años han trabajado el eje de derechos indígenas y participación social.

El proyecto incluyó a gobiernos locales, centros e instituciones formales e informales, y se desarrolló mediante procesos artísticos y culturales y otros elementos que han creado nuevas formas de ver la experiencia comunitaria, una nueva forma de entender la participación, la ciudadanía y los derechos.

La sistematización, realizada por un equipo de docentes de la UPS (Darwin Reyes, director del proyecto, Rubén Bravo y Luis Fernando Villegas), consta de seis documentos: 1) Sistematización general del proyecto; 2) Sistematización del eje derechos indígenas; 3 ) Sistematización del eje participación social e inclusión política, y, 4) Tres guías sobre la historia de las federaciones Cofán, Kichwa y Shuar.
Conversatorio sobre sistema preventivo $y$ derechos colectivos. El 1 de diciembre de 2008, el Centro de Estudios Interculturales realizó un conversatorio sobre el tema la relación entre el Sistema Preventivo de Don Bosco y el enfoque de derechos, orientado hacia la estructuración de una propuesta ecuatoriana para participar en el Congreso "Sistema Preventivo y Derechos Humanos" convocado por el Rector Mayor de los Salesianos, Don Pascual Chaves, en Roma, los últimos días del año pasado.

Se concluyó que es necesario construir una ciudadanía intercultural que supere a la ciudadanía liberal, rompiendo con el legado colonial y que implique el goce de derechos individuales y colectivos.

Participaron en este conversatorio, profesores invitados de la UPS-Quito. Rubén Bravo, Director de la Carrera de Comunicación social, y el P. Robert García como delegado de la UPS y de los salesianos, respectivamente. El aporte de la UPS consistió, fundamentalmente, en identificar los retos y los caminos para construir una ciudadanía intercultural.

\section{Actividades académicas de la Carrera Gestión para el Desarrollo Local Sostenible}

Asesoría pedagógica al proyecto URBAL9: "Sistema intermunicipal de capacitación en planificación y gestión local participativa" en el marco del convenio con el Municipio del Distrito Metropolitano de Quito. En el marco de un convenio firmado entre la Universidad Politécnica Salesiana-Sede Quito- y el Municipio del Distrito Metropolitano de Quito, se realizó el acompañamiento y asesoría pedagógica al módulo de capacitación Participación de las mujeres en la Gestión Local, Políticas Públicas de Equidad de géne- ro y al proceso de aplicación del Proyecto URBAL-9 de la Unión Europea "Sistema intermunicipal de capacitación en Planificación y Gestión Local Participativa." URB-AL es un Programa de cooperación descentralizada de la Comisión Europea que tiene como objetivo el acercamiento de las ciudades, entidades y colectividades locales de América Latina y de la Unión Europea a través del intercambio de experiencias en políticas urbanas entre sus socios. Durante el periodo de 2003 a la fecha, la Municipalidad de Porto 
Alegre fue responsable por la coordinación de la Red 9, cuyo tema central fue Financiamiento Local y Presupuesto Participativo.

El Proyecto B, Sistema inter-municipal de Capacitación en Planificación y Gestión Local Participativa, coordinado por la Municipalidad de Porto Alegre, es una acción concreta para cualificar y optimizar los contenidos de los intercambios entre las ciudades y dar a estos intercambios una estructura más duradera y de más largo alcance. La producción de materiales pedagógicos a partir de la experiencia acumulada por las ciudades y la presentación de las experiencias en un ámbito de capacitación, permite a su vez una reflexión crítica sobre su propio que hacer por cada una de las ciudades participantes.

El Municipio del Distrito Metropolitano de Quito seleccionó a la Universidad Politécnica Salesiana y a la Carrera de Gestión para el Desarrollo Local como su contraparte académica. De allí, la selección de la terna de docentes remitida por la Universidad Politécnica Salesiana a la profesora Viviana Maldonado Posso, quien como especialista en Políticas públicas, Género y Gestión del Desarrollo Local asumió la responsabilidad como integrante del Comité académico del Proyecto, desde abril hasta diciembre de 2008. Del 10 al 12 de junio de 2008 asistió a Florencia, Italia con la vicealcaldesa del MDMQ, Margarita Carranco, a fin de presentar los resultados de este aval académico en el II Encuentro Internacional del Proyecto URBAL-9.

Curso de graduación en desarrollo, reforma del Estado y Políticas públicas. Este curso de graduación inició en septiembre de 2008 y culminó el 14 de febrero de 2009, estuvo dirigido a los/as estudiantes de varias promociones y egresados de la Carrera de Gestión para el Desarrollo Local Sostenible, a fin de que culminen con su proceso de graduación y obtengan el grado de licenciatura.

Los módulos que se abordaron durante el curso fueron los siguientes: Desarrollo, Territorio y nuevas ruralidades; Reforma del Estado, Políticas públicas, Descentralización y autono- mías; Cambios urbanos y actores sociales; Nuevos enfoques económicos: Economía Solidaria.

En general, el curso fue evaluado positivamente, en especial porque permitió a los/as estudiantes actualizar sus conocimientos y prácticas de desarrollo en el contexto de la actual reforma del Estado y de las Políticas públicas.

Curso de sistematización documental y de experiencias de aplicación de planes y programas para funcionarios/as del Consejo Nacional de Salud. Se dictó en el mes de marzo y estuvo dirigido al personal técnico y directivos de este organismo del Estado. A fin de desarrollar y mejorar sus capacidades, conocimientos, competencias, habilidades y destrezas en el campo de la sistematización de experiencias.

De igual manera, se pretendió interiorizar los procedimientos metodológicos y comprender que toda producción de conocimientos basada en la experiencia requiere de acciones sistemáticas, por lo que el curso fortalecerá la capacidad de planificación, gestión y dirección técnicopolítica de los/as funcionarios/as del CONASA.

Convenio con GTZ. La Carrera de Gestión para el Desarrollo Local, en el marco del convenio suscrito entre la GTZ y la UPS, se encuentra ejecutando el Proyecto "Capacitación en políticas sobre interculturalidad con gobiernos locales". El objetivo de este proyecto es proporcionar a los funcionarios y autoridades de los gobiernos locales un proceso de capacitación que les permita fortalecer sus capacidades individuales e institucionales, así como crear herramientas teórico prácticas para incorporar un enfoque intercultural en la definición de políticas públicas, de gestión local.

Encuentro de formación de líderes sociales. En Viña de Mar, Chile, del 8 al 13 de diciembre de 2008 , se celebró el encuentro de organizaciones sociales y universidades de varios continentes para trabajar el tema de la "Formación de Líderes Sociales". Esto responde a un largo proceso iniciado en ese país, y que fue ampliándose hacia otras regiones y sectores sociales en la década de los noventa, en la que se priorizó la necesidad de 
formación de organizaciones de pescadores y de sectores urbano populares.

El encuentro tuvo como objetivo discutir la creación de una Universidad que sistematice y recoja la riqueza de este proceso ya que existen decenas de iniciativas y de diversos tipos en los diferentes continentes. Resulta particularmente interesante que esta búsqueda de formación de nuevos liderazgos sociales se haga no solamente al interior de las organizaciones sino que se tienda puentes con la academia.

El encuentro dejó marcado también la responsabilidad social que tienen las universida- des para inscribirse en la línea de la reflexión y de la práctica social.

La participación de la Carrera de Gestión para el Desarrollo Local, de la UPS-Quito, fue importante porque en su experiencia se logra precisamente unir las dos modalidades: la formación de líderes sociales desde la práctica y la organización social con la formación académica, que es el reto que la Universidad de la Tierra se está planteando hoy. El conocimiento de la $\mathrm{Ca}$ rrera de Gestión Local será expuesto mediante un video, en un nuevo encuentro que se realizará en París, en abril de 2009.

\section{Actividades académicas de la Carrera de Antropología Aplicada}

Concluye investigación sobre Etnografía y actorías sociales en Latinoamérica. El proyecto formó parte de la primera convocatoria de proyectos de investigación efectuada por la Universidad Politécnica Salesiana y el informe final fue publicado en el tomo Investigación, ciencia y sociedad (UPS, Quito 2009), junto a otras investigaciones del área de ciencias sociales que participaron en la misma convocatoria. La investigación identificó el estado de la cuestión en torno al rol de la investigación etnográfica como herramienta para fortalecer las actorías sociales en Latinoamérica y reforzó la convicción de que el trabajo de campo etnográfico es una dimensión esencial de la antropología. Asimismo, permitió acceder a diversos enfoques y metodologías que deben ser tomadas en cuenta en los diversos espacios académicos y de investigación tales como los mapas identitarios, la etnografía de los archivos de la memoria, la investigación entre pares, el documental etnográfico y la asesoría intercultural. Productos inesperados del proyecto fueron los siguientes: una mejor definición del perfil del antropólogo y una lectura del saber y experiencia acumulados por la Carrera sobre el trasfondo de la discusión latinoamericana. En el proyecto participaron profesores de la Carrera (Patricio Guerrero, Luis Herrera, René Unda y José Juncosa), estudiantes (Amanda Tello, Hans Bertenbreiter y Andrés Rojas), profesores invitados de otras universidades ecuatorianas (Jorge Nuñez y Andrés Pantoja, FLACSO), así como investigadores invitados de centros de investigación y universidades del Cono Sur, principalmente (Rosana Guber, Argentina; Teresa Durán, Chile; y Raquel Wiggers, Manaus, Brasil).

Talleres sobre antropología visual, arte $y$ cultura. La Carrera de Antropología Aplicada ha priorizado los cursos presenciales como espacios clave de aprendizaje para estudiantes y profesores. En los dos últimos cursos, se dictaron talleres sobre antropología visual, arte y cultura con la participación de especialistas invitados y de la UPS. En el taller sobre antropología visual participaron como profesores invitados el Dr. Edizon León, antropólogo de la Universidad Andina y 
fotógrafo; y la fotógrafa Martina León, contactada por el Centro multimedial de la UPS. El taller sobre arte y cultura fue facilitado por la doctoranda Marisol Cárdenas, quien disertó sobre la semiótica y los discursos visuales de las mantas rituales elaboradas en Oaxaca (México) a través de los cuales la colectividad se representa a sí misma y a los otros.

Inicia Curso de graduación de la Carrera de Antropología Aplicada. El curso de graduación inició en marzo del 2009 y el tema central es el siguiente: Escenarios contemporáneos de la antropología latinoamericana. Consta de cuatro módulos: Enografías y actorías sociales, Antropología y conocimientos locales, Antropología y espacios y, finalmente, Antropología de las emociones. Los profesores responsables de los módulos son Alexandra Martínez, Ricardo Carrillo, Patricio Guerrero y José Juncosa quienes, a su vez, han convocado a otros docentes y especialistas. El curso de graduación pretende situar a los graduandos en los debates centrales de la antropología latinoamericana cuidando, sobre todo, de identificar las consecuencias teóricas y metodológicas de los diversos enfoques. Por último, el curso permite acceder a temas que reclaman de la antropología respuestas urgentes, como por ejemplo, los movimientos sociales, la necesidad de tomar en cuenta los conocimientos locales en las estrategias del desarrollo, la migración y los desplazamientos humanos y las culturas juveniles.

Culminación del Proyecto de revitalización cultural del Noroccidente de Quito. En agos- to de 2008, y mediante convenio entre la UPS y Fundación Esquel, la Carrera de Antropología Aplicada ejecuta el Proyecto de revitalización cultural comunitaria del Noroccidente de Quito. Uno de los componentes del proyecto es la producción de un folleto sobre la identidad local para cada una de las parroquias de Calacalí, Nanegal y Nanegalito y del cantón Puerto Quito y un mapa identitario, en formato poster, cuyos destinatarios son los niños de las escuelas de las localidades mencionadas. Estos productos rescatan los aspectos espaciales, históricos y contemporáneos de la identidad local así como los lugares significativos y referentes. Estos productos están acompañados de una Guía docente y de una agenda anual escolar. La información se fue consolidando mediante talleres participativos en los que se involucraron profesores, personas de la tercera edad, autoridades e investigadores, cada uno con su respectivo proceso de validación. Varios han sido los aprendizajes: ha sido muy positiva la integración entre profesores y estudiantes de la Carrera; asimismo, se ha comprendido que los productos comunicativos implican tensiones muy peculiares para la investigación y condicionan en gran medida los temas y el lenguaje. Por último, se ha aprendido que nuestra investigación debe comparecer ante exigencias y expectativas que no son sólo nuestras sino de la comunidad y de las contrapartes. Al momento de esta crónica, todos los productos están en prensa y se están realizando los talleres de capacitación para los profesores. 


\section{Galería de arte}

\section{Lilia Luján (México D.F. 1965) www.lilialujan-arte.com}

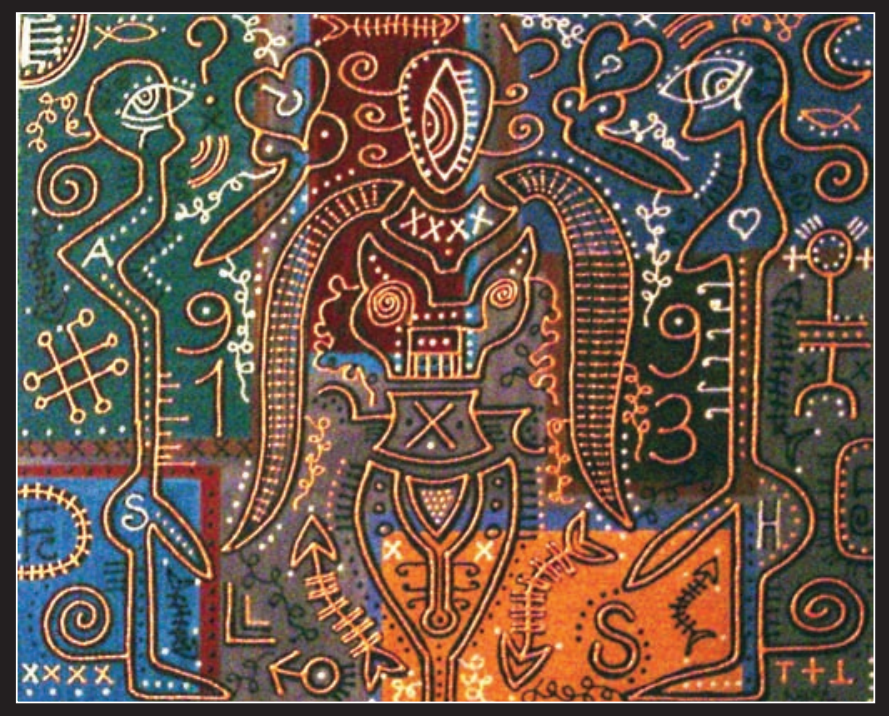

Conclusiones. Técnica mixta sobre lienzo

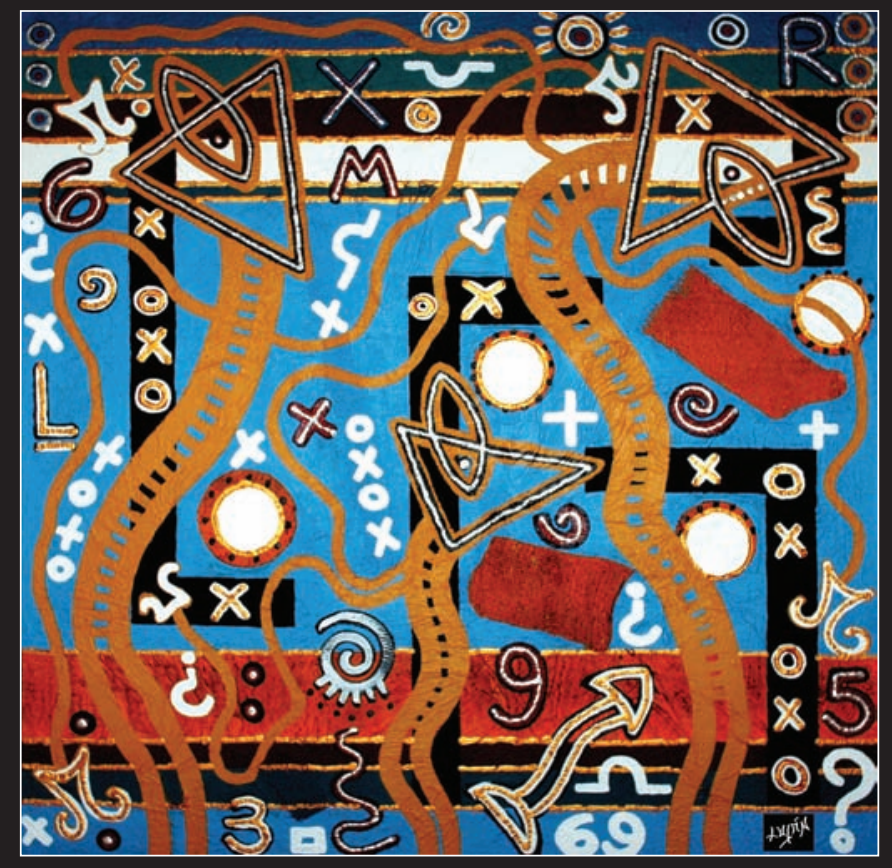

Enfoques II. Técnica mixta sobre lienzo

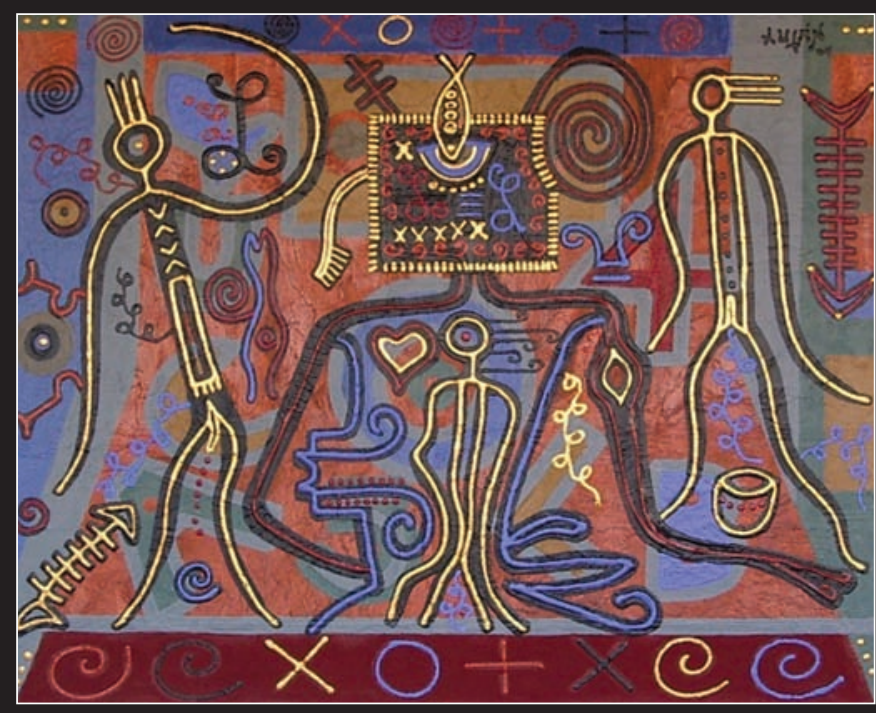

Cosas mías. Técnica mixta sobre lienzo

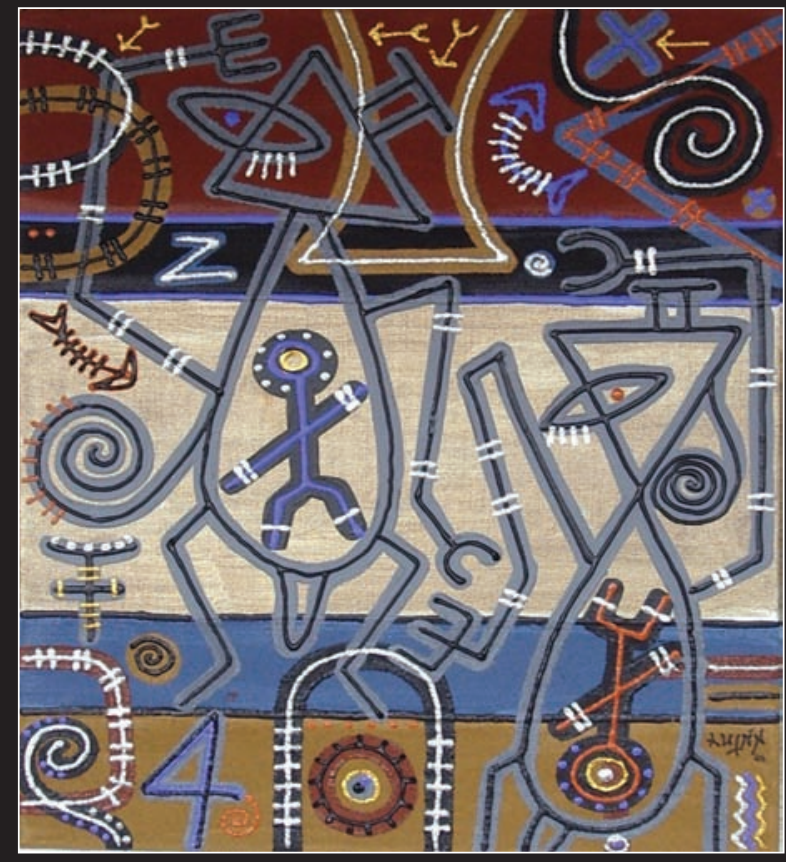

Reminiscencias. Técnica mixta sobre lienzo 


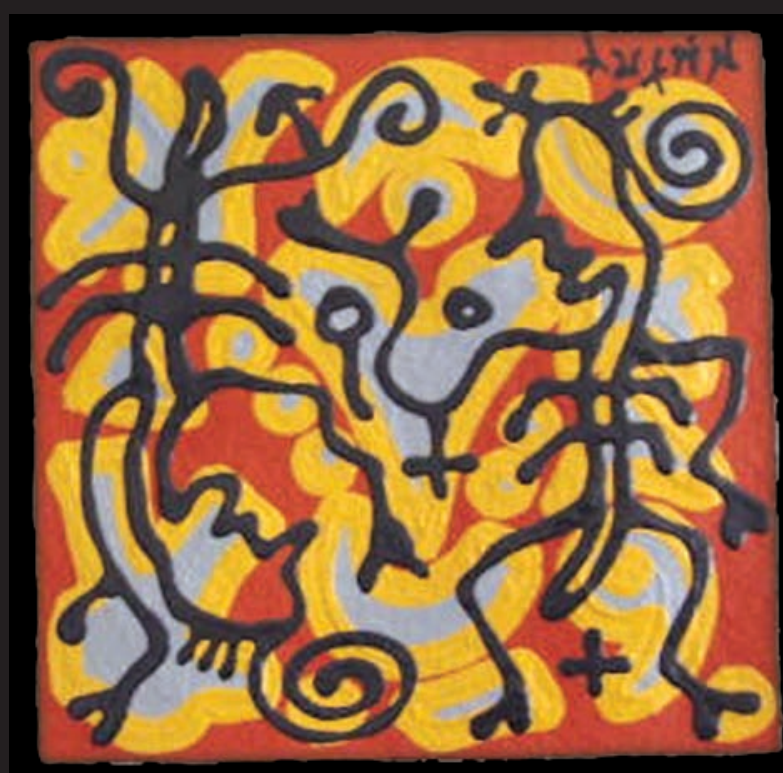

Acrílico sobre papel hecho a mano

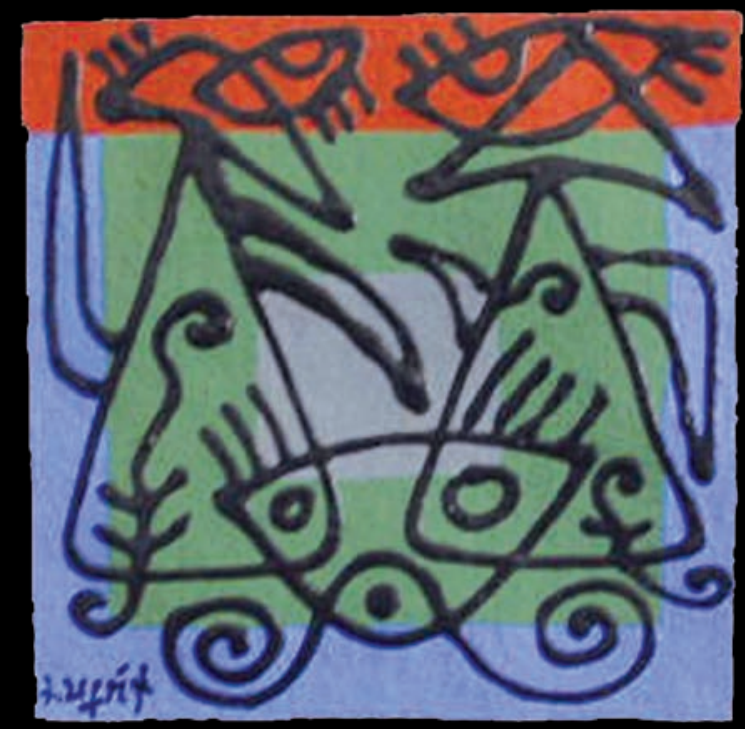

Acrílico sobre papel hecho a mano

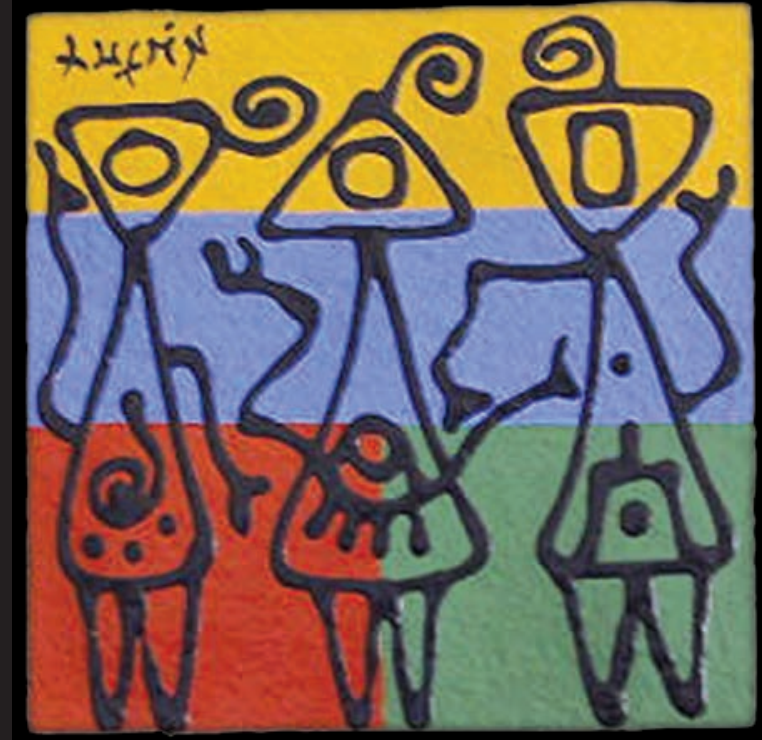

Acrílico sobre papel hecho a mano

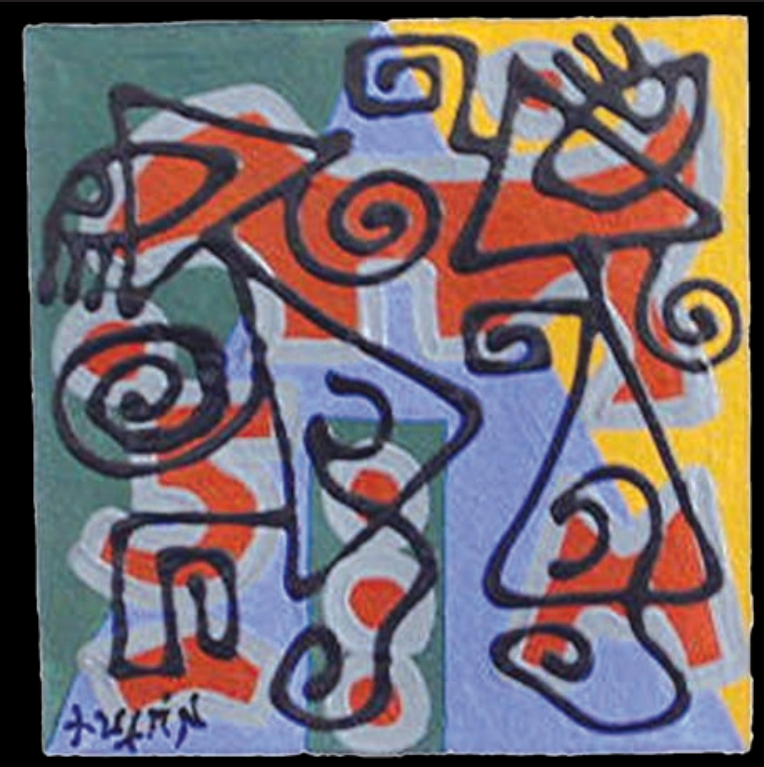

Acrílico sobre papel hecho a mano

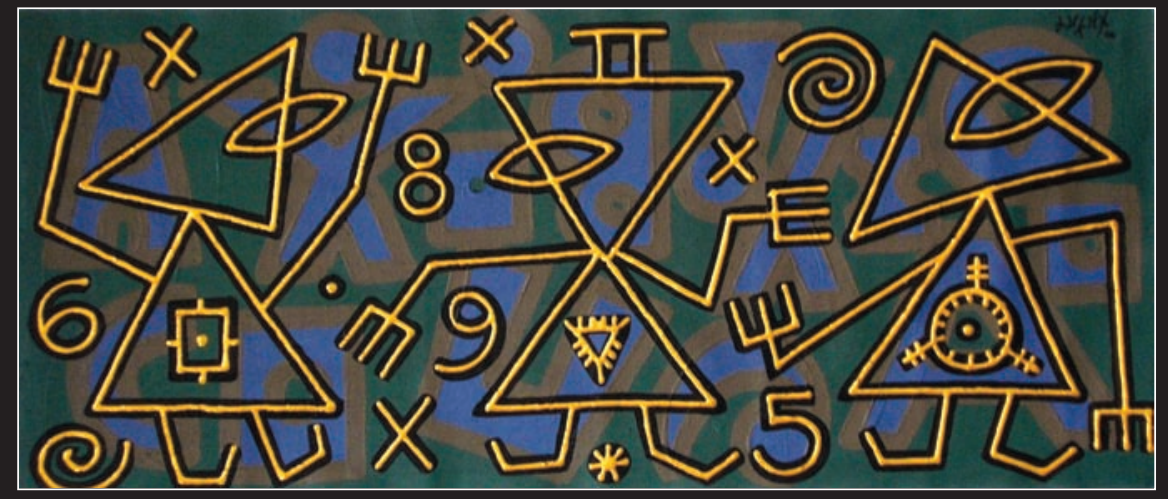

Informalismo panorámico. Lienzo sobre tela 